Silvia Regina Dowgan Tesseroli de Siqueira

\title{
Avaliação funcional mandibular e sensitiva orofacial de doentes com neuralgia trigeminal tratados com compressão do gânglio trigeminal com balão
}

Tese apresentada à Faculdade de Medicina da Universidade de São Paulo para a obtenção do título de Doutor em Ciências

Área de concentração: Neurologia

Orientador: Dr. Manoel Jacobsen Teixeira

São Paulo

2006 
Dados Internacionais de Catalogação na Publicação (CIP)

Preparada pela Biblioteca da

Faculdade de Medicina da Universidade de São Paulo

Creprodução autorizada pelo autor

Siqueira, Silvia Regina Dowgan Tesseroli de

Avaliação funcional mandibular e sensitiva orofacial de doentes com neuralgia trigeminal tratados com compressão do gânglio trigeminal com balão / Silvia Regina Dowgan Tesseroli de Siqueira. -- São Paulo, 2006.

Tese(doutorado)--Faculdade de Medicina da Universidade de São Paulo. Departamento de Neurologia.

Área de concentração: Neurologia.

Orientador: Manoel Jacobsen Teixeira.

Descritores: 1.Neuralgia do trigêmeo/complicações 2.Síndrome da disfunção da articulação temporomandibular 3.Neuralgia do trigêmeo/cirurgia 4.Dor facial 5.Neurocirurgia 6.Medição da dor

USP/FM/SBD-293/06 


\section{Dedicatória}

Dedico à minha família e em especial a todos os pacientes e

familiares para os quais espero já ter acrescentado (e ainda futuramente acrescentar) algo de melhor em suas vidas. 


\section{Agradecimentos}

Ao Dr. Manoel Jacobsen Teixeira, pela orientação e pelos ensinamentos sobre dor;

Ao meu pai, José Tadeu, pela amizade, carinho, companheirismo, aprendizado, fundamentalmente em dor, mas também sobre a vida, sobre a ciência, e também sobre as artes de CURAR e TRATAR, nas suas essências;

À minha mãe, Irene, pela paciência, por ensinar o que aprendi sobre ensinar, e pelo estímulo ao espírito indagador;

Ao meu irmão, Márcio, também pela paciência, mas ainda pela amizade e carinho;

Ao Luiz Galdino, por ouvir algumas das minhas aulas e textos, pelo apoio, e pela força de vontade e dedicação que eu admiro e procuro seguir;

À Maria Teresa, minha amiga, por estar sempre perto e por sempre me apoiar;

Ao Cláudio Marinho, pela amizade, pelo apoio e pela enorme vivência em ambiente interdisciplinar;

À Cláudia Lara, pela fundamental participação para no desenvolvimento e conclusão deste trabalho;

A todos os meus colegas pela amizade e pelas contrbuições para realizar esta obra, especialmente à Cynthia, Carol, Fábio Kurogi e Fábio Fujarra;

Aos atendentes e funcionários da Divisão de Odontologia e da Divisão Clínica Neurológica do Hospital das Clínicas da FMUSP, especialmente ao Adilson e ao Erli;

Por fim, aos doentes, razão da realização desta pesquisa. 
Esta tese está de acordo com:

Referências: adaptado de International Comittee of Medical Journals Editors (Vancouver)

Universidade de São Paulo. Faculdade de Medicina. Serviço de Biblioteca e Documentação. Guia de apresentação de dissertações, teses e monografias. Elaborado por Anneliese Carneiro da Cunha, Maria Júlia de A. L. Freddi, Maria F. Crestana, Marinalva de Souza Aragão, Suely Campos Cardoso, Valéria Vilhena. São Paulo: Serviço de Biblioteca e Documentação: 2004.

Abreviaturas dos títulos dos periódicos de acordo com List of Journals Indexed in Index Medicus. 


\section{SUMÁRIO}

Lista de siglas

Lista de tabelas

Lista de figuras

Resumo

Summary

1. INTRODUÇÃO

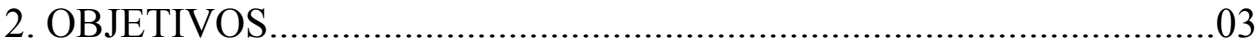

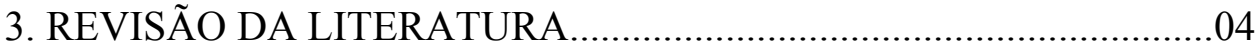

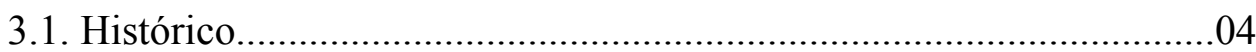

3.2. Definição, critérios e principais características da NIT.....................05

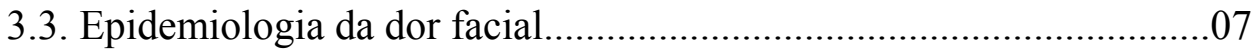

3.4. Anatomia e histologia da raiz e gânglio trigeminal ..........................09

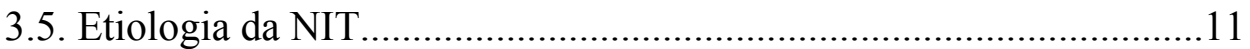

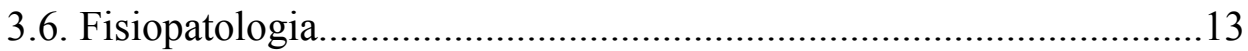

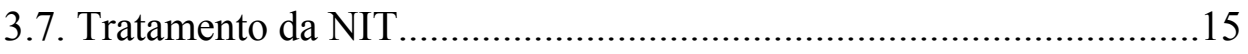

3.7.1. TRATAMENTO MEDICAMENTOSO.....................................16

3.7.2. TRATAMENTO CIRÚRGICO...................................................18

3.7.2.1. Eliminação das causas...................................................18

3.7.2.1.1. Descompressão neurovascular................................18

3.7.2.1.2. Eliminação de fatores irritantes teciduais.................20

3.7.2.2. Interrupção das vias trigeminais...................................20 
3.7.2.2.2. Rizotomia percutânea por radiofreqüência...............20

3.7.2.2.3. Compressão radicular e ganglionar com balão........22

3.7.2.2.4. Rizotomia percutânea com glicerol........................24

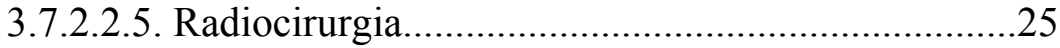

4. MÉTODOS

5. RESULTADOS

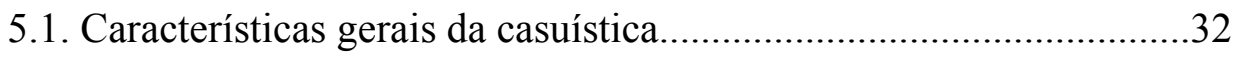

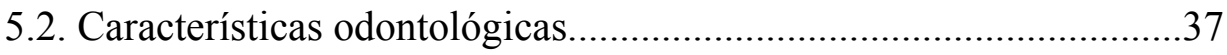

5.3. Análise das avaliações ao longo do período de acompanhamento...38

5.3.1. AVALIAÇÃO DA FUNÇÃO MANDIBULAR .........................39

5.3.2. AVALIAÇÃO EMOCIONAL E FUNCIONAL DIÁRIA..........46

5.3.3. SENSIBILIDADE SUPERFICIAL FACIAL ............................50

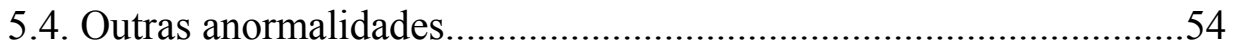

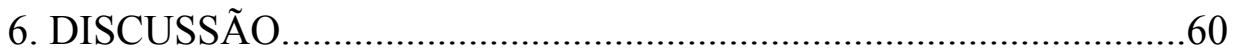

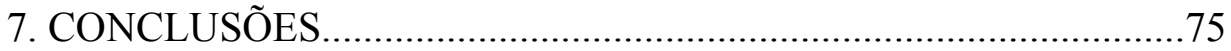

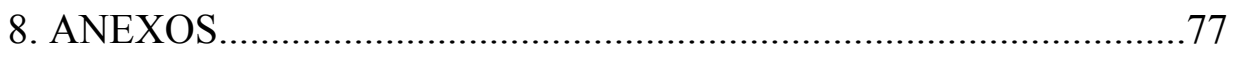

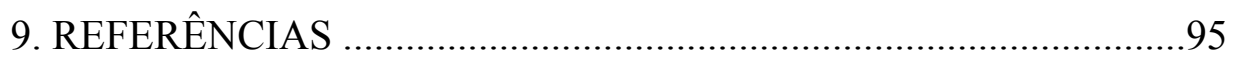

Apêndice 


\section{LISTA DE SIGLAS}

$\begin{array}{ll}\text { ATM } & \text { Articulação Temporomandibular } \\ \text { DP } & \text { Desvio Padrão } \\ \text { DTM } & \text { Disfunção Temporomandibular } \\ \text { EDOF } & \text { Equipe de Dor Orofacial do Hospital das Clínicas } \\ \text { EVA } & \text { Escala Visual Analógica } \\ \text { EUA } & \text { Estados Unidos da América } \\ \text { FMUSP } & \text { Faculdade de Medicina da Universidade de São Paulo } \\ \text { IASP } & \text { International Association for the Study of Pain } \\ \text { NMDA } & \text { N-metil-D-aspartato } \\ \text { NIT } & \text { Neuralgia Idiopática do Trigêmeo } \\ \text { PT } & \text { Prótese Total } \\ \text { RDC } & \text { Research Diagnostic Criteria } \\ \text { SAB } & \text { Síndrome da Ardência Bucal } \\ \text { SNC } & \text { Sistema Nervoso Central } \\ \text { SNP } & \text { Sistema Nervoso Periférico }\end{array}$




\section{LISTA DE TABELAS}

Tabela 1 - Distribuição dos doentes em números absolutos $(\mathrm{N})$ e em percentagens (\%) quanto aos procedimentos neurocirúrgicos prévios para a NIT. .31

Tabela 2 - Distribuição dos doentes em números absolutos $(\mathrm{N})$ e em percentagens (\%) quanto a doenças prévias ou concomitantes. .32

Tabela 3 - Distribuição dos doentes em números absolutos $(\mathrm{N})$ e em percentagens

(\%) quanto ao ramo trigeminal acometido. 32

Tabela 4 - Distribuição dos doentes em números absolutos $(\mathrm{N})$ e em percentagens (\%) quanto às zonas de gatilho. .34

Tabela 5 - Distribuição dos doentes em números absolutos $(\mathrm{N})$ e em percentagens

(\%) quanto às expressões utilizadas para descrever a dor. 36

Tabela 6 - Distribuição dos doentes em números absolutos $(\mathrm{N})$ e em percentagens

(\%) quanto aos procedimentos prévios para tratar a dor.

Tabela 7 - Distribuição dos doentes em números absolutos $(\mathrm{N})$ e em percentagens (\%) quanto às características dentárias. 38

Tabela 8 - Distribuição dos doentes em números absolutos $(\mathrm{N})$ e em percentagens (\%) quanto ao desconforto facial. 39

Tabela 9 - Distribuição dos doentes em números absolutos $(\mathrm{N})$ e em percentagens (\%) quanto às anormalidades da ATM. 40

Tabela 10 - Distribuição dos doentes em números absolutos $(\mathrm{N}) \mathrm{e}$ em percentagens (\%) quanto a abertura bucal em relação à amplitude, desvios e dor.

Tabela 11 - Distribuição dos doentes em números absolutos (N) e em percentagens (\%) quanto ao incômodo de mastigação. .44

Tabela 12 - Distribuição dos doentes em números absolutos (N) e em percentagens $(\%)$ quanto à gravidade de dor crônica, segundo o RDC. .46

Tabela 13 - Distribuição dos doentes em números absolutos (N) e em percentagens $(\%)$ quanto à qualidade do sono..... 48

Tabela 14 - Distribuição dos doentes em números absolutos (N) e em percentagens $(\%)$ quanto à perda de elementos pela boca. 
Tabela 15 - Distribuição dos doentes em números absolutos $(\mathrm{N})$ e em percentagens $(\%)$ quanto à sensação subjetiva de dormência....................51

Tabela 16 - Distribuição de doentes em números absolutos $(\mathrm{N})$ e em percentagens (\%) quanto à queixa de disestesia..........................................................51

Tabela 17 - Distribuição dos doentes em números absolutos (N) e em percentagens $(\%)$ quanto à sensibilidade facial superficial.....................52

Tabela 18 - Distribuição dos doentes em números absolutos $(\mathrm{N})$ e em percentagens (\%) quanto às anormalidades na avaliação de 7 dias..........54

Tabela 19 - Distribuição dos doentes em números absolutos (N) e em percentagens (\%) quanto a ocorrência de outras anormalidades na avaliação de 30 dias.

Tabela 20 - Distribuição dos doentes em números absolutos (N) e em percentagens (\%) quanto à ocorrência de outras anormalidades na avaliação de 120 dias. .56

Tabela 21 - Distribuição dos doentes em números absolutos $(\mathrm{N})$ e em percentagens (\%) quanto à ocorrência de outras anormalidades na avaliação de 210 dias 


\section{LISTA DE FIGURAS}

Figura 1 - Distribuição dos doentes em percentagens (\%) quanto à ocorrência de dor miofascial na musculatura mastigatória; incluídos doentes com limitação da abertura bucal....

Figura 2 - Distribuição de doentes em percentagens (\%) quanto às queixas mastigatórias espontâneas.

Figura 3 - Distribuição dos doentes em percentagens (\%) quanto à mobilidade mandibular, segundo o Índice de Helkimo.

Figura 4 - Distribuição dos doentes em percentagens (\%) quanto à disfunção clínica segundo o Índice de Helkimo.

Figura 5 - Distribuição dos doentes em percentagens (\%) quanto ao lado em qual a dor se localizava em relação ao lado da mastigação.

Figura 6 - Distribuição dos doentes em percentagens (\%) quanto ao grau de depressão, segundo o RDC. 46

Figura 7 - Distribuição dos doentes em percentagens (\%) quanto aos sintomas físicos não-específicos, segundo o RDC.

Figura 8 - Distribuição dos doentes em percentagens (\%) quanto à ocorrência de dor no corpo e cefaléia. 47

Figura 9 - Distribuição dos doentes em percentagens (\%) quanto à dormência subjetiva e à avaliação de sensibilidade superficial na face...... .50

Figura 10 - Distribuição dos doentes em números absolutos $(\mathrm{N})$ quanto à algiometria.....

Figura 11 - Anquilose em articulação temporomandibular direita na avaliação de 210 dias .58

Figura 12 - Despapilação lingual no lado operado (esquerdo) na avaliação de 210 dias .58

Figura 13 - Despapilação ligual em região anterior esquerda na avaliação de 210 dias.

Figura 14 - Hiperqueratose em mucosa jugal no lado direito ou seja, o mesmo da cirurgia na avaliação de 210 dias 


\section{RESUMO}

Siqueira SRDT. Avaliação funcional mandibular e sensitiva orofacial de doentes com neuralgia trigeminal tratados com compressão do gânglio trigeminal com balão [tese]. São Paulo: Faculdade de Medicina, Universidade de São Paulo; 2005. 113p.

Este trabalho teve como objetivo avaliar as características odontológicas, verificar a ocorrência de complicações sensitivas faciais e determinar os aspectos funcionais mandibulares em 105 doentes com neuralgia idiopática do nervo trigêmeo (NIT) submetidos à compressão radiculo-ganglionar trigeminal com balão. Foram realizadas 5 avaliações para cada doente: uma pré-cirúrgica e 4 póscirúrgicas $(7,30,120$ e 210 dias). Ocorreu comprometimento sensitivo mais intenso no território dos ramos maxilar e mandibular do nervo trigêmeo $(\mathrm{p}<0,001)$ e poucas anormalidades no território do ramo oftálmico $(\mathrm{p}=0,1815)$. As qualidades sensitivas calor, frio, tato e dor foram afetadas. As queixas subjetivas de dormência foram mais freqüentes do que as objetivadas durante o exame sensitivo facial $(p<0,001)$. Foi elevada a ocorrência de disfunção oclusal $(62,9 \%)$; $42,6 \%$ dos doentes apresentaram queixas espontâneas relacionadas à mastigação; houve intensificação da dor miofascial na musculatura mastigatória após a cirurgia $(\mathrm{p}<0,001)$, que retornou aos valores iniciais em média após 210 dias; a mobilidade mandibular também agravou-se $(p<0,001)$. Os autores concluíram que o procedimento é eficaz e seguro quando aplicado em doentes com NIT envolvendo o ramo oftálmico. Entretanto, recidiva é freqüente e as complicações sensitivas e ou motoras orofaciais poderiam comprometer a qualidade de vida e dificultar a reabilitação funcional dos doentes.

Descritores: neuralgia do trigêmeo/complicações, síndrome da disfunção da articulação temporomandibular, neuralgia do trigêmeo/cirurgia, dor facial, neurocirurgia, medição da dor. 


\section{SUMMARY}

Siqueira SRDT. Sensitive and functional evaluation of the orofacial region of patients with trigeminal neuralgia treated with balloon compression [thesis]. São Paulo: "Faculdade de Medicina, Universidade de São Paulo"; 2005. 113p.

The aim of this study was to determine dental characteristics, abnormalities in the masticatory function and occurrence of orofacial sensorial complications in 105 patients with idiopathic trigeminal neuralgia (ITN) treated with radiculoganglionar trigeminal compression with balloon. The patients were evaluated in the pre-operative and in 4 post-operative periods (7, 30, 120 and 210 days). Sensory deficits were more severe at area innervated by the maxillary and mandibular trigeminal branches $(\mathrm{p}<0.001)$; the ophthalmic branch presented abnormalities in very few cases. The sensory qualities, cold, heat, tactile and pain were affected. Subjective numbness was more frequent than sensory abnormalities findings at the post-operative sensitive evaluation $(\mathrm{p}<0.001)$. Dental occlusion abnormalities were observed in $62.9 \%$ of cases; $42.6 \%$ of the patients' complaints were spontaneously masticatory difficulties. During the post-operative period, the myofascial pain was statistically significant $(p<0.001)$, but normalized after 210 days in average. It also compromised the jaw mobility $(p<0.001)$. It was concluded that this procedure is safe for patients with idiopathic trigeminal neuralgia involving the ophthalmic branch; however, sensory and motor complications of the method can affect the quality of life and rehabilitation of these patients.

Descriptors: trigeminal neuralgia/complications, temporomandibular joint dysfunction syndrome, trigeminal neuralgia/surgery, facial pain, neurosurgery, pain measurement. 


\section{INTRODUÇÃO}

Apesar do grande progresso observado nos últimos anos no campo do diagnóstico laboratorial e de imagem da dor facial, muitos aspectos sobre a anatomia, fisiologia e fisiopatologia das estruturas neurais envolvidas na dor facial e, especialmente, sobre as estratégias terapêuticas destinadas a seu controle e sobre prevenção e tratamento das complicações resultantes necessitam ser esclarecidos.

O histórico das cirurgias destinadas ao tratamento da neuralgia idiopática do trigêmeo (NIT) atesta como, no passado, para seu tratamento, foram empregados abusivamente procedimentos empíricos incapacitantes e ineficazes, que os avanços nos procedimentos surgiram acaso seguindo o conceito de tentativas e erros ou, objetivando maior eficácia, simplicidade e segurança. A existência de diversas técnicas demonstra que o procedimento ideal ainda não foi descrito e que não devem ser considerados curativos ou desprovidos de complicações.

As cirurgias destinadas ao tratamento da NIT podem ser realizadas percutaneamente com objetivo de interromper as vias trigeminais periféricas ou a céu aberto visando à eliminação das supostas causas ou apenas ao alívio da sintomatologia via secção das fibras trigeminais periféricas. A escolha do método depende do estado clínico dos doentes, da etiologia da dor facial, da experiência do neurocirurgião e das condições do ambiente onde o doente é tratado. Os procedimentos ablativos atualmente em uso mais utilizados são representados pelas neurólises térmica, actímica, a química e a mecânica e contemplam critérios de simplicidade, segurança e eficácia. Dentre estes destaca-se a compressão do gânglio e da raiz trigeminal com balão. Entretanto, os critérios para indicação deste 
procedimento e as complicações resultantes de sua execução ainda não foram claramente determinados, o que justifica a realização de pesquisas visando a analisar as anormalidades dele decorrentes. 


\section{OBJETIVOS}

O presente estudo teve como objetivos avaliar em doentes com NIT tratados com a técnica de compressão radículo-ganglionar com balão:

1. A eficácia e a freqüência de recidiva do tratamento;

2. A ocorrência de cefaléia e de dor no corpo e a qualidade de vida;

3. As características odontológicas, a função mastigatória e a ocorrência de disfunção temporomandibular (DTM);

4. A sensibilidade geral superficial nos territórios inervados pelo nervo trigêmeo e as sensibilidades gustatória e visual;

5. A ocorrência de modificações da expressão facial, de anormalidades tróficas e de complicações graves. 


\section{REVISÃO DA LITERATURA}

Neuralgias são síndromes dolorosas restritas à área de inervação de um determinado nervo (Rothman e Monson, 1973). Dor neuropática é dor desencadeada ou causada por lesão primária ou disfunção do sistema nervoso (Merskey e Bogduk, 1994). Dentre as neuralgias essenciais da face, destaca-se NIT, também denominada de tique doloroso, neuralgia essencial do trigêmeo, neuralgia maior do trigêmeo (Loeser, 1985). A NIT é uma das dores mais excruciantes que acometem o ser humano (Kruger e Reynolds, 1965).

\subsection{Histórico}

Segundo Teixeira (1984), a primeira descrição da NIT foi realizada por Arateus no século I d.C. Devido à baixa expectativa de vida, os casos de NIT eram raros na Antigüidade (Teixeira, 1984). De acordo com Ameli (1965), Avicenna (980 - 1036 d.C.), médico e filósofo persa, classificou a paralisia facial juntamente com a NIT, sendo a primeira denominada de paralítica e a segunda, espasmódica, devido ocorrência de contração da musculatura facial. O tratamento NIT era difícil no passado. De acordo com Ameli (1965), diagnóstico, como ainda hoje ocorre, era confundido a dor com doenças dentárias, apesar de já acreditar-se que, na ausência de doenças infecciosas dos tecidos orais os nervos estariam acometidos. Segundo o mesmo autor, Jurjani (1066-1136 d.C.), médico persa, associou a dor e o espasmo facial à ansiedade intensa; atribuiu a dor à proximidade dos vasos com os nervos nas raízes dentárias. 
De acordo com Teixeira (1984), o primeiro caso comprovado de NIT foi o do bispo Button, falecido em 1274 e sepultado na catedral de Wells em Somerset, GrãBretanha; este se queixava de dor dentária e mesmo após inúmeras avaliações realizadas por peregrinos, faleceu sem cura; em sua lápide há a figura de um homem com a face expressando extrema agonia apontando um dente; o exame realizado ulteriormente revelou ausência de anormalidades dentárias.

De acordo com Teixeira, (1984) a primeira descrição mais completa da NIT deveu-se a John Locke (1677). De acordo com Stookey e Ransohoff 1756, Nicolaus Andre sugeriu o termo tic douloureux, devido à sua semelhança com a epilepsia $\mathrm{e}$ John Fothergill, em 1776, contribuiu para a descrição clássica mas ignorou a definição realizada previamente (Katusic et al., 1990; Kanpolat et al., 2001). De acordo com Teixeira, (1984), Thouret (1782) observou que o nervo mais freqüentemente acometido era o infraorbitário e Chaussier, em 1812, classificou-a quanto ao ramo envolvido, mas incluiu o nervo facial no mecanismo de ocorrência. De acordo com Teixeira, (1984), após a identificação anatômica e funcional do nervo trigêmeo realizada por Bell em 1821 que o distinguiu do nervo facial, estratégias cirúrgicas foram elaboradas para tratar NIT, especialmente a partir da segunda metade do século XIX (Marbach, 1999).

\subsection{Definição, critérios e principais características da NIT}

A NIT é classificada no $12^{\circ}$ grupo das dores craniofaciais da Classificação Internacional das Cefaléias (International Headache Society, 2004) e também na Classificação de Dores Crônicas da International Association for the Study of Pain (IASP) (Merskey e Bogduk, 1994). 
O diagnóstico da NIT é fundamentado na história clínica e no exame físico. Trata-se de dor intensa e paroxística, descrita como choque, agulhada ou pontada limitada ao território de distribuição de um ou mais ramos do nervo trigêmeo, desencadeada ou não por eventos definidos e que se instala e desaparece subitamente e reaparece a intervalos variados (Teixeira, 1984). Eventualmente a dor irradia-se para fora da área de distribuição do nervo trigêmeo. Raramente ocorrem pródromos precedendo as crises, descritos como incômodo mal-definido ou formigamento na hemiface ipsilateral. Dor constante precedendo a instalação da NIT caracteriza a “neuralgia pré-trigeminal” (Fromm er al., 1990). A NIT constitui entidade distinta das neuralgias sintomáticas, em que doenças causais são geralmente evidentes e em que se evidenciam anormalidades aos exames neurológico e ou subsidiários (Teixeira, 1998).

Os períodos de remissão podem ser muito longos, mas crises muito freqüentes podem ser descritas como contínuas (Teixeira, 1998). Pode ocorrer dor moderada no intervalo intercrítico. As crises ocorrem geralmente durante meses frios ou quentes e úmidos com baixas condições barométricas (Teixeira, 1984). Ao longo do tempo, os paroxismos prolongam-se e os intervalos de acalmia encurtam-se (Siqueira e Teixeira, 2003).

Fenômenos neurovegetativos representados por salivação, lacrimejamento, rinorréia podem acompanhar as crises (Penman, 1950 apud Teixeira, 1984). Muitas vezes ocorrem contrações clônicas ou espasmos voluntários ou não na hemiface homolateral (Davidoff e Feiring, 1949; Thurel, 1961), expressando sofrimento (Stookey e Ransohoff, 1959; Perkin e Illingworth, 1989), ou talvez visando à correção da postura e ao bloqueio de novas crises (Teixeira, 1998). Essas contrações podem comprometer funcionalmente a musculatura que, por sua vez, gera síndrome 
dolorosa miofacial e agravamento da dor (Siqueira e Teixeira, 2001). A impossibilidade de realizar as atividades habituais compromete a qualidade de vida e do que podem resultar depressão e até suicídio (Patterson, 1999).

Apesar das controvérsias (Lang et al., 2005), nas neuropatias trigeminais os testes sensitivos demonstraram envolvimento de fibras amielínicas caracterizado como aumento no limiar aos estímulos frios e ao calor (Renton et al., 2003) e sensibilização de nociceptores periféricos do tipo C (Eide and Rabben, 1998; Eide and Stubhaug, 1998). Essas anormalidades podem ser bilaterais (Jaaskelainen et al., 2005).

\subsection{Epidemiologia da dor facial}

Mais de $90 \%$ dos indivíduos apresenta dor no segmento cefálico em algum momento da vida; a dor torna-se crônica em 10\% destes casos (Lipton e Stwart, 1997). Cerca de $80 \%$ da população apresenta ou apresentou cefaléia tipo tensão (Schoenen e Sandor, 1999). Admite-se que 90\% dos homens e 95\% das mulheres apresentem cefaléia, pelo menos uma vez ao ano, e que $22 \%$ dos indivíduos apresentem dor facial (Lipton, 1997). De acordo com Von Korff et al. (1989), 39 milhões de adultos norte-americanos (cerca de $22 \%$ de toda a população) haviam sofrido dor orofacial durante mais de seis meses. A dor no segmento cefálico é bastante freqüente nos brasileiros: cefaléia tensional (60,2\%), migrânea $(48,6 \%)$ e odontalgia $(38,4 \%)$ são as mais comuns queixas de dor craniana ou facial na nossa população (Teixeira et al., 1995).

A neuropatia causada pelo vírus Herpes zoster acomete 1,3 indivíduo a cada 1.000 habitantes ao ano (Teixeira, 1990) e manifesta-se na face em $17 \%$ a $25 \%$ dos 
doentes; destes, $88 \%$ a 94\% apresentam acometimento do nervo trigêmeo (Siqueira e Teixeira, 2001).

Ocorre esclerose múltipla em um a três/100.000 habitantes ao ano na América do Norte (Kurtzke, 1985); ocorre dor neurogênica em 28\% dos casos de esclerose múltipla em 1\% a 4\% dos doentes com histórico de NIT (Lazar et al., 1980).

Identificou-se dor na articulação temporomandibular (ATM) em 63,5\% dos indivíduos incluídos no levantamento comunitário organizado por Von Korff et al. (1988).

Ocorreu dor orofacial em $17,4 \%$ dos 5860 adultos com idade igual ou superior a 65 anos atendidos pela na Equipe de Dor Orofacial do Hospital das Clínicas da Faculdade de Medicina da Universidade de São Paulo (EDOF FMUSP) (Siqueira e Teixeira, 2001). Segundo Siqueira e Ching (1999), 5\% de 80 doentes edêntulos avaliados com o suposto diagnóstico de DTM na EDOF FMUSP apresentavam NIT. Prado (2002), observou que 50\% dos 20 doentes avaliados com diagnóstico de dor facial atípica apresentavam DTM como causa primária da sintomatologia. Siqueira et al. (2004) avaliaram as condições odontológicas de 50 doentes com NIT; 72\% dos doentes apresentava zona de gatilho intraoral, 16\%, DTM e 6\%, síndrome da ardência bucal; um doente com DTM apresentava trismo secundário à compressão do gânglio trigeminal com balão e $42 \%$, limitações importantes para a execução das atividades.

A NIT é 100 vezes mais freqüente do que a neuralgia do glossofaríngeo (White e Sweet, 1940; Bruzustowcz, 1955; Bohm e Strang, 1962; Chawla e Falconer, 1967; Zarzewska, 1999). Ocorreram 155 casos de NIT a cada 1.000.000 de habitantes nos Estados Unidos da América (EUA) (Beaver, 1965); prevalência similar foi constatada na Itália (Buscaino, 1980) e na França (Zarkewska, 1999). Houve 4,3 
casos novos anuais a cada 100.000 habitantes de NIT em Rochester, Minnesota (EUA), de 1945 a 1984 (Katusic et al., 1990); identificaram-se cinco casos novos de NIT ao ano a cada 100.000 mulheres e 2,7 casos novos ao ano a cada 100.000 homens nos EUA no levantamento de Yoshimasu et al. (1972). Estima-se que ocorram 7000 casos novos de NIT por ano nos EUA (Rothman e Monson, 1973).

Rothman e Monson (1973) realizaram levantamento epidemiológico no Hospital Geral de Massachusetts (Boston, EUA) envolvendo doentes com NIT de 1955 a 1970. O acometimento foi superior nas mulheres; tabagismo e alcoolismo não foram relacionados ao desenvolvimento da neuralgia. Os não-judeus e doentes com esclerose múltipla compuseram grupo de risco; outros imigrantes e indivíduos com história pregressa de tonsilectomia apresentaram menor risco de desenvolvimento de NIT.

No levantamento de Katusic et al. (1990), a prevalência de NIT foi maior no sexo feminino e nos idosos e o risco foi mais elevado em doentes com hipertensão arterial ou esclerose múltipla. A NIT não reduziu a expectativa de vida dos doentes.

Em Singapura e na Malásia, onde 2/3 da população é chinesa, Loh et al. (1998) observaram resultados semelhantes; houve maior tendência de ocorrência de NIT na população chinesa do que na população local e aumento progressivo da intensidade e da freqüência das crises paralelamente à ocorrência dos sintomas de depressão ou tendência suicida nos doentes refratários ao tratamento.

\subsection{Anatomia e histologia da raiz e gânglio trigeminal}

Proximamente ao gânglio trigeminal, nas proximidades da ponte, identificamse duas raízes trigeminais: uma motora e outra sensitiva, que penetram separadamente no tronco encefálico (Janneta, 1963). A raiz sensitiva contém cerca de 
144.000 fibras, quase nunca paralelas. De acordo com Jannetta (1963) há numerosas anastomoses entre as duas raízes, constituindo o denominado plexo triangular descrito por Krause em 1896. Há também fibras sensitivas acessórias entre a raiz principal e a motora, possivelmente responsáveis pela sensação do toque suave e pela preservação desta e da sensibilidade corneana em doentes submetidos à rizotomia trigeminal por via suboccipital (Teixeira, 1984). Enquanto as fibras da raiz principal coalescem num tecido gelatinoso, fibras intermediárias deixam a raiz principal, penetram na ponte nas proximidades da raiz motora e alcançam os núcleos trigeminais. Aparentemente, essas fibras são relacionadas ao ramo mandibular (Jannetta, 1963).

A transição é abrupta entre o sistema nervoso central (SNC) e o periférico (SNP); processos astrocitários e oligodendrocitários do SNC relacionam-se com as células de Schwann do SNP na chamada "zona da entrada da raiz nervosa" (Teixeira, 1999). Nessa região, comumente a mielina é desorganizada e mal-preservada e podem ocorrer herniações (Maxwell, 1963).

Histologicamente, o gânglio trigeminal do ser humano é similar ao das outras espécies. A coloração dos corpos celulares, do citoplasma e do núcleo dos neurônios é homogênea e ocorrem pigmentos citoplasmáticos semelhantes aos da melanina, encontrados também no loco cerúleo e na substância negra do homem e de alguns macacos (Moses, 1963). Há pigmentos estruturalmente semelhantes à lipofuscina nos neurônios também observados em outras espécies; estes aumentam de concentração no citoplasma com o progredir da idade e estabilizam-se no indivíduo adulto (Moses, 1963). As células ganglionares apresentam muitos mitocôndrias, ribossomos livres, grânulos de glicogênio, retículo endoplasmático exuberante e extensos microtúbulos e microfilamentos entre os corpos de Nissl (Maxwell, 1963). 
A relação dos neurônios com as células satélites aparenta ser mais complexa nos seres humanos do que em outras espécies; estes, muitas vezes, formam interdigitações. As fibras amielínicas são menores e freqüentemente parcialmente envolvidas pelas células de Schwann. As fibras mielinizadas apresentam muitos mitocôndrias na região dos nódulos de Ranvier (Moses, 1963). A desmielinização que ocorre em áreas isoladas com o progredir da idade aparentemente não gera alterações histológicas intra-neuronais e é menos freqüente no gânglio trigeminal (Kerr, 1963a). As alterações características da autólise postmortem são mais freqüentes nas fibras mais grossas (Moses, 1963).

\subsection{Etiologia da NIT}

Observou-se vacuolização do citoplasma não associada à autólise, ruptura das células de Schwann e dispersão de seu conteúdo, células sadias circundando bainhas de mielina desorganizadas, irregulares, fragmentadas e com aparência de degeneração e tortuosidade axonial (microneuromas) nos neurônios em material de biópsia do gânglio trigeminal de doentes com NIT (Kerr, 1963b). Esses achados podem ser tanto causa como conseqüência da NIT, são característicos da degeneração neuronal e são também observados em doentes com esclerose múltipla, condição em que pode ocorrer neuralgia facial com características semelhantes das NIT, e em doentes com outras neuropatias, como a síndrome de Guillian-Barré (Beaver, 1963; Kerr, 1963b).

A NIT foi atribuída à infecção pelo vírus Herpes simplex pois a erupção viral é comum nestes casos (Teixeira, 1984); a neuropatia infecciosa poderia gerar hiperexcitabilidade neuronal e dor decorrente das alterações das proteínas relacionadas aos canais iônicos (Ecker e Smith, 2002). Cavidades ósseas infectadas 
na maxila e ou na mandíbula também foram relacionadas à NIT (Lazar et al., 1980; Shira, 1984). Graff-Radford (1991), entretanto, observou que estas cavidades eram comuns em indivíduos sem NIT e que não pareciam estar envolvidas na sua ocorrência.

É possível haver predisposições constitucional e genética que, associadas aos estressores ambientais, poderiam resultar na manifestação da NIT (Riddoch, 1941; Waisbrod et al., 1984; Teixeira, 1998). A NIT é familiar em 2,6\% a 6\% dos casos, condição em que há maior prevalência de neuralgia bilateral; herança autossômica dominante, autossômica recessiva e, possivelmente ligada ao cromossomo X, pode estar envolvida na ocorrência de quadros familiares (King, 1963).

Processos tumorais intracranianos (neurinoma do nervo acústico, cisto epidermóide, osteoma, meningioma) (Graff-Radford, 1991; Teixeira, 1998; Pemberton et al., 2001) ocorrem em até 5\% dos doentes com quadro clínico semelhante ao da NIT e caracterizam a neuralgia trigeminal sintomática (Teixeira, 1998). Outras causas da dor são representadas por malformações arteriovenosas, aneurismas, aderências aracnoídeas ou deformidades ósseas (Malis, 1963; KrmpoticNematic et al., 1999). A distorção da "zona de entrada da raiz trigeminal" por artérias ou veias parece estar relacionada à ocorrência da NIT porque a descompressão neurovascular dessa região freqüentemente resulta em melhora da dor (Janneta, 1973a); exames de imagem tridimensionais (interferência construtiva constante) são bastante precisos para identificar o vaso responsável pela compressão. A artéria superior do cerebelo é a mais comum causa da compressão; foi identificada em $46 \%$ dos casos de Yoshino et al. (2003). A descompressão venosa geralmente associa-se a recorrência após a cirurgia (Kerr, 1963c; Hussein et al., 1982). 


\subsection{Fisiopatologia}

A fisiopatologia da NIT é desconhecida (Kruger e Reynolds, 1965). A neuralgia sintomática do trigêmeo pode ser decorrente de anormalidades estruturais evidenciáveis nas unidades anatômicas trigeminais centrais ou periféricas (IASP, 1996); a média das idades dos doentes com neuralgia sintomática, entretanto, geralmente é menor que dos doentes com NIT (Pemberton et al., 2001).

Doenças localizadas nas raízes ou gânglios dos nervos sensitivos cranianos podem causar dor lancinante e intensa, constante ou intermitente, que pode ser aliviada após o bloqueio ou secção radicular (Kruger e Reynolds, 1965). A dor neuropática de origem central é a "dor espontânea ou reação excessiva à estimulação objetiva, incluindo a disestesia e as sensações desagradáveis, resultantes de lesões confinadas ao sistema nervoso central" (Pert e Snyder, 1973).

Foram evidenciadas alterações eletromiográficas nos músculos temporal e masseter no lado afetado pela NIT possivelmente decorrentes de anormalidades do ramo motor do nervo trigêmeo. $\mathrm{O}$ fato de este ser misto, de haver maior prevalência de acometimento dos ramos maxilar e mandibular e freqüência mais elevada de zonas de gatilho na região perioral, podem implicar esta estrutura na gênese da dor em casos de NIT (Saunders et al., 1971).

Sensibilização de receptores, ocorrência de focos ectópicos de potenciais de ação nas fibras nervosas periféricas e centrais e atividade anormal das unidades de processamento central das aferências sensitivas e dos sistemas supressores são mecanismos que contribuem para a ocorrência da dor neuropática (Teixeira, 1990). Há evidências de degeneração axonal no gânglio e raiz trigeminal no material de autopsia de doentes com NIT (Devor et al., 2002). Modelos de dor neuropática revelam que as alterações da sensibilidade mecânica são mais evidentes que as 
alterações da sensibilidade térmica e que estas são mais relacionadas aos mecanismos de sensibilização periférica (Danziger et al., 2001). Há organização do tecido nervoso em neuromas ou microneuromas que se tornam fonte de atividade ectópica e correntes efáticas em casos de dor neuropática periférica (não-paroxística) (Teixeira, 2003). Devido a anormalidades da bainha de mielina na "zona de entrada do trigêmeo", ou seja no local onde as bainha de mielina produzida no SNC entra em contato com a bainha de mielina produzida no SNP, potenciais ectópicos seriam gerados causando as crises (Lazar et al., 1980; Teixeira, 1998; Patterson, 1999; Pemberton et al., 2001).

A inflamação neurogênica no local da lesão ou das terminações nervosas participa também do mecanismo de geração e manutenção da dor neuropática; ocorre inflamação crônica mesmo após período prolongado de tempo que se segue à lesão dos ramos trigeminais (Anderson et al., 2002).

Não ocorre proliferação dos elementos nervosos do sistema nervoso simpático no gânglio trigeminal após a lesão do nervo trigêmeo tal como observado nos nervos sensitivos espinais (Teixeira, 2003). Os fenômenos neurovegetativos simpáticos são mais comumente observados após a lesão de estruturas nervosas periféricas espinais, talvez porque, nesses casos, haja mais atividade de fatores de crescimento nervoso que induzem brotamento neuronal (Benoliel et al., 2001).

Acredita-se que mecanismos centrais estejam primariamente envolvidos na geração da NIT (King, 1963). Mecanismos centrais justificariam o porquê que tanto a descompressão quanto a compressão nervosa melhoram a sintomatologia (Kerr, 1963c). Entretanto, é difícil imaginar que a lesão ou disfunção do SNC privilegia-se apenas os neurônios trigeminais, ainda mais alguns ramos específicos. Fibras nervosas provenientes dos V, VII, XI e X nervos cranianos e dos três primeiros 
nervos cervicais convergem no subnúcleo caudal do nervo trigêmeo o que se possibilita a ampliação da área de dor (Namba et al., 1985). A hiperatividade das fibras nervosas lesadas ativa os receptores N-metil-D-aspartato presentes nos neurônios do complexo nuclear trigeminal (Christensen et al., 1999), sensibilizandoos.

Elicia-se reflexo cervical ventral e não apenas nos músculos dorsais em suínos após estimulação do complexo nuclear trigeminal devido à existência de aferências para o subnúcleo oral (Kato et al., 2003). Conexões recíprocas entre neurônios do subnúcleo caudal e núcleos rostrais do complexo nuclear trigeminal podem causar hiperpolarização prolongada o que corrobora a importância dos mecanismos centrais na geração da NIT (King, 1963).

\subsection{Tratamento da NIT}

Apesar de reconhecida há mais de 2000 anos, os tratamentos realmente eficazes e seguros para alívio da NIT passaram a ser aplicados somente a partir do fim do século (Teixeira, 1984).

Diversos métodos empíricos foram propostos no passado para tratar a NIT ao longo da história. De acordo com Teixeira (1984), Locke (1677) utilizou laxantes e Fothergill (1773) fez uso de quinino. Outras substâncias também foram utilizadas, como arsênico, ácido hidrociânico, aspirina, atropina, ópio, estriquinina, protamina, veneno de abelha ou de cobra, vacina antitífica, ácido ósmico, iodo, carbonato de ferro, brometo de potássio, sais de cálcio ou de cobre, vasodilatadores (nitrito de amila, histamina, nitroglicerina, carbogênio, ácido nicotínico, papaverina, tolasolina), ergotamina, anti-histamínicos (piribenzamina, difenidramina), complexos vitamínicos (Stoodey e Ransohoff, 1959). Acupuntura, tratamento da sinusite, uso de 
óculos, exodontias e cirurgias endodônticas, dentre outras modalidades terapêuticas, foram também utilizados no passado sem beneficiar os doentes (Lazar et al., 1980; Okeson e Falace, 1997; Siqueira e Ching, 2001, Siqueira et al., 2004).

Atualmente, recomenda-se que doentes com NIT devam ser tratados primordialmente com fármacos. Entretanto, apesar de ocorrer inicialmente controle satisfatório com o uso de medicamentos na maioria dos casos, ao longo do tempo, cerca de $75 \%$ dos doentes necessita procedimentos neurocirúrgicos funcionais para tratar a dor (Teixeira, 1998).

\subsubsection{TRATAMENTO MEDICAMENTOSO}

De acordo com Teixeira, (1984), no início do século XX, verificou-se que o tricloroetileno causava hipalgesia da face e proporcionava melhora da NIT. Este foi o primeiro fármaco realmente eficaz para tratar NIT. Entretanto, sem uso clínico foi abandonado ulteriormente, pois causava lesão de outros nervos. Verificou-se, também que a estilbamidina proporcionava o mesmo efeito, mas a sua eficácia era inferior.

Atualmente, utilizam-se anticonvulsivantes, miorrelaxantes de ação central, neurolépticos e anestésicos locais para tratar farmacologicamente doentes com NIT (Neidle e Yagiela, 1989).

Os anticonvulsivantes são os agentes farmacológicos mais utilizados. Segundo Teixeira (1984), Bergoignan, em 1942, utilizou pela primeira vez a difenil-hidantoína para tratar doentes com NIT; este agente proporciona melhora em $54 \%$ a $70 \%$ dos casos. A carbamazepina passou a ser utilizada em 1962 e ainda é o medicamento mais empregado (Graff-Radford, 1991; Chapman et al., 1998; Reisner e Pettengill, 2001), pois proporciona resultados iniciais excelentes em $40 \%$ a $100 \%$ dos doentes; a 
melhora inicial mantém-se em $81 \%$ dos casos durante seis meses e adicionalmente em mais $7 \%$ a $10 \%$ quando a carbamazepina é associada à difenil-hidantoína ou à mefenesina (Teixeira, 1998; Idanpaan-Heikkila e Guilbald, 1999). Entretanto, ocorrem efeitos adversos em 15\% a 20\% dos casos (Lazar et al., 1980; Dalessio, 1982; Graff-Radford, 1991; Teixeira, 1998; Patterson, 1999; Pemberton et al., 2001), o que justifica a necessidade da freqüente monitorização hematológica ou sua substituição por outros anticonvulsivantes (Teixeira, 1998; Garcia Callejo et al., 1999). A oxicarbazepina apresenta menos efeitos colaterais do que a carbamazepina e na sua eficácia necessita ainda ser melhor analisada (Sindrup e Jensen, 1999; Ichikawa et al., 2001; Kiguchi et al., 2001; Reisner e Pettengill, 2001). O clonazepam proporciona alívio da dor em $22 \%$ a $50 \%$ dos casos, mas é menos tolerado. O valproato de sódio, o topiramato, a gabapentina, a vigabatrina e a lamotrigina parecem também ser eficazes, mas são menos utilizadas (Christensen et al., 2001; Reisner e Pettengill, 2001).

O baclofeno proporciona melhora inicial em 60\% dos casos (King, 1958). A lidocaína, administrada por via parenteral ou aplicada topicamente, a capsaicina aplicada topicamente, a mexiletina, o propanolol e a pimozida (Lazar et al., 1980; Guerrero Figueroa et al., 1999), os agonistas serotoninérgicos 5HT $\mathrm{HA}_{1 \mathrm{~A}}$ (Deseure et al., 2002) e a toxina botulínica (Micheli et al., 2002) também parecem ser úteis em alguns doentes. O bloqueio dos ramos trigeminais com anestésicos locais pode proporcionar melhora temporária, mas necessita ser realizado freqüentemente para manter o benefício (Goto et al., 1999). 


\subsubsection{TRATAMENTO CIRÚRGICO}

Os tratamentos cirúrgicos podem consistir da eliminação das supostas causas da NIT ou da ablação ou interrupção de estruturas sensitivas trigeminais periféricas ou centrais (neurotomias, gangliotomias, rizotomias a céu aberto pela fossa média ou posterior; rizotomias percutâneas pelo calor, agentes químicos, radiação ionizante, compressão do gânglio trigeminal a céu aberto ou com balão, tratotomia trigeminal, nucleotratotomia bulbar ou pontina, talamomesencefalotomia, topectomia) (Lazar et al., 1980; Teixeira, 1984).

De acordo com estudo metaanalítico recentemente publicado, não foi possível determinar-se qual a melhor técnica cirúrgica para tratar doentes com NIT, pois apesar de existirem inúmeros trabalhos que avaliam a eficácia, a recidiva e as complicações das diversas cirurgias funcionais, a metodologia utilizada em muitos deles não possibilita a comparação entre elas (Zakrzewska e Lopez, 2003). Os métodos percutâneos são mais utilizados por serem mais simples e seguros. Entretanto, podem causar complicações relacionadas a anormalidades do aparelho mastigatório, comprometimento da sensibilidade ou à desaferentação, como dor neuropática contínua, lesões oculares, lesões tróficas cutâneas e ou mucosas, infecção pelo vírus do Herpes simplex, etc (Teixeira, 1998).

\subsubsection{Eliminação das causas}

\subsection{Descompressão neurovascular}

A descompressão neurocirúrgica da raiz trigeminal visa a eliminar a distorção da "zona de entrada" da raiz do nervo trigêmeo por vasos alongados, tumores, granulomas, aderências aracnóideas etc. (Broggi et al., 1990; Kanpolat et al., 2001). De acordo com Teixeira (1984) foi descrita por Dandy na década de 1920; durante a 
abertura da fossa craniana posterior de doentes submetidos à rizotomia trigeminal a céu aberto esse autor notou que freqüentemente havia anormalidades na raiz trigeminal. $\mathrm{O}$ aperfeiçoamento do conceito de anormalidade da região da raiz trigeminal deveu-se a Gardner e Miklos (1958) e a Jannetta (1963).

A descompressão neurovascular proporciona melhora imediata na maioria dos casos. Entretanto, para a sua realização é necessária a abertura do crânio, a manipulação mecânica do tecido nervoso e a monitorização do doente. Não se evidenciam anormalidades em um número significativo de casos havendo necessidade da secção da raiz sensitiva do nervo trigêmeo em até $26 \%$ dos casos especialmente quando não há transtornos evidentes. A descompressão neurovascular é a técnica que proporciona melhora mais prolongada. Ocorre alívio da dor em $66 \%$ dos doentes durante mais de cinco anos (Pollack et al., 1988). Hipoestesia ou hipalgesia facial, anestesia dolorosa, comprometimento intenso da sensibilidade, fraqueza do músculo masseter, paresia do IV nervo craniano $(4,3 \%)$, déficit auditivo, ataxia, déficit motor facial, tromboembolismo pulmonar, infecções e fístulas liquóricas são as complicações mais comuns desse procedimento (Pollack et al., 1988) A taxa de taxa de mortalidade é de $1 \%$ a 4,3\% (Pollock et al., 2000; Kanpolat et al., 2001). A insatisfação expressada por doentes com NIT até 20 anos após a descompressão neurovascular deve-se não apenas à persistência ou recorrência da dor, mas também à hipoacusia ou ao déficit motor facial (Kondo, 1997).

O método é especialmente indicado para tratar indivíduos jovens que pretendem preservar a sensibilidade facial, ou quando há suspeita de lesão expansiva intracraniana, ou há associação da NIT com outras neuralgias ou com espasmo hemifacial ou ocorre NIT bilateral (Pollack et al., 1988; Taha e Tew, 1996; Teixeira, 1998; Siqueira e Teixeira, 2003). 
3.7.2.1.2. Eliminação de fatores irritantes teciduais

A curetagem óssea intraoral proporcionou alívio completo da dor em $88 \%$ dos doentes com NIT (Graff-Radford, 1991) talvez porque remova os tecidos desaferentados de regiões infectadas e inflamadas e estimule fibras nervosas de grosso calibrosas (fibras do tipo A) (Melzack e Wall, 1965; Shira, 1984).

\subsubsection{Interrupção das vias trigeminais}

\subsection{Neurotomias}

A alcoolização ou a neurotomia dos troncos distais do nervo trigêmeo proporcionam eficácia de curta duração, geralmente durando menos de um ano (Lazar et al., 1980). Apesar de seguras, especialmente quando repetidas, mesmo com a crioanalgesia é elevada a ocorrência de recidiva, pois podem gerar neuromas trigeminal atípica e não são mais muito realizada (Chindia e Ng’ang’a, 1994; Frady e Patton, 1994; Peters e Nurmikko, 2002). Entretanto, são úteis para proporcionar alívio temporário enquanto os doentes não são encaminhados para os centros de neurocirurgia especializados em dor (Fardy e Patton, 1994), ou quando os há anormalidades clínicas que tornam as cirurgias sob sedação ou anestesia geral muito arriscadas (Oturai et al., 1996), ou quando ambiente assistencial que não dispõe de equipamentos para realização de microcirurgia ou neurocirurgia funcional (Chindia e Ng'ang'a, 1994; Peters e Nurmikko, 2002).

\subsection{Rizotomia percutânea por radiofreqüência}

A radiofreqüência lesa irreversivelmente fibras finas mielínicas e amielínicas por ação do calor variando de $55^{\circ} \mathrm{C}$ a $70^{\circ} \mathrm{C}$ (Yoon et al., 1999); originalmente imaginou-se que poupava fibras nervosas de diâmetro médio (Gregg et al., 1978; 
Broggi et al., 1990); entretanto, demostrou-se em animais que fibras mielinizadas grossas são preferencialmente desnaturadas pelo procedimento (Pollock et al., 2000). Desde sua descrição por Sweet (1969) é amplamente utilizada para tratar doentes com NIT (Brown et al., 1993). O resultado do tratamento depende da experiência do neurocirurgião pois sua execução inadequada pode ocasionar complicações graves (Broggi et al., 1990; Egan et al., 2001), Proporciona melhora inicial da NIT em 97,6\% a 99\% dos doentes (Teixeira, 1984; Taha et al., 1995; Kanpolat et al., 2001); às custas de recidiva ao longo de cinco anos em $21 \%$ a $28 \%$ dos casos (Lichtor e Mullan, 1990; Taha et al., 1995; Choudhury et al., 1999; Mathews e Scrivani, 2000), principalmente durante os três primeiros anos após a cirurgia, e de $18 \%$ a $20 \%$ em 10 anos (Taha e Tew, 1996). É provável que quanto mais intenso for o déficit sensitivo imediato, mais expressiva deverá ser a manutenção da melhora ao longo do tempo (Broggi et al., 1990; Peters e Nurmikko, 2002). Os resultados foram melhores em doentes com NIT típica envolvendo um ramo isoladamente da casuística de Yoon et al. (1999). Os mesmos autores observaram que quanto mais prolongado foi o período de tempo sem dor, mais rara foi a recidiva.

A mortalidade decorrente da rizotomia por radiofreqüência é baixa (1\%); quando ocorre, relaciona-se principalmente a hemorragias intracranianas (Goçer et al., 1997; Peters e Nurmikko, 2002). A morbidade pode ser elevada e representada por lesão inadvertida dos ramos vizinhos àquele acometido pela dor $(12,3 \%$ a $46 \%)$, hipoestesia $(16 \%$ a $23 \%)$ ou anestesia da córnea $(2 \%$ a $12 \%)$, déficit do reflexo córneo-palpebral sem dano da córnea $(19,7 \%)$, ceratite $(0,6 \%$ a 4\%), úlcera de córnea (1\% a $2 \%)$, parestesias $(8 \%$ a $10,9 \%)$, anestesia dolorosa da face (em até $5 \%$ ), analgesia e preservação do tato $(1,7 \%)$, anestesia em pelo menos um ramo do nervo trigêmeo (17\%), erupção pelo vírus Herpes simplex (40\%), sensação de dormência 
$(58 \%$ a $79 \%)$, disestesias $(0,5 \%$ a $20 \%$ destes necessitam uso prolongado de medicamentos para controlá-la), déficit motor da mastigação (4\% a 53\%), trismo mandibular (1\%), DTM (1\%), déficit auditivo (1\%) paralisia dos nervos oculares III ou IV, rinorréia vasomotora, aumento ou redução da salivação, atrofia da mucosa nasal, disfagia etc. (Lichtor e Mullan, 1990; Coudhury et al., 1991; Brown et al., 1993; Taha et al., 1995; Yoon et al., 1999; Kanpolat et al., 2000; Mathews e Scrivani, 2000; Pollock et al., 2000). Disestesias ocorrem geralmente quando a sensibilidade facial torna-se intensamente comprometida (Taha et al. 1995). A mastigação unilateral pode resultar da hipoestesia da mucosa oral e dificultar a adaptação de próteses dentárias (Teixeira, 1984).O déficit sensitivo da córnea é mais freqüente em doentes com neuralgia do ramo oftálmico (31,4\%).

Complicações graves são raras e representadas por fístula carótido-cavernosa (Yoon et al., 1999), meningite, abscesso do lobo temporal, hemorragia intracraniana, lesões vasculares isquêmicas e infarto do miocárdio (Teixeira, 1984, Bilgin et al., 2002).

Segundo Salar et al. (1983), doentes submetidos à lesão sob temperatura de $60^{\circ} \mathrm{C}$ a $70^{\circ} \mathrm{C}$ apresentam alterações sensitivas discretas e mais recorrência enquanto que os submetidos a tratamento com temperaturas mais elevadas (superiores a $70^{\circ} \mathrm{C}$ ) apresentam mais parestesias. Mathews e Scrivani (2000) referem melhora das complicações mastigatórias após o tratamento com exercícios mandibulares.

\subsection{Compressão radículo-ganglionar com balão}

A técnica de compressão do gânglio e da raiz trigeminal com balão foi desenvolvida em 1978 e divulgada em 1983 (Lichtor e Mullan, 1990; Brown et al., 1993). Consiste na insuflação de um balão via cateter introduzido por punção do 
forame oval com agulha para comprimir o gânglio e as raízes trigeminais (Brown et al., 1993; Úrculo et al., 1998; Peters e Nurmikko, 2002). As características anatômicas individuais parecem ser mais importantes do que a pressão do balão para influenciar o resultado da cirurgia (Lobato et al., 1990). Em 1\% dos doentes o forame oval não é largo o suficiente para ser transfixado pela agulha de punção que é muito calibrosa (Kanpolat et al., 2001). Quando o balão adquire formato de pera, a melhora é mais satisfatória (Úrculo et al., 1998; Kanpolat et al., 2001). A lesão decorre da distorção e descompressão da dura-máter ganglionar, de fenômenos isquêmicos imediatos e fisiológicos tardios. A compressão rápida causa mais edema pois aumenta a permeabilidade microvascular. Quando é lenta, causa mais isquemia, hemorragia, infiltrado macrofágico, fragmentação, edema, degeneração axonal retrógrada (Preul et al., 1990) aumento da substância P e da proteína relacionada ao gene da calcitonina (CGRP) nas lâminas I e II de Rexed do subnúcleo caudal do trato espinal do nervo trigêmeo. Evidencia-se redução do diâmetro da raiz sensitiva 270 dias após o procedimento. Pressões superiores a $500 \mathrm{mmHg}$ geram alterações celulares discretas e degeneração insignificante das fibras nervosas, enquanto que pressões superiores a $1.000 \mathrm{mmHg}$ mais freqüentemente causam trans-secção que compressão das fibras (Brown et al., 1996). Fibras grossas sofrem mais os efeitos da compressão, sendo o ramo mandibular o mais acometido (Brown et al., 1996; Peters e Nurmikko, 2002). Em gatos, a compressão do gânglio a céu aberto induziu alterações degenerativas proporcionais à magnitude da pressão nas fibras do nervo trigêmeo até o tronco encefálico; os corpos celulares presentes no gânglio trigeminal foram relativamente preservados, o que significa possibilidade de regeneração nervosa (Kerr, 1963c) e de recuperação, pelo menos parcial, da sensibilidade (Preul et al., 1990). O mesmo foi observado em coelhos (Brown et al., 1996). 
Provavelmente, o alívio decorre da lesão das fibras mielinizadas envolvidas no desencadeamento da dor pela a estimulação da "zona de gatilho" (Brown et al., 1996).

A cirurgia é mais simples que a rizotomia por radiofreqüência pois não depende da participação do doente, pode ser realizada sob anestesia local e com o doente desperto ou sob anestesia geral (Belber e Rak, 1987; Lobato et al., 1990; Abdennebi et al., 1995; Natarajan, 2000). É especialmente indicada em casos em que há risco elevado para a realização da descompressão neurovascular ou quando os doentes são jovens e pretendem preservar a função trigeminal, principalmente a sensitiva (Brown et al., 1993), quando o cirurgião não é familiarizado com o procedimento de radiofreqüência, quando os doentes são pouco cooperativos ou anacúsicos (Lichtor e Mullan, 1990) ou quando a dor localiza-se no território do ramo oftálmico.

\subsection{Rizotomia percutânea com glicerol}

A rizotomia química com o uso do glicerol foi desenvolvida por Hakanson em 1981. Consiste da aplicação percutânea, via punção do forame oval, glicerol no gânglio trigeminal sob anestesia local e sedação (Schädelin et al., 1988; Jho e Lunsford, 1997) para induzir desmielinização e fragmentação axonal (Peters e Nurmikko, 2002). São necessários quatro a seis dias para ocorrer melhora em cerca de metade dos doentes (Brown et al., 1993); proporciona alívio da dor em 55\% dos casos em até 11 anos de acompanhamento (Kanpolat et al., 2001). É indicada principalmente quando a dor localiza-se no território do ramo oftálmico do nervo trigêmeo. 
Não é necessária indução de déficit sensitivo para aliviar a sintomatologia (Jho e Lunsford, 1997). De acordo com Eide e Stubhaug (1997), a somação temporal de estímulos decorrente da estimulação das fibras grossas é abolida pelo glicerol.

Jho e Lunsford (1997) observaram hipertensão arterial em 20\% dos casos, hipotensão e bradicardia em $15 \%$ durante a punção do forame oval, tromboembolia em $15 \%$, pneumocéfalo em $3 \%$, hematoma subdural em $2,3 \%$, hemiparesia e ou disfunção de nervos cranianos, geralmente reversíveis em pequeno número; ao longo do tempo, ocorreu disestesia importante em $2 \%$ dos doentes, Rambacher et al. (2000) observaram ocorrência de anosmia. De acordo com Kondo (1997), ocorre déficit da função auditiva em 5,9\% a 19,5\% dos doentes. Kumar et al. (1995) observaram melhora significante do reflexo córneo-palpebral previamente alterado em $54 \%$ dos doentes após o procedimento. Mais raramente, pode ocorrer meningite (Peters e Nurmikko, 2002). A ocorrência freqüente de disestesias faciais (20\%) (Broggi et al., 1990; Brown et al., 1993); e outras complicações e a elevada freqüência de recorrência ( $9 \%$ a $50 \%$ dos casos) foram razões do abandono de seu uso na maioria dos centro neurocirúrgicos (Teixeira, 1998).

\subsection{Radiocirurgia}

De acordo com Kondziolka et al. (1997), a radiocirurgia foi utilizada por Leksell para tratar doentes com NIT desde 1951. Proporciona melhora inicial em mais de $80 \%$ dos doentes com NIT tratados. Entretanto, pouco mais que 50\% deles permanece sem dor ao longo do tempo após o procedimento. Sua repetição é necessária em 13\% a 20\% dos doentes (Lichtor e Mullan, 1990). Para reduzir a freqüência de recidiva, utilizaram-se doses de irradiação mais elevadas em alguns centros. A radiação ionizante altera o fluxo axonal e gera lesão, incluindo a necrose 
de fibras trigeminais grossas e finas em macacos; o gânglio trigeminal é preservado e os nervos periféricos apresentaram alta resistência à irradiação. Não há, entretanto, evidências de que o método seja seletivo para fibras amielínicas (Kondziolka et al., 2000). Há maioria dos doentes instala-se disfunção trigeminal e ocorrem dormência facial ou parestesias em 2,6\% a 10\% dos casos (Pollock et al., 2000).

A técnica radiocirúrgica é indicada em doentes em que as condições clínicas não são favoráveis para a realização de anestesia geral necessária para a descompressão neurovascular, ou quando há discrasias sangüíneas, lesões anatômicas, infecciosas ou vasculares que impossibilitam a realização dos procedimentos percutâneos (Siqueira e Teixeira, 2003). 


\section{MÉTODOS}

Foram avaliados 105 doentes com o diagnóstico de NIT de acordo com os critérios da IASP (Merskey e Bogduk, 1994) e com indicação de tratamento neurocirúrgico funcional selecionados do Ambulatório de Dor Crânio-Facial do Centro de Dor da Divisão de Clínica Neurológica do Hospital das Clínicas da Faculdade de Medicina da Universidade de São Paulo.

Foram incluídos apenas os doentes que concordaram em participar do estudo, que assinaram o termo de consentimento livre e esclarecido e que estavam em condições de participar e entender o programa de avaliação funcional. Todos haviam sido previamente submetidos a avaliação clínica, neurológica e odontológica e a exames de imagem (tomografia computadorizada do crânio com e sem contraste e ou ressonância magnética do segmento cefálico) e tratamento farmacológico com anticonvulsivantes (carbamazepina, fenitoína, oxicarbazepina) e ou baclofeno dentre outros antineurálgicos. Em nenhum evidenciaram-se anormalidades nos exames de imagem relacionadas à neuralgia. A cirurgia foi indicada porque não havia ocorrido melhora, ou manifestaram-se efeitos colaterais com as drogas ou ocorreu recidiva da dor mesmo após o ajustamento das doses do(s) fármaco(s). Foram excluídos indivíduos com idade inferiores a 18 anos as gestantes, e doentes com histórico de afecções oncológicas auto-imunes.

Todos os doentes foram atendidos por um único membro na Equipe de Dor Orofacial da Divisão de Odontologia e do ambulatório de Algias Crânio-faciais da Divisão de Clínica Neurológica do Hospital das Clínicas da Faculdade de Medicina da Universidade de São Paulo. Foram também foram operados nas dependências da 
Divisão de Neurocirurgia Funcional do Instituto de Psiquiatria do Hospital das Clínicas da Faculdade de Medicina da Universidade de São Paulo por apenas um neurocirurgião.

O projeto de pesquisa foi avaliado e aprovado pela Comissão de Ética em Pesquisa sob o $n^{\circ}$ 551/03 (Anexo A).

Desenho do estudo: coorte.

\author{
Avaliações: a) pré-operatória: até 60 dias antes da cirurgia; \\ b) pós-operatórias: \\ b.1. sete dias, mais ou menos dois dias; \\ b.2. 30 dias, mais ou menos sete dias; \\ b.3. 120 dias, mais ou menos 14 dias; \\ b.4. 210 dias, mais ou menos 14 dias.
}

\title{
Técnica operatória:
}

Em ambiente de centro cirúrgico, os doentes foram monitorizados com cardioscopia e oximetria de pulso e foi providenciado acesso venoso para administração de fluidos, fármacos anestésicos e drogas vasoativas. Com o doente em posição supina, tendo a cabeça em posição neutra e a $90^{\circ}$ em relação ao plano horizontal, a assepsia da hemiface ipsilateral foi realizada com sabão líquido e polivinilpirrolidona. 
Sob anestesia geral de curta duração proporcionada por propofol e fentanil e combinada com infiltração com lidocaína a $2 \%$ de um ponto localizado no tegumento a $2 \mathrm{~cm}$ lateralmente à comissura oral no plano que passa entre elas e com ventilação proporcionada com o uso de máscara, foi realizada punção da pele com uma agulha e 14 Gauge $14 \mathrm{~cm}$ de comprimento, dirigida com o auxílio de radioscopia na incidência lateral, para o ângulo diedro formado pelo cruzamento do plano frontal que passa na junção do terço posterior com o terço médio do arco zigomático, com o plano axial que passa pelo conduto auditivo externo e canto externo da órbita e plano sagital que passa pelo bordo medial da pupila ipsilateral. A extremidade da agulha foi posicionada no cruzamento do plano que passa no dorso da sela com o que passa na superfície da pirâmide petrosa. Foi administrada atropina por via endovenosa quando ocorreu bradicardia acentuada.

A seguir, através da luz da agulha, um cateter de Fogarty 4F (American Edwards Laboratory, EUA) foi introduzido no interior do gânglio trigeminal e deslocado até sua extremidade alcançar o plano paralelo ao dorso da sela turca para que o balão fosse lentamente inflado com 0,7 a $1,0 \mathrm{ml}$ de iopamidol (Iopamiron 125®, Schering, São Paulo, Brasil) até adquirir a forma de pera ou ampulheta e assim ser mantido durante 60 segundos, após o que foi desinsuflado. A pressão do contraste no interior do balão foi aferida com manômetro digital (Micromar, Diadema, Brasil). Por fim, o cateter, a agulha e o balão foram removidos. 


\section{Métodos de avaliação:}

1- Questionários:

1.1 - RDC - Research Diagnostic Criteria (Critérios de Diagnóstico em Pesquisa) para o diagnóstico de DTM, validados para o português (Dworkin e LeResche, 1992) (Anexo B). Os dados pelo eixo I possibilitaram avaliar os diagnósticos relacionados ao aparelho mastigatório e os do eixo II, os aspectos emocionais e funcionais relativos à dor crônica.

1.2 - Ficha clínica - EDOF - Divisão de Odontologia do Hospital das Clínicas da Faculdade de Medicina da Universidade de São Paulo (Siqueira, 2001; Siqueira et al., 2004), incluindo a Escala Visual Analógica (EVA) (Anexo C).

1.3 - Questionário de Dor McGill (Pimenta e Teixeira, 1996) (Anexo D).

1.4 - Avaliação articular, muscular e de oclusão pelo Índice de Helkimo (Helkimo, 1974) traduzido para a língua portuguesa (Anexo E).

1.5 - Questionário reduzido (para as avaliações de 07 e 120 dias) para identificar complicações pós-operatórias relacionadas ao aparelho mastigatório e anormalidades gustatórias e visuais (Anexo F).

2- Exame da sensibilidade facial: áreas padronizadas (Anexo G):

2.1. Sensibilidade dolorosa

2.1.1. Aplicação manual de alfinetes;

2.1.2. Algiômetro eletrônico de pressão (Micromar, Diadema, Brasil);

2.2. Sensibilidade táctil: microfilamentos de vonFrey manuais; 
2.3. Sensibilidade térmica: ThermoSensi TS1 e TS2 (Senlis e Teixeira, São Caetano, Brasil), variando a temperatura de $-5^{\circ}$ até $+55^{\circ}$.

3- Avaliação da motricidade da mímica facial:

3.1 - Foram realizadas fotografias da face mantendo-se a distância entre a câmera e o doente com 1 metro e mantendo a sua cabeça com o plano de Frankfurt paralelo ao solo, em três situações: repouso (tono basal); sorriso; fechamento forçado dos olhos e da boca. A análise foi realizada segundo os critérios de Gregoret (1999).

4- Análise estatística: Os dados foram tabulados e analisados com testes paramétricos e não-paramétricos pelo programa SPSS 11.0 para Windows. Inicialmente as variáveis foram analisadas descritivamente. Para as variáveis quantitativas contemplaram-se os valores mínimos e máximos, as médias e os desvios-padrões; para as variáveis qualitativas foram calculadas as freqüências absolutas e relativas; para avaliar o comportamento das médias dos grupos ao longo das avaliações foi utilizado teste de Análise de Variância com medidas repetidas (Timm, 1975); para testar o comportamento dos grupos em relação às proporções ao longo das avaliações foi utilizado o teste não-paramétrico de McNemar (Rosner, 1986).

Os testes admitiram nível de significância de 5\%. 


\section{RESULTADOS}

\subsection{Características gerais da casuística}

Eram mulheres, 60 (57,1\%) doentes; 79 eram brancos, 17 pardos, seis negros e três amarelos; 32 estavam aposentados, 29 mulheres trabalhavam apenas em casa, e 46 doentes trabalhavam fora; 77, eram casados, nove solteiros, dois separados, 13, viúvos e quatro divorciados; 14 , doentes nunca estudaram, 47, freqüentaram até o curso primário, 15, o ginasial, 20, o colegial e nove, o superior.

A idade quando da primeira avaliação variou de 35 a 85 anos (média 60,8 anos; DP $=12,134$ anos); a duração das queixas de dor variou de 0,5 a 30 anos (média 9,5 anos; DP =7,3168). Nunca haviam sido submetidos a cirurgias prévias para tratar a neuralgia 76 dos 105 doentes com NIT selecionados. Devido às recidivas e à necessidade de mais de uma cirurgia em dois pacientes (em três, após três meses e em um, após um mês), 109 procedimentos cirúrgicos foram realizados. (Tabela 1).

Tabela 1 - Distribuição dos doentes em números absolutos (N) e em percentagens (\%) quanto aos procedimentos neurocirúrgicos prévios para tratar a NIT

\begin{tabular}{lc}
\hline \multicolumn{1}{c|}{ CIRURGIA } & $\mathrm{N}(\%)$ \\
\hline Compressão com balão & $15(14,3)$ \\
Rizotomia por radiofreqüência & $10(9,5)$ \\
Neurotomia & $2(1,9)$ \\
Alcoolização & $2(1,9)$ \\
TOTAL & $29(27,6)$ \\
\hline
\end{tabular}


As doenças prévias ou concomitantes à NIT são apresentadas na Tabela 2.

Tabela 2 - Distribuição dos doentes em números absolutos (N) e em percentagens (\%) quanto às doenças prévias ou concomitantes

\begin{tabular}{lc}
\hline \multicolumn{1}{c}{ DOENÇAS PRÉVIAS } & $\mathrm{N}(\%)$ \\
\hline Hipertensão arterial sistêmica & $40(38,1)$ \\
Esclerose Múltipla & $2(1,9)$ \\
Migrânea & $4(3,8)$ \\
Cardiopatia & $4(3,8)$ \\
Diabetes mellitus & $3(2,9)$ \\
Hipertensão arterial e diabetes mellitus & $8(7,6)$ \\
Artrite reumatóide & $1(1,0)$ \\
Depressão & $3(2,9)$ \\
Outros & $10(9,5)$ \\
TOTAL & $75(71,4)$ \\
\hline
\end{tabular}

O lado direito estava acometido, em $73(69,5 \%)$ doentes, o esquerdo em 31 $(29,5 \%)$, e ambos os lados em $1(1,0 \%)$. Os ramos mais acometidos foram o maxilar (29,5\%), o mandibular $(29,5 \%)$ e ambos $(20,1 \%)$ (Tabela 3$)$.

Tabela 3 - Distribuição dos doentes em números absolutos (N) e em percentagens (\%) quanto ao ramo trigeminal acometido

\begin{tabular}{lc}
\hline \multicolumn{1}{c|}{ RAMO } & $\mathrm{N}(\%)$ \\
\hline Ramo oftálmico (V1) & $5(4,8)$ \\
Ramo maxilar (V2) & $31(29,5)$ \\
Ramo mandibular (V3) & $31(29,5)$ \\
Ramos oftálmico e maxilar (V1-2) & $10(9,5)$ \\
Ramos maxilar e mandibular (V2-3) & $22(20,1)$ \\
Ramos oftálmico, maxilar e mandibular (V1-2-3) & $6(5,7)$ \\
TOTAL & $105(100,0)$ \\
\hline
\end{tabular}


A dor era muito freqüente em 74 (70,5\%) doentes, ocorria em crises sendo os episódios de acalmia longos em 17 (16,2\%) e era eventual em 11 (10,5\%).

As zonas de gatilho mais comuns localizavam-se nos lábios, asa do nariz e ou rebordo alveolar (Tabela 4).

Tabela 4 - Distribuição dos doentes em números absolutos (N) e em percentagens (\%) quanto à localização das zonas de gatilho

\begin{tabular}{lc}
\hline \multicolumn{1}{c}{ ZONAS DE GATILHO } & $\mathrm{N}(\%)$ \\
\hline Lábios & $24(22,9)$ \\
Asa do nariz & $19(18,1)$ \\
Rebordo alveolar & $18(17,1)$ \\
Zigoma & $9(8,6)$ \\
Fronte & $5(4,8)$ \\
Dente & $4(3,8)$ \\
Lábio e asa do nariz & $4(3,8)$ \\
Mento & $3(2,9)$ \\
Sulco vestibular & $1(1,0)$ \\
Mucosa jugal & $1(1,0)$ \\
Língua & $1(1,0)$ \\
Comissura do olho & $1(1,0)$ \\
Inespecífica & $15(14,3)$ \\
TOTAL & $105(100,0 \%)$ \\
\hline
\end{tabular}

Os fatores de piora relatados foram: frio em 24 (22,9\%) doentes, qualquer atividade em 24 (22,9\%), durante as refeições em 12 (11,4\%), durante atividades mandibulares em dez $(9,5 \%)$, emoções em seis $(5,7 \%)$, período matutino em cinco $(4,8 \%)$, refeições frias em cinco $(4,8 \%)$, período noturno em quatro $(3,8 \%)$ e refeições ácidas em um (1,0\%). 
Os fatores de melhora relatados foram: compressão facial em nove $(8,6 \%)$ doentes, imobilidade da face em seis $(5,7 \%)$, dormir em quatro $(3,8 \%)$, calor no rosto em quatro $(3,8 \%)$, analgésicos comuns em dois $(1,9 \%)$, mastigar em um $(1,0 \%)$ e rémedios caseiros em um $(1,0 \%)$.

A intensidade da dor no momento da avaliação variou de 0 a 10 pela EVA (média 8,2; DP = 2,27). Houve predomínio do grupo das expressões discriminativas (Questionário de Dor McGill) em 93 doentes, das expressões afetivas em dez, das avaliativas em um e das do grupo miscelânea em um; o índice discriminativo de dor foi o mais destacado em 88 doentes. Quanto às expressões espontâneas, houve diminuição do emprego da expressão “choque" $(p<0,001)$ no período pós-operatório e a manutenção das expressões queimação, picada, raios, espinho, agulhada e ou relâmpago. As expressões que passaram a ser utilizadas no período pós-operatório foram: pesada, cansada, pressão, dolorida e ou enjoada (Tabela 5). 
Tabela 5 - Distribuição dos doentes em números absolutos (N) e em percentagens $(\%)$ quanto às expressões utilizadas para descrever a dor

\begin{tabular}{|c|c|c|c|}
\hline EXPRESSÃO & $\begin{array}{l}\text { PRÉ- } \\
\text { OPERATÓRIO } \\
(\mathrm{N}=105)\end{array}$ & $\begin{array}{c}\text { PÓS-OPERATÓRIO } \\
\text { (30 DIAS) } \\
(\mathrm{N}=100)\end{array}$ & $\begin{array}{c}\text { PÓS-OPERATÓRIO } \\
(210 \text { DIAS }) \\
(\mathrm{N}=96)\end{array}$ \\
\hline Choque & $73(69,5)$ & $15(15,0)^{1}$ & $11(11,5)^{1}$ \\
\hline Queimação & $6(5,7)$ & $5(5,0)$ & $5(5,2)$ \\
\hline Dolorida & - & $8(8,0)$ & $5(5,2)$ \\
\hline Pontada & $3(2,9)$ & $5(5,0)$ & - \\
\hline Ferroadas & $5(4,8)$ & - & - \\
\hline Agulhadas & $5(4,8)$ & - & $1(1,0)$ \\
\hline Dor de dente & $5(4,8)$ & - & - \\
\hline Latejante & $3(2,9)$ & $3(3,0)$ & $2(2,1)$ \\
\hline Pancada & - & $1(1,0)$ & - \\
\hline Repuxando & $2(1,9)$ & $1(1,0)$ & - \\
\hline Enjoada & - & $3(3,0)$ & - \\
\hline Pesada & - & $4(4,0)$ & $2(2,1)$ \\
\hline Cansada & - & $9(9,0)$ & $2(2,1)$ \\
\hline Aperto & - & $2(2,0)$ & - \\
\hline Incômodo & - & $3(3,0)$ & - \\
\hline Aguda & $1(1,0)$ & - & - \\
\hline Vibração & $1(1,0)$ & - & - \\
\hline Picada & - & $1(1,0)$ & $1(1,0)$ \\
\hline Formigamento & $1(1,0)$ & - & - \\
\hline Pressão & - & $1(1,0)$ & - \\
\hline Raios & - & - & $1(1,0)$ \\
\hline Espinho & - & - & $1(1,0)$ \\
\hline Fisgada & - & - & $1(1,0)$ \\
\hline Relâmpago & - & $1(1,0)$ & - \\
\hline Indefinida & - & $6(6,0)$ & - \\
\hline TOTAL & $105(100,0)$ & $68(68,0)$ & $32(33,3)$ \\
\hline
\end{tabular}


O procedimento prévio mais comum para tratar a dor foi a exodontia múltipla, realizada em $25(23,8 \%)$ doentes (Tabela 6).

Tabela 6 - Distribuição dos doentes em números absolutos (N) e em percentagens (\%) quanto aos procedimentos prévios para tratar a dor

\begin{tabular}{lcc}
\hline \multicolumn{1}{c|}{ TRATAMENTOS REALIZADOS } & $\mathrm{N}$ & $\%$ \\
\hline Exodontias múltiplas & 25 & 23,8 \\
Exodontias, cirurgias ósseas e alcoolizações periféricas & 6 & 5,7 \\
Cirurgias ósseas & 6 & 5,7 \\
Endodontias & 5 & 4,8 \\
Exodontias e placa de mordida & 3 & 2,9 \\
Exodontias e troca de prótese & 3 & 2,9 \\
Procedimentos protéticos & 3 & 2,9 \\
Neurotomia periférica e exodontias & 2 & 1,9 \\
Outros & 11 & 10,5 \\
TOTAL & 64 & 61,0 \\
\hline
\end{tabular}

\subsection{Características odontológicas}

Eram edêntulos totais (superior e inferior) 46 (43,8\%) dos 105 doentes; 19 eram edêntulos totais em um só arco e 40 não eram edêntulos.

Dos edêntulos em ambas as arcadas, 27 apresentavam diminuição da dimensão vertical; 16 não eram edêntulos antes da ocorrência da NIT e haviam perdido seus últimos dentes em decorrência da dor; 15 não utilizavam prótese total inferior e cinco não usavam nenhuma das duas próteses. Dos edêntulos em um único arco, dois não utilizavam a prótese (Tabela 7). 
Tabela 7 - Distribuição dos doentes em números absolutos (N) e em percentagens (\%) quanto às características dentárias

\begin{tabular}{|c|c|c|c|c|}
\hline & \multicolumn{2}{|c|}{$\begin{array}{l}\text { EDÊNTULOS } \\
\text { TOTAIS } \\
\text { BIMAXILARES }\end{array}$} & \multicolumn{2}{|c|}{$\begin{array}{c}\text { DENTADOS } \\
(\mathrm{N}=40 ; 38,1 \%) \mathrm{E} \\
\text { EDÊNTULOS } \\
\text { PARCIAIS }(\mathrm{N}=19 ; 18,1 \%)\end{array}$} \\
\hline & $\mathrm{N}$ & $\%$ & $\mathrm{~N}$ & $\%$ \\
\hline Perda de dimensão vertical & 27 & 25,7 & 15 & 14,3 \\
\hline $\begin{array}{l}\text { Não faz uso de prótese total em } \\
\text { um arco }\end{array}$ & 15 & 14,3 & 2 & 1,9 \\
\hline $\begin{array}{l}\text { Não faz uso de prótese total } \\
\text { superior e inferior }\end{array}$ & 5 & 4,8 & - & - \\
\hline $\begin{array}{l}\text { Perda dos últimos dentes pela } \\
\text { dor }\end{array}$ & 16 & 15,2 & - & - \\
\hline Mordida cruzada direita & - & - & 3 & 2,9 \\
\hline Mordida cruzada esquerda & - & - & 1 & 1,0 \\
\hline Mordida cruzada anterior & - & - & 7 & 6,7 \\
\hline Sobremordida profunda & - & - & 6 & 5,7 \\
\hline Periodontite leve & - & - & 22 & 21,0 \\
\hline Periodontite moderada & - & - & 14 & 13,3 \\
\hline Periodontite grave & - & - & 4 & 3,8 \\
\hline TOTAL DE DOENTES & 46 & 48,8 & 59 & 66,2 \\
\hline
\end{tabular}

\subsection{Análise das avaliações ao longo do período de acompanhamento}

Um $(1,0 \%)$ dos 105 doentes não apresentou alívio da dor após a primeira operação e necessitou outra cirurgia (rizotomia por radiofreqüência), um $(1,0 \%)$ não compareceu para reavaliação, um $(1,0 \%)$ apresentou pseudo-aneurisma da artéria carótida interna e outro (1,0\%), meningite e comprometimento cognitivo. Dos 101 doentes restantes, uma não compareceu a partir da avaliação de 30 dias por impossibilidade financeira e de locomoção. Aos 120 dias, três doentes haviam apresentado recidiva e dor intensa e para eles foi indicada nova cirurgia. Uma doente 
não retornou na avaliação de 210 dias. Portanto, restaram $96(91,4 \%)$ doentes ao final do período de acompanhamento em condições de contemplar as exigências do protocolo de estudo. A taxa total de recidiva foi de $17(16,2 \%)$ doentes.

Ao final do período completo de acompanhamento (210 dias), os dados foram tabulados e analisados comparativamente entre os demais períodos.

\subsubsection{AVALIAÇÃO DA FUNÇÃO MANDIBULAR}

No período pré-operatório, 19 doentes queixavam-se espontaneamente de limitações para a mastigação: sete relatavam dor, dois medo, um incômodo ao mastigar alimentos duros e nove limitações devidas a outras razões (próteses maladaptadas, ausência de dentes). Cansaço para a execução de todas as atividades faciais foi o principal desconforto facial relatado; manifestou-se em $18(17,1 \%)$ doentes (Tabela 8).

Tabela 8 - Distribuição dos doentes em números absolutos (N) e em percentagens (\%) quanto ao desconforto facial

\begin{tabular}{l|c|c}
\hline \multicolumn{1}{c|}{ DESCONFORTO FACIAL } & $\mathrm{N}$ & $\%$ \\
\hline Cansaço ao acordar & 6 & 5,7 \\
Cansaço ao mastigar & 6 & 5,7 \\
Cansaço ao falar & 1 & 1,0 \\
Cansaço para executar todas as atividades faciais & 18 & 17,1 \\
Cansaço ao mastigar e acordar & 1 & 1,0 \\
Cansaço à noite & 1 & 1,0 \\
Morder a língua & 5 & 4,8 \\
Morder a bochecha & 7 & 6,7 \\
Morder o lábio & 2 & 1,9 \\
Morder os lábios, a língua e a bochecha & 5 & 4,8 \\
TOTAL & 52 & 49,5 \\
\hline
\end{tabular}


Queixaram-se de otalgia no lado direito dez doentes, no esquerdo quatro, e bilateral em um; um não soube informar sobre o lado acometido. Queixavam-se de zumbidos 38 doentes.

Bruxismo noturno foi relatado por 23 doentes (17 comprovados por familiar ou cuidador); quatro não souberam responder (3,8\%). Apresentavam apertamento diurno 23 doentes e rigidez ou dor maxilar matinal, 33.

Quatro doentes apresentavam crepitação na ATM direita, quatro, na esquerda, e dois, bilateral; seis, estalo à direita, 13 estalo à esquerda e dois, bilateral. Foram observadas anormalidades articulares em 60 (57,1\%) ATM (Tabela 9).

Tabela 9 - Distribuição dos doentes em números absolutos (N) e em percentagens (\%) quanto às anormalidades da ATM

\begin{tabular}{l|c|c}
\hline \multicolumn{1}{c|}{ ANORMALIDADES ARTICULARES } & N & $\%$ \\
\hline Deslocamento do disco direito com redução & 6 & 5,7 \\
Deslocamento do disco direito sem redução & 5 & 4,8 \\
Deslocamento do disco esquerdo com redução & 9 & 8,6 \\
Deslocamento do disco esquerdo sem redução & 4 & 3,8 \\
Artralgia direita & 5 & 4,8 \\
Artraldia esquerda & 5 & 4,8 \\
Osteoartrose direita & 9 & 8,6 \\
Osteoartrose esquerda & 17 & 16,2 \\
TOTAL & 60 & 57,1 \\
\hline
\end{tabular}

A limitação da abertura bucal foi estatisticamente significante no período pósoperatório imediato $(p<0,001)$ e manteve-se até a última avaliação $(p=0,0148)$. Também houve diferença estatisticamente significativa quanto à ocorrência de dor durante abertura máxima $(p<0,001)$ e quanto aos desvios em abertura $(p<0,001)$ (Tabela 10). Ocorreu diferença estatisticamente significativa quanto à mordida 
desconfortável apenas entre os momentos pré e pós-operatório de sete dias $(p=0,006)$.

Tabela 10 - Distribuição dos doentes em números absolutos $(\mathrm{N})$ e em percentagens $(\%)$ quanto a abertura bucal em relação à amplitude, desvios e dor

\begin{tabular}{|c|c|c|c|c|c|}
\hline $\begin{array}{l}\text { ABERTURA } \\
\text { BUCAL }\end{array}$ & $\begin{array}{l}\text { PRÉ-OP } \\
\text { N (\%) }\end{array}$ & $\begin{array}{l}\text { PÓS-OP } \\
(7 \text { DIAS) } \\
\mathrm{N}(\%)\end{array}$ & $\begin{array}{c}\text { PÓS-OP } \\
\text { (30 DIAS) } \\
\mathrm{N}(\%)\end{array}$ & $\begin{array}{c}\text { PÓS-OP } \\
(120 \text { DIAS) } \\
\text { N(\%) }\end{array}$ & $\begin{array}{c}\text { PÓS-OP } \\
(210 \text { DIAS }) \\
\text { N(\%) }\end{array}$ \\
\hline Reto & $90(85,7)$ & $35(34,7)^{1}$ & $44(44,0)$ & $59(59,0)$ & $69(71,9)^{2}$ \\
\hline $\begin{array}{l}\text { Direita sem } \\
\text { correção }\end{array}$ & $3(2,9)$ & $42(41,6)$ & $26(26,0)$ & $14(14,0)$ & $8(8,3)$ \\
\hline $\begin{array}{l}\text { Esquerda sem } \\
\text { correção }\end{array}$ & $2(1,9)$ & $16(15,8)$ & $14(14,0)$ & $9(9,0)$ & $10(10,4)$ \\
\hline $\begin{array}{l}\text { Direita com } \\
\text { correção }\end{array}$ & $6(5,7)$ & $6(5,9)$ & $14(14,0)$ & $6(6,0)$ & $8(8,3)$ \\
\hline $\begin{array}{l}\text { Esquerda com } \\
\text { correção }\end{array}$ & $4(3,8)$ & $2(2,0)$ & $2(2,0)$ & $12(12,0)$ & $1(1,0)$ \\
\hline $\begin{array}{l}\text { Variação e média } \\
\text { de abertura bucal } \\
\text { máxima (em mm) }\end{array}$ & $\begin{array}{c}25-53 \text { (média } \\
45,97 ; \mathrm{DP}= \\
7,089)\end{array}$ & $\begin{array}{c}21-59 \text { (média } \\
37,84 ; \mathrm{DP}= \\
7,671)^{1}\end{array}$ & $\begin{array}{c}\text { 24-60 (média } \\
41,63 ; \mathrm{DP}= \\
7,202)\end{array}$ & $\begin{array}{c}\text { 17-62 (média } \\
43,0 ; \mathrm{DP}=8,0)\end{array}$ & $\begin{array}{c}\text { 17-63 (média } \\
44,38 ; \\
\mathrm{DP}=7,584)^{1}\end{array}$ \\
\hline $\begin{array}{l}\text { Dor em abertura } \\
\text { bucal máxima }\end{array}$ & $25(23,8)$ & $65(64,4)^{1}$ & $68(68,0)$ & $36(36,0)$ & $32(33,3)^{3}$ \\
\hline $\begin{array}{l}\text { Mordida } \\
\text { desconfortável }\end{array}$ & $42(40,0)$ & $59(58,4)^{2}$ & $42(42,0)$ & $38(38,0)$ & $37(38,5)^{4}$ \\
\hline TOTAL & $105(100,0)$ & $101(100,0)$ & $100(100,0)$ & $100(100,0)$ & $96(100,0)$ \\
\hline
\end{tabular}

No período pré-operatório foi diagnosticada DTM em 46 (43,8\%) doentes e algum grau de dor miofascial em 59 (56,2\%); em 7,6\% desses, havia limitação da abertura bucal. A ocorrência de dor miofascial na musculatura mastigatória aumentou na avaliação de 30 dias, quando foi identificada em $79(75,2 \%)$ doentes 
$(\mathrm{p}<0,001)$, e reduziu-se, aos 210 dias mas sem diferença significativa em relação ao período pré-operatório $(\mathrm{p}=0,763)$ (Figura 1$)$.

Figura 1 - Distribuição dos doentes em percentagens (\%) quanto à ocorrência de dor miofascial na musculatura mastigatória; incluídos doentes com limitação da abertura bucal
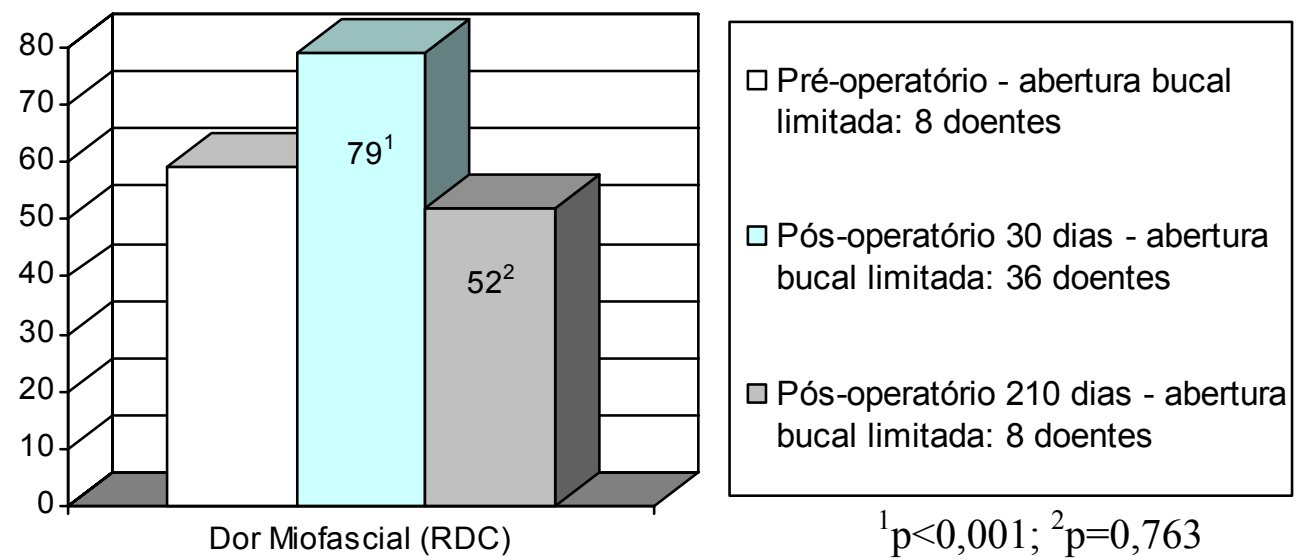

Dormência foi a principal queixa mastigatória durante todo o período pósoperatório $(\mathrm{p}<0001)$. Ocorreu dor ao mastigar em todas as avaliações. Outras queixas são representadas na Figura 2.

Figura 2 - Distribuição dos doentes em percentagens (\%) quanto às queixas mastigatórias espontâneas

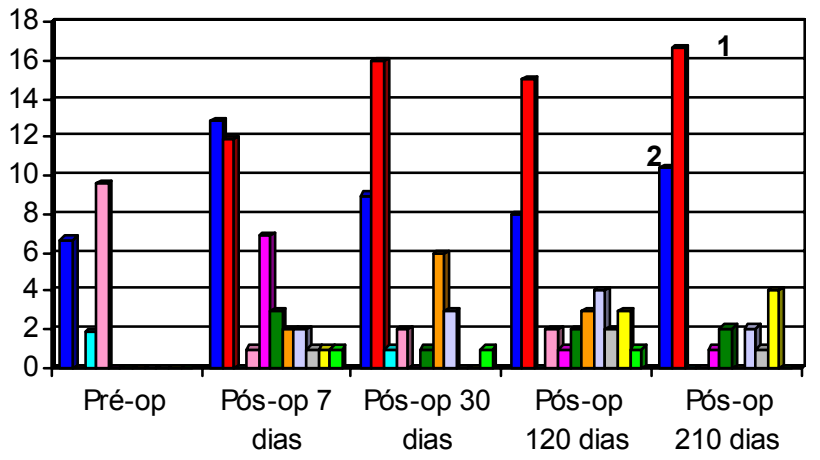

Dor ao mastigar

$\square$ Dormência

$\square$ Medo

$\square$ Problemas dentários

$\square$ Limitação para abertura bucal

$\square$ Cansaço ao mastigar

$\square$ Fraqueza ao mastigar

$\square$ Morder língua

$\square$ Maxilar deslocado

$\square$ Não cosegue usar protese total $\square$ Outros

$\mathrm{p}<0,001 ;{ }^{2} \mathrm{p}=0,197$

OP: Operatório 
Segundo o índice anamnético de Helkimo, 18 doentes apresentavam sintomas discretos e 50, sintomas graves; segundo o índice de oclusão, 28 doentes apresentavam anormalidade moderada e 65 , grave.

A mobilidade mandibular normal diminuiu $(p=0,016)$ e a freqüência de comprometimento grave aumentou $(\mathrm{p}<0,001)$ no período pós-operatório de 30 dias. Não houve diferença estatisticamente significativa entre as avaliações 30 e 210 dias $(p=0,239)$ (Figura 3).

Figura 3 - Distribuição dos doentes em percentagens (\%) quanto à mobilidade mandibular, segundo o Índice de Helkimo

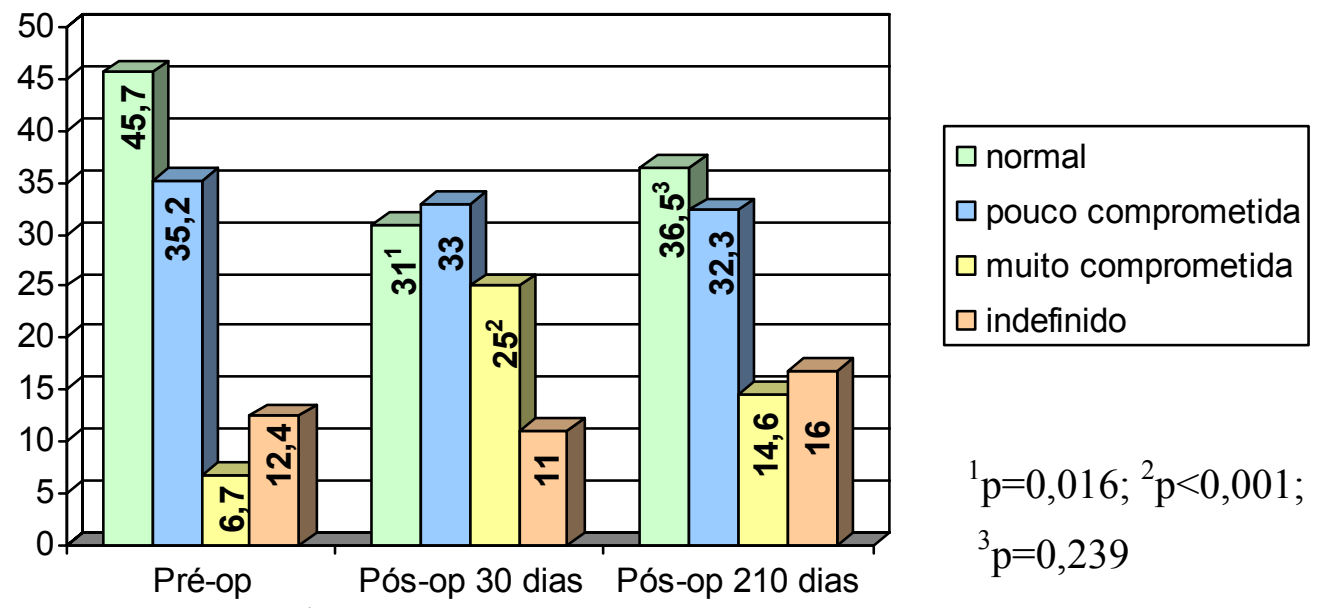

Op: Operatório

Não ocorreu diferença estatisticamente significativa quanto ao número de doentes que apresentavam incômodo para mastigar $(\mathrm{p}=0,053)$ ou quanto à intensidade média do incômodo $(\mathrm{p}=0,1227)$ durante o acompanhamento em relação ao período pré-operatório (Tabela 11). 
Tabela 11 - Distribuição dos doentes em números absolutos (N) e em percentagens (\%) quanto ao incômodo de mastigação

\begin{tabular}{lcccccc}
\hline $\begin{array}{c}\text { OCORRÊNCIA E } \\
\text { CARACTERÍSTICAS } \\
\text { DO INCÔMODO }\end{array}$ & PRÉ-OP & $\begin{array}{c}\text { PÓS-OP } \\
(7 \text { DIAS }) \\
\mathrm{N}(\%)\end{array}$ & $\begin{array}{c}\text { PÓS-OP } \\
(30 \text { DIAS }) \\
\text { N(\%) }\end{array}$ & $\begin{array}{c}\text { PÓS-OP } \\
(120 \text { DIAS }) \\
\text { N(\%) }\end{array}$ & $\begin{array}{c}\text { PÓS-OP } \\
(210 \text { DIAS }) \\
\text { N(\%) }\end{array}$ \\
\hline Número de casos & $33(31,4)$ & $44(43,6)^{1}$ & $39(39,0)$ & $29(29,0)$ & $28(29,2)^{2}$ \\
Variação do incômodo & 1,0 a 10,0 & 2,0 a 10,0 & 1,0 a 10,0 & 2,0 a 10,0 & 2,0 a 10,0 \\
$\begin{array}{l}\text { Intensidade média do } \\
\text { incômodo }\end{array}$ & 7,80 & 7,53 & 2,85 & 6,18 & 2,03 \\
TOTAL & $\mathrm{DP}=2,29$ & $\mathrm{DP}=2,271$ & $\mathrm{DP}=3,782$ & $\mathrm{DP}=2,54$ & $\mathrm{DP}=3,478^{2}$ \\
& 105 & $101(100,0)$ & $100(100,0)$ & $100(100,0)$ & $96(100,0)$ \\
\hline
\end{tabular}

OP: Operatório

O número de doentes sem sintomas de disfunção clínica aumentou principalmente no período pós-operatório de 210 dias ( $\mathrm{p}<0,001)$ (Figura 4).

Figura 4 - Distribuição dos doentes em percentagens (\%) quanto à disfunção clínica segundo o Î́ndice de Helkimo

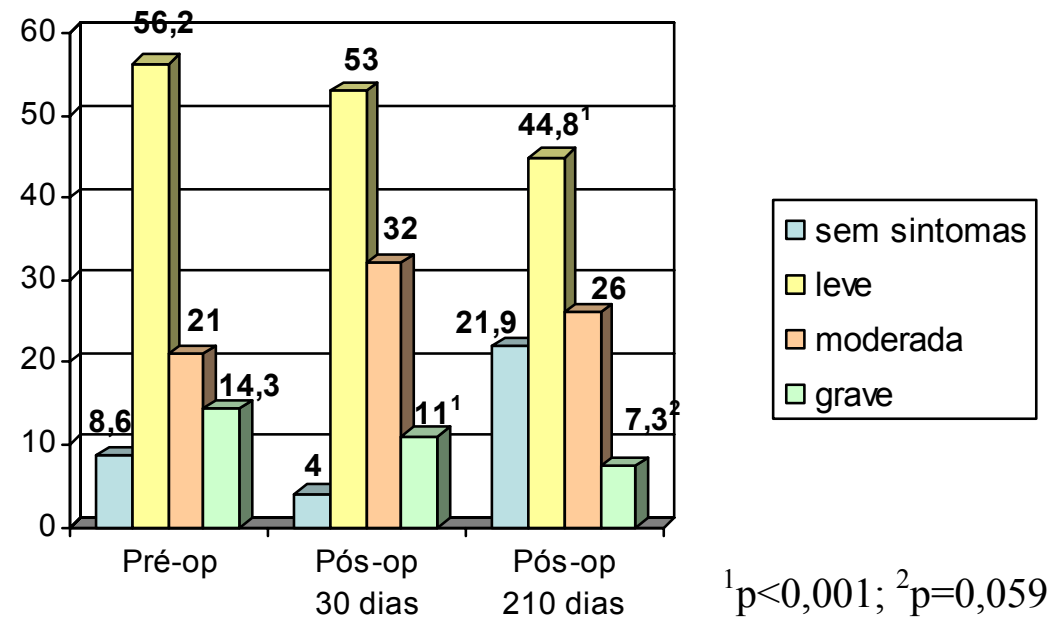

Op: Operatório 
O lado da mastigação (considerando-se apenas o lado operado em casos de dor bilateral) deixou de ser o oposto ao da localização dor na maioria dos doentes na avaliação de 210 dias ( $\mathrm{p}=0,023)$ (Figura 5).

Figura 5 - Distribuição dos doentes em percentagens (\%) quanto ao lado em qual a dor se localizava em relação ao lado da mastigação

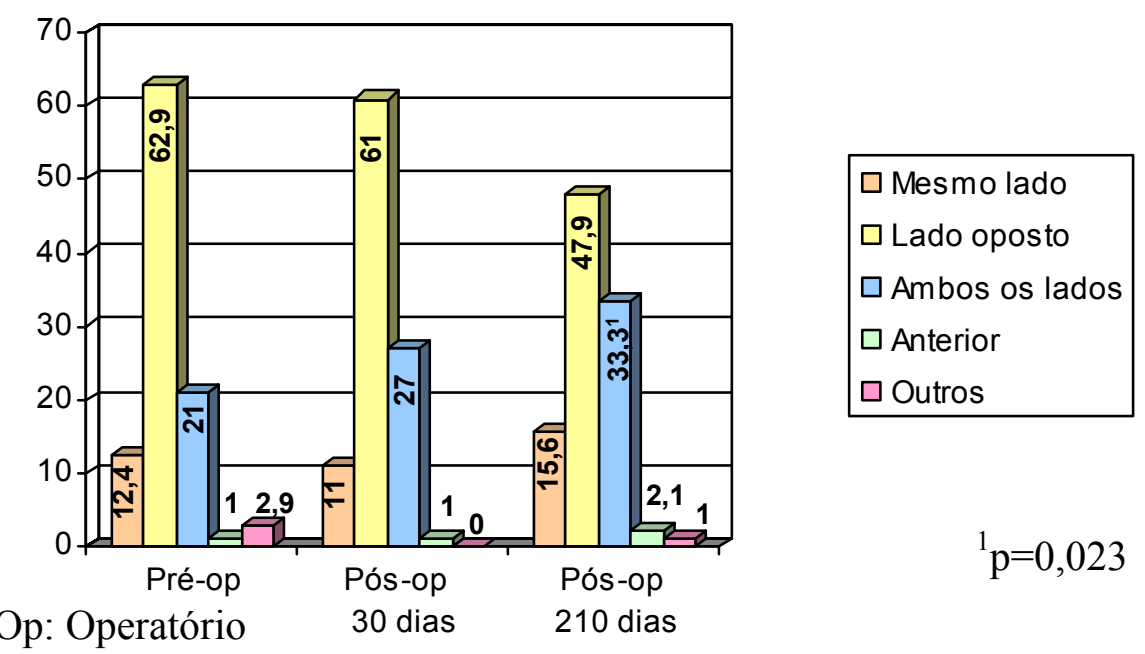

Na avaliação pós-operatória de 7 dias, evidenciou-se dor à palpação muscular intraoral à direita em $83(82,2 \%)$ doentes (grau 1 da EDOF em 16, grau 2 em 9, grau 3 em 24 e grau 4 em 34; média 2,4; DP =1,531) e à esquerda em $75(74,3 \%)$ (grau 1 em 21, grau 2 em 13, grau 3 em 23 e grau 4 em 18; média 1,86; DP =1,480). Nesses casos, ocorreu dor à palpação da nuca em 20 (19,8\%) doentes (grau 1 em 13, grau 2 em dois, grau 3 em quatro e grau 4 em um; média 0,33; DP =0,789). A intensidade da dor durante a palpação intra e extraoral variou de 1 a 4 na avaliação de 120 dias e apresentou média 1,8 no lado direito $(\mathrm{DP}=1,4), 1,7$ no lado esquerdo $(\mathrm{DP}=1,7)$ e 0,5 na nuca $(\mathrm{DP}=1,0)$. 


\subsubsection{AVALIAÇÃO EMOCIONAL E FUNCIONAL DIÁRIA}

Houve diminuição do número de casos catalogados como grau 4 (grave) quanto à gravidade da dor crônica segundo eixo II do RDC $(p=0,034)$ nas avaliações de 30 e 210 dias em relação ao período pré-operatório (Tabela 12).

Tabela 12 - Distribuição dos doentes em números absolutos (N) e em percentagens $(\%)$ quanto à gravidade da dor crônica, segundo o RDC

\begin{tabular}{l|c|c|c}
\hline $\begin{array}{c}\text { GRAVIDADE } \\
\text { DE DOR } \\
\text { CRONICA }\end{array}$ & $\begin{array}{c}\text { PRÉ- } \\
\text { OPERATÓRIO } \\
\text { N(\%) }\end{array}$ & $\begin{array}{c}\text { PÓS-OPERATORIO } \\
(30 \text { DIAS) } \\
\text { N(\%) }\end{array}$ & $\begin{array}{c}\text { PÓS-OPERAT } \\
\text { ORIO (210 DIAS) } \\
\text { N(\%) }\end{array}$ \\
\hline Ausente & $6763,8)$ & $42(42,0)$ & $70(72,9)$ \\
Grau 1 & $1(1,0)$ & $26(26,0)$ & $9(9,4)$ \\
Grau 2 & $4(3,8)$ & $16(16,0)$ & $6(6,3)$ \\
Grau 3 & $3(2,9)$ & $6(6,0)$ & $2(2,1)$ \\
Grau 4 & $21(20,0)$ & $10(10,0)$ & $9(9,4)$ \\
TOTAL & $105(100,0)$ & $100(100,0)$ & $96(100,0)$ \\
\hline
\end{tabular}

Houve redução dos casos com graus moderado $(\mathrm{p}=0,007)$ ou grave de depressão $(\mathrm{p}=0,012)$ (Figura 6).

Figura 6 - Distribuição dos doentes em percentagens (\%) quanto ao grau de depressão, segundo o RDC
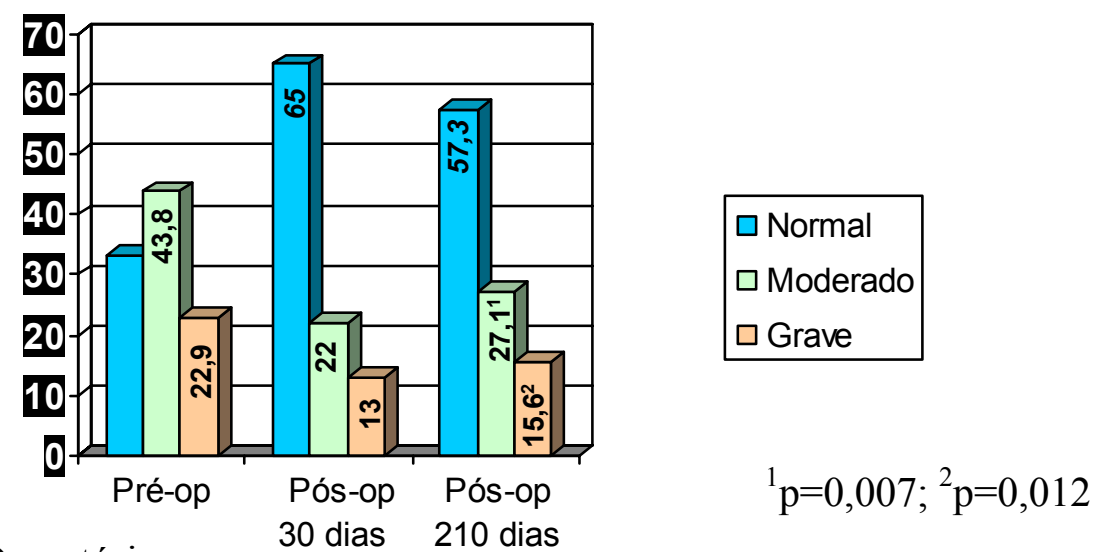

Op: Operatório 
O mesmo ocorreu com os sintomas físicos não-específicos (Figura 7).

Figura 7 - Distribuição dos doentes em percentagens (\%) quanto aos sintomas físicos não-específicos, segundo o RDC
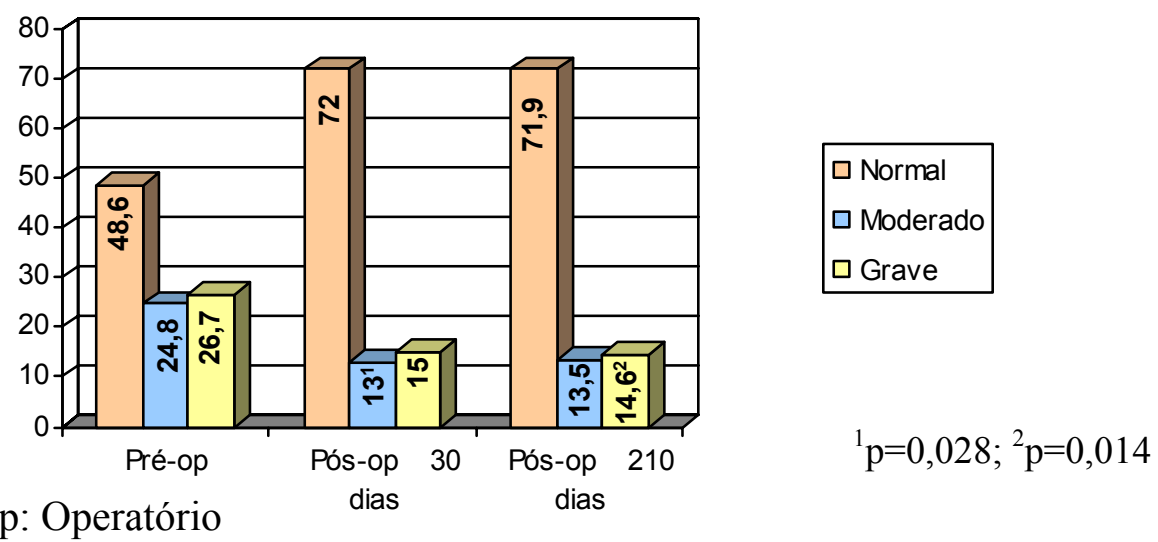

Op: Operatório

Queixas de dor de cabeça ou dor e no corpo diminuíram no período pósoperatório de 30 dias $(\mathrm{p}<0,001$ e $\mathrm{p}=0,002$ respectivamente). Não houve diferença estatística entre as avaliações realizadas nos períodos de 30 e 210 dias (Figura 8).

Figura 8 - Distribuição dos doentes em em percentagens (\%) quanto à ocorrência de dor no corpo ou cefaléia

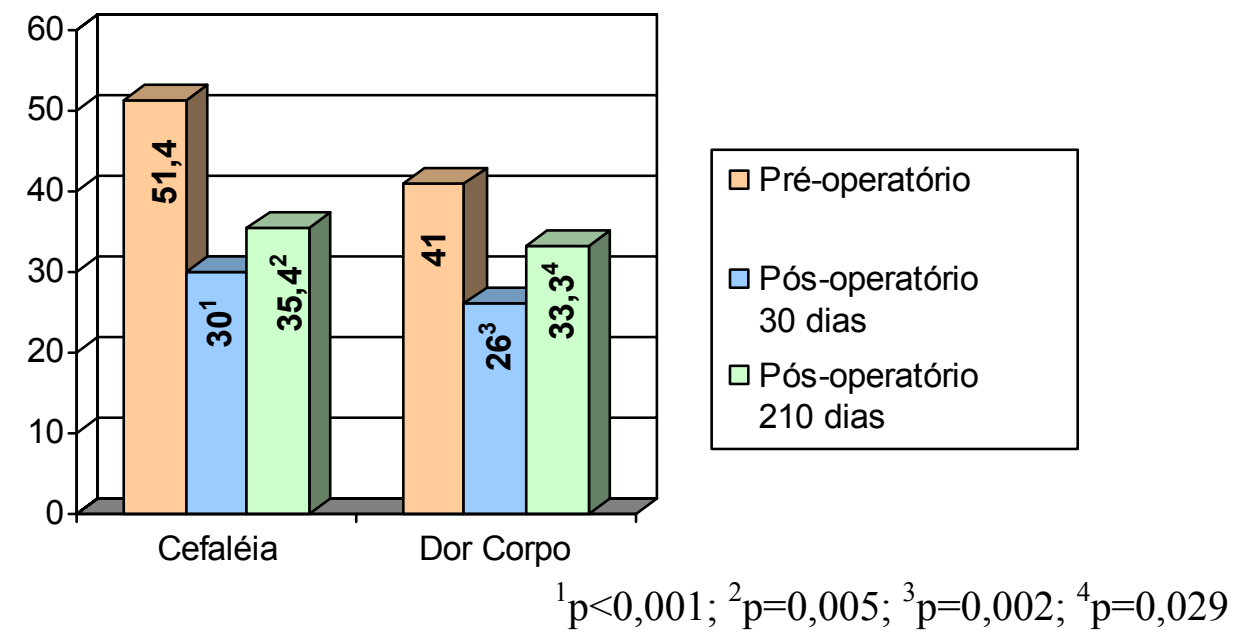


Não houve alterações significantes quanto à avaliação subjetiva da qualidade do sono ao longo do período de avaliação $(\mathrm{p}=0,670)$ (Tabela 13).

Tabela 13 - Distribuição dos doentes em números absolutos (N) e em percentagens (\%) quanto a qualidade do sono

\begin{tabular}{lcc|c|c|c}
\hline $\begin{array}{c}\text { COMPROME- } \\
\text { TIMENTO DO } \\
\text { SONO }\end{array}$ & $\begin{array}{c}\text { PRÉ-OP } \\
\text { N(\%) }\end{array}$ & $\begin{array}{c}\text { PÓS-OP } \\
(7 \text { DIAS }) \\
\text { N(\%) }\end{array}$ & $\begin{array}{c}\text { PÓS-OP } \\
(30 \text { DIAS }) \\
\text { N(\%) }\end{array}$ & $\begin{array}{c}\text { PÓS-OP } \\
(120 \text { DIAS }) \\
\text { N(\%) }\end{array}$ & $\begin{array}{c}\text { PÓS-OP } \\
(210 \text { DIAS }) \\
\text { N(\%) }\end{array}$ \\
\hline Ausente & $74(70,5)$ & $78(77,2)$ & $65(65,0)$ & $69(69,0)$ & $71(74,0)^{1}$ \\
Um pouco & $11(10,5)$ & $9(8,9)$ & $15(15,0)$ & $14(14,0)$ & $14(14,6)$ \\
Moderado & $5(4,8)$ & $3(3,0)$ & $5(5,0)$ & $2(2,0)$ & $3(3,1)$ \\
Muito & $15(14,3)$ & $14(13,9)$ & $15(15,0)$ & $13(13,0)$ & $8(8,3)$ \\
Extremo & - & $3(3,0)$ & - & $2(2,0)$ & - \\
TOTAL & $105(100,0)$ & $101(100,0)$ & $100(100,0)$ & $100(100,0)$ & $96(100,0)$ \\
\hline
\end{tabular}

OP: Operatório

Houve alteração estatisticamente significativa quanto ao número de doentes que se queixavam de perda de elementos (alimentos e saliva) pela boca nas avaliações de $7(p=0,002), 30(p=0,002)$ e 120 dias $(0,048)$ (Tabela 14). 
Tabela 14 - Distribuição dos doentes em números absolutos (N) e em percentagens $(\%)$ quanto à perda de elementos pela boca

\begin{tabular}{|c|c|c|c|c|c|}
\hline $\begin{array}{c}\text { NATUREZA } \\
\text { DO } \\
\text { ELEMENTO }\end{array}$ & $\begin{array}{l}\text { PRÉ- } \\
\mathrm{OP}^{(1)} \\
\mathrm{N}(\%)\end{array}$ & $\begin{array}{c}\text { PÓS-OP } \\
\text { (7 DIAS) } \\
\mathrm{N}(\%)\end{array}$ & $\begin{array}{c}\text { PÓS-OP } \\
\text { (30 DIAS) } \\
\text { N(\%) }\end{array}$ & $\begin{array}{c}\text { PÓS-OP } \\
\text { (120 DIAS) } \\
\text { N(\%) }\end{array}$ & $\begin{array}{c}\text { PÓS-OP } \\
\text { (210 DIAS) } \\
\mathrm{N}(\%)\end{array}$ \\
\hline Saliva sempre & - & $2(1,9)$ & $3(3,0)$ & - & - \\
\hline $\begin{array}{l}\text { Alimentos } \\
\text { sempre }\end{array}$ & - & $2(1,9)$ & $3(3,0)$ & - & - \\
\hline $\begin{array}{l}\text { Ambos } \\
\text { sempre }\end{array}$ & - & $3(2,9)$ & $4(4,0)$ & $1(1,0)$ & - \\
\hline $\begin{array}{l}\text { Saliva } \\
\text { freqüente }\end{array}$ & - & $16(15,8)$ & $1(1,0)$ & $3(3,0)$ & $1(1,0)$ \\
\hline $\begin{array}{l}\text { Alimentos } \\
\text { freqüente }\end{array}$ & - & - & $5(5,0)$ & $1(1,0)$ & $2(2,1)$ \\
\hline $\begin{array}{l}\text { Ambos } \\
\text { freqüente }\end{array}$ & - & $2(1,9)$ & $6(6,0)$ & $3(3,0)$ & $10(10,4)$ \\
\hline $\begin{array}{l}\text { Saliva } \\
\text { eventual }\end{array}$ & $19(18,1)$ & $1(1,0)$ & $15(15,0)$ & $9(9,0)$ & $8(8,3)$ \\
\hline $\begin{array}{l}\text { Alimentos } \\
\text { eventual }\end{array}$ & $4(3,8)$ & $5(4,8)$ & $4(4,0)$ & $5(5,0)$ & $6(6,25)$ \\
\hline $\begin{array}{l}\text { Ambos } \\
\text { eventual }\end{array}$ & $7(6,7)$ & $9(8,9)$ & $5(5,0)$ & $16(16,0)$ & $7(7,3)$ \\
\hline $\begin{array}{l}\text { Saliva } \\
\text { eventual e } \\
\text { alimentos } \\
\text { sempre }\end{array}$ & - & $2(1,9)$ & - & - & - \\
\hline $\begin{array}{l}\text { Saliva sempre } \\
\text { e limentos } \\
\text { eventual }\end{array}$ & - & $2(1,9)$ & - & - & - \\
\hline $\begin{array}{l}\text { Saliva } \\
\text { freqüente e } \\
\text { alimentos } \\
\text { eventual }\end{array}$ & - & $1(1,0)$ & - & - & - \\
\hline $\begin{array}{l}\text { Saliva } \\
\text { eventual e } \\
\text { alimentos } \\
\text { freqüente }\end{array}$ & - & $1(1,0)$ & - & $1(1,0)$ & - \\
\hline TOTAL & $30(28,6)$ & $46(45,5)^{1}$ & $46(46,0)^{2}$ & $39(39,0)^{3}$ & $34(35,4)^{4}$ \\
\hline
\end{tabular}

OP: Operatório 


\subsubsection{SENSIBILIDADE SUPERFICIAL FACIAL}

Não houve diferença estatisticamente significativa entre os doentes que haviam sido previamente operados em relação aos não-operados quanto à sensibilidade facial no pré-operatório. Foi observado comprometimento do reflexo córneo-palpebral em $21(20,0 \%)$ doentes, sendo bilateral em nove $(8,6 \%)$ e unilateral em $12(13,0 \%)$, mas não ocorreram diferenças significativas entre os não-operados e os previamente operados $(p=1,000)$.

As queixas de dormência foram mais freqüentes do que as anormalidades sensitivas evidenciadas nos exames da sensibilidade $(p<0,001)$. Não houve diferença quanto às alterações entre as qualidades sensitivas frio, calor e tato $(p=1,000)$ (Figura 9).

\section{Figura 9 - Distribuição dos doentes em percentagens (\%) quanto à dormência} subjetiva e à avaliação de sensibilidade superficial na face
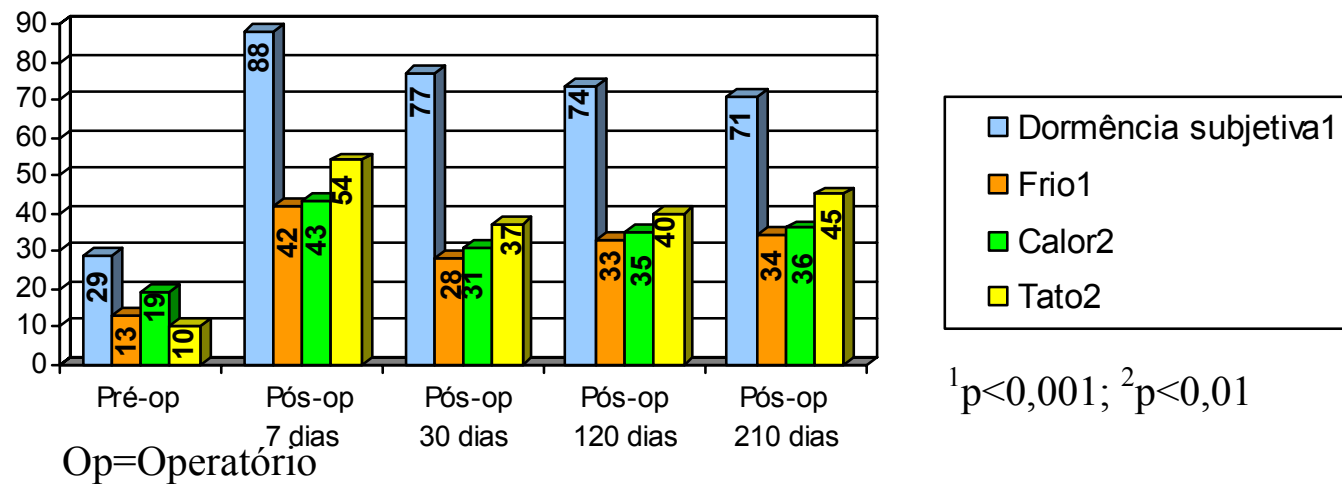

${ }^{1} \mathrm{p}<0,001 ;{ }^{2} \mathrm{p}<0,01$

Ocorreu aumento do número de casos com queixa de dormência de 27,6\% para mais de $70 \%$ dos casos ao longo do acompanhamento e um aumento significativo da intensidade da dormência $(\mathrm{p}<0,001)$ (Tabela 15) e da disestesia $(\mathrm{p}=0,0292)$ na avaliação pós-operatória (Tabela 16). Entretanto, o incômodo causado pela dormência manteve-se ao longo do tempo $(\mathrm{p}<0,001)$ (Tabela 15). 
Tabela 15 - Distribuição dos doentes em números absolutos (N) e em percentagens (\%) quanto à sensação subjetiva de dormência

\begin{tabular}{|c|c|c|c|c|c|}
\hline DORMÊNCIA & $\begin{array}{l}\text { PRÉ-OP } \\
\mathrm{N}(\%) \\
\end{array}$ & $\begin{array}{c}\text { PÓS-OP } \\
\text { (7 DIAS) } \\
\mathrm{N}(\%) \\
\end{array}$ & $\begin{array}{c}\text { PÓS-OP } \\
\text { (30 DIAS) } \\
\mathrm{N}(\%) \\
\end{array}$ & $\begin{array}{c}\text { PÓS-OP } \\
(120 \text { DIAS }) \\
\mathrm{N}(\%) \\
\end{array}$ & $\begin{array}{c}\text { PÓS-OP } \\
\text { (210 DIAS) } \\
\mathrm{N}(\%) \\
\end{array}$ \\
\hline Ausente & $76(72,4)$ & $23(22,8)$ & $23(23,0)$ & $26(26,0)$ & $25(26,0)^{1}$ \\
\hline Eventual & $19(18,1)$ & $7(6,9)$ & $5(5,0)$ & $17(17,0)$ & $14(14,6)$ \\
\hline Freqüente & $2(1,9)$ & $2(2,0)$ & $12(12,0)$ & $1(1,0)$ & $4(4,2)$ \\
\hline Constante & $9(8,5)$ & $79(78,2)^{1}$ & $60(60,0)$ & $56(56,0)$ & $53(55,2)^{1}$ \\
\hline $\begin{array}{l}\text { Incômodo da } \\
\text { dormência }\end{array}$ & $29(27,6)$ & $60(59,4)$ & $48(48,0)$ & $48(48,0)$ & $46(47,9)^{4}$ \\
\hline $\begin{array}{l}\text { Intensidade } \\
\text { (média;DP) }\end{array}$ & $\begin{array}{c}2,0-9,0 \\
(5,10 ; 2,29)\end{array}$ & $\begin{array}{c}1,0-10,0 \\
(6,7 ; 2,40)^{1}\end{array}$ & $\begin{array}{c}1,0-10,0 \\
(4,31 ; 3,37)\end{array}$ & $\begin{array}{c}1,0-10,0 \\
(5,34 ; 2,51)\end{array}$ & $\begin{array}{c}1,0-10,0 \\
(5,27 ; 2,89)^{1}\end{array}$ \\
\hline $\begin{array}{l}\text { Intensidade do } \\
\text { incômodo } \\
\text { (média;DP) }\end{array}$ & $\begin{array}{l}1,0 \text { a } 10,0 \\
(6,33 ; 2,8)\end{array}$ & $\begin{array}{c}1,0 \text { a } 10,0 \\
(6,78 ; 2,69)^{3}\end{array}$ & $\begin{array}{c}1,0 \text { a } 10,0 \\
(3,04 ; 3,72)\end{array}$ & $\begin{array}{l}2,0 \text { a } 10,0 \\
(5,76 ; 2,3)\end{array}$ & $\begin{array}{c}1,0 \text { a } 10,0 \\
(5,61 ; 2,85)^{5}\end{array}$ \\
\hline TOTAL & $105(100,0)$ & $101(100,0)$ & $100(100,0)$ & $100(100,0)$ & $96(100,0)$ \\
\hline
\end{tabular}

OP: Operatório

Tabela 16 - Distribuição dos doentes em números absolutos (N) e em percentagens $(\%)$ quanto à queixa de disestesia

\begin{tabular}{|c|c|c|c|c|c|}
\hline DISESTESIA & $\begin{array}{l}\text { PRE-OP } \\
\mathrm{N}(\%)\end{array}$ & $\begin{array}{c}\text { PÓS-OP } \\
\text { (7 DIAS) } \\
\text { N(\%) }\end{array}$ & $\begin{array}{c}\text { PÓS-OP } \\
\text { (30 DIAS) } \\
\text { N(\%) } \\
\end{array}$ & $\begin{array}{c}\text { PÓS-OP } \\
\text { (120 DIAS) } \\
\mathrm{N}(\%) \\
\end{array}$ & $\begin{array}{c}\text { PÓS-OP } \\
\text { (210 DIAS) } \\
\mathrm{N}(\%) \\
\end{array}$ \\
\hline $\mathrm{N}$ casos $(\%)$ & $4(3,9)$ & $10(9,9)$ & $9(9,0)$ & $19(19,0)$ & $22(22,9)^{1}$ \\
\hline $\begin{array}{l}\text { Intensidade } \\
\text { (média;DP) }\end{array}$ & $\begin{array}{c}8,0 \text { a } 10,0 \\
(7,6 ; 3,78)\end{array}$ & $\begin{array}{c}3,0 \text { a } 10,0 \\
(7,4 ; 2,01)^{1}\end{array}$ & $\begin{array}{c}2,0 \text { a } 8,0 \\
(0,60 ; 1,86)\end{array}$ & $\begin{array}{c}1,0 \text { a } 10,0 \\
(5,35 ; 2,78)\end{array}$ & $\begin{array}{c}1,0 \text { a } 10,0 \\
(5,59 ; 2,91)^{1}\end{array}$ \\
\hline TOTAL & $105(100,0)$ & $101(100,0)$ & $100(100,0)$ & $100(100,0)$ & $96(100,0)$ \\
\hline
\end{tabular}

OP: Operatório 
A avaliação algiométrica pré-operatória revelou diferença estatisticamente significativa nos valores mensurados nas áreas de distribuição dos ramos maxilar e mandibular entre o lado afetado e o controle $(\mathrm{p}<0,001)$. Ocorreu comprometimento significativo da sensibilidade dolorosa apenas nos territórios dos ramos maxilar $(p=0,007)$ e mandibular $(p=0,002)$ do nervo trigêmeo na avaliação de 7 dias; a diferença deixou de ser significativa nas avaliações de 120 e 210 dias $(p=0,5650$ e $\mathrm{p}=0,0049)$. Não ocorreram variações estatisticamente significativas na avaliação algiométrica no território do ramo oftálmico $(\mathrm{p}=0,1815)$ (Figura 10).

\section{Figura 10 - Distribuição dos doentes em números absolutos (N) quanto à algiometria}

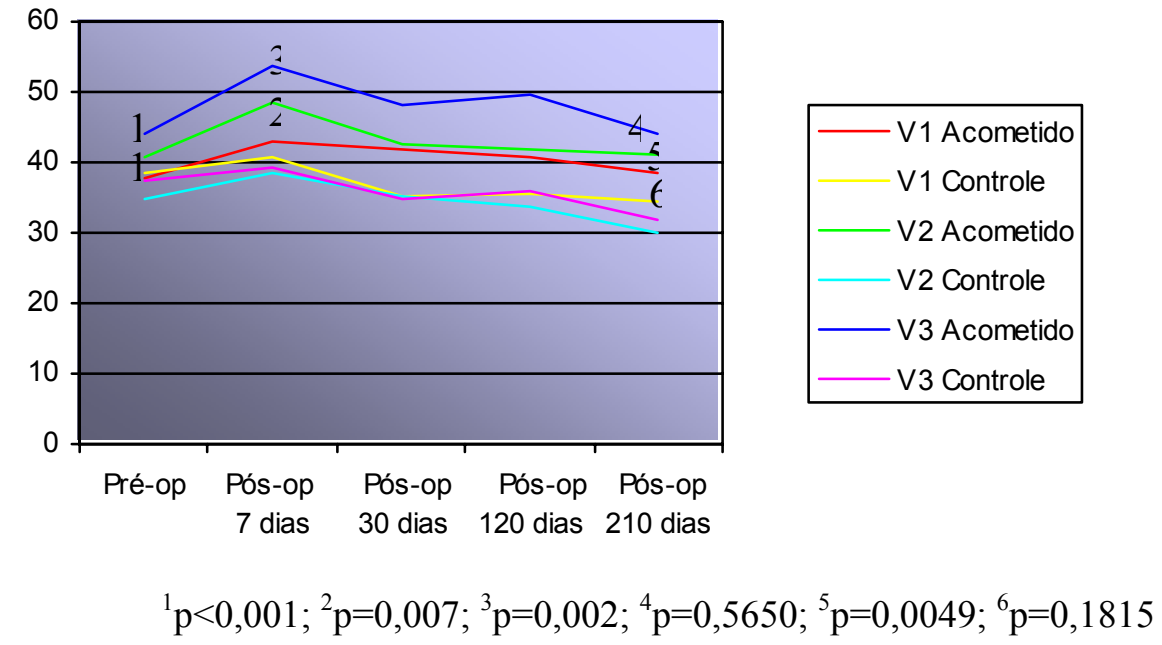

V1: Ramo oftálmico; V2: Ramo maxilar; V3: Ramo mandibular; Op: Operatório

Não ocorreram diferenças estatisticamente significativas quanto ao número de doentes com alterações sensitivas avaliadas por estímulos dolorosos com picada de alfinete, aplicação de frio, ou calor e táctil (Tabela 17).

Tabela 17 - Distribuição dos doentes em números absolutos (N) e em percentagens $(\%)$ quanto à sensibilidade facial superficial 


\begin{tabular}{|c|c|c|c|c|c|c|}
\hline \multicolumn{2}{|c|}{$\begin{array}{c}\text { TIPO DE } \\
\text { ESTÍMULO }\end{array}$} & $\begin{array}{l}\text { PRE-OP } \\
\mathrm{N}(\%)\end{array}$ & $\begin{array}{l}\text { POS-OP } \\
\text { (7 DIAS) } \\
\text { N(\%) }\end{array}$ & $\begin{array}{c}\text { PÓS-OP } \\
\text { (30 DIAS) } \\
\text { N(\%) }\end{array}$ & $\begin{array}{c}\text { PÓS-OP } \\
\text { (120 DIAS) } \\
\text { N(\%) }\end{array}$ & $\begin{array}{c}\text { PÓS-OP } \\
\text { (210 DIAS) } \\
\text { N(\%) }\end{array}$ \\
\hline \multirow{6}{*}{ Picada } & V1 & 1 & - & 1 & - & - \\
\hline & V2 & 2 & 6 & 4 & 3 & 2 \\
\hline & V3 & 7 & 13 & 9 & 8 & 6 \\
\hline & V1-2 & 1 & - & 3 & 3 & 1 \\
\hline & V2-3 & 5 & 15 & 13 & 13 & 10 \\
\hline & V1-2-3 & 5 & 14 & 12 & 16 & 17 \\
\hline \multirow{7}{*}{ Frio } & V1 & - & 2 & - & - & - \\
\hline & $\mathrm{V} 2$ & 1 & 5 & 5 & 3 & 3 \\
\hline & V3 & 3 & 15 & 7 & 8 & 14 \\
\hline & V1-2 & - & 5 & 4 & 7 & 2 \\
\hline & V2-3 & 2 & 8 & 5 & 7 & 4 \\
\hline & V1-3 & - & - & - & - & 1 \\
\hline & V1-2-3 & 7 & 7 & 7 & 8 & 10 \\
\hline \multirow{7}{*}{ Calor } & V1 & - & - & - & - & - \\
\hline & V2 & 4 & 7 & 5 & 5 & 3 \\
\hline & V3 & 5 & 15 & 6 & 6 & 12 \\
\hline & V1-2 & - & 4 & 3 & 1 & 3 \\
\hline & V2-3 & - & 6 & 6 & 11 & 4 \\
\hline & V1-2-3 & 10 & 10 & 11 & 12 & 13 \\
\hline & V1-3 & - & 1 & - & - & 1 \\
\hline \multirow{7}{*}{ Tato } & V1 & - & - & - & 1 & 4 \\
\hline & $\mathrm{V} 2$ & 2 & 7 & 4 & 2 & 1 \\
\hline & V3 & 4 & 17 & 11 & 10 & 9 \\
\hline & V1-2 & 1 & 2 & 1 & 2 & 8 \\
\hline & V2-3 & 3 & 7 & 9 & 10 & 7 \\
\hline & V1-2-3 & - & 16 & 9 & 14 & 14 \\
\hline & V1-3 & - & 5 & 3 & 1 & 2 \\
\hline TOTAI & & $105(100,0)$ & $101(100,0)$ & $100(100,0)$ & $100(100,0)$ & $96(100,0)$ \\
\hline
\end{tabular}




\subsection{Outras anormalidades}

Ocorreu dor durante a abertura bucal pós-operatória em $65(64,4 \%)$ doentes na avaliação de 7 dias com intensidade variando de 1 a 10 (média 5,3; DP =2,8484); 45 doentes $(44,6 \%)$ apresentaram erupção pelo vírus Herpes simplex no lado operado; 19 (18,8\%) apresentaram úlcera cutânea e 29 (28,7 \%), úlceras na mucosa oral associadas à infecção herpética e ou ao traumatismo no local da punção. Estas anormalidades são apresentadas na Tabela 18; $33(32,7 \%)$ doentes apresentaram dificuldades para alimentar-se, um, para ingerir líquidos, dois, para falar e 15 $(14,9 \%)$, para exercer qualquer atividade mandibular.

Tabela 18 - Distribuição dos doentes em números absolutos (N) e em percentagens (\%) quanto às anormalidades na avaliação de 7 dias

\begin{tabular}{l|c|c}
\hline \multicolumn{1}{c}{ ANORMALIDADES NO PÓS-OPERATÓRIO IMEDIATO } & $\mathrm{N}$ & $\%$ \\
\hline Pseudoaneurisma & 1 & 1,0 \\
Meningite & 1 & 1,0 \\
Herpes simplex & 45 & 44,6 \\
Dor significativa & 67 & 66,3 \\
Úlceras cutâneas & 19 & 18,8 \\
Úlceras mucosas & 29 & 28,7 \\
Hematoma facial & 30 & 29,7 \\
Equimose intraoral & 4 & 4,0 \\
Eritema em face & 1 & 1,0 \\
Alteração auditiva & 1 & 1,0 \\
Edema facial & 1 & 1,0 \\
Alteração visual & 1 & 1,0 \\
Mordida desconfortável & 59 & 58,4 \\
Limitação para execução das atividades mandibulares em geral & 51 & 50,5 \\
Dor durante abertura bucal máxima & 65 & 64,4 \\
TOTAL & 101 & 100,0 \\
\hline
\end{tabular}


Após 30 dias, $68(64,8 \%)$ doentes queixaram-se de dor com intensidade variando de 1 a 10 (média=3,46; $\mathrm{DP}=3,4595)$. Quanto avaliados com a aplicação do Questionário de Dor McGill, 52 doentes utilizaram expressões do grupo discriminativo, cinco, do afetivo, um, do miscelânea, um, equivalência das do sensitivo e afetivo e nove foram indefinidos; 55 doentes apresentaram índice do grupo sensitivo mais elevado, dois, do grupo afetivo, dois, do grupo avaliativo, dois, do grupo miscelânea, sete não apresentaram preferência. As anormalidades apresentadas na avaliação de 30 dias são apresentadas na Tabela 19.

Tabela 19 - Distribuição dos doentes em números absolutos (N) e em percentagens (\%) quanto à ocorrência de outras anormalidades na avaliação de 30 dias

\begin{tabular}{l|c|c}
\hline \multicolumn{1}{c|}{ ANORMALIDADES } & $\mathrm{N}$ & $\%$ \\
\hline Piora da acuidade auditiva & 1 & 1,0 \\
Xerostomia e surdez & 1 & 1,0 \\
Alteração de paladar & 1 & 1,0 \\
Úlcera intraoral & 1 & 1,0 \\
Despapilação lingual & 1 & 1,0 \\
Fissura lingual & 1 & 1,0 \\
Queilite angular & 1 & 1,0 \\
Candidíase em palato & 1 & 1,0 \\
Leucoplasia em assoalho de boca & 1 & 1,0 \\
Amiotrofia do músculo temporal & 1 & 1,0 \\
Mordida de lábios, língua e ou bochecha & 8 & 8,0 \\
TOTAL & 100 & 100,0 \\
\hline
\end{tabular}

$\mathrm{Na}$ avaliação de 120 dias, 33 doentes ainda apresentavam limitação para executar algumas atividades ou seja, dez, para exercer atividades mandibulares, 17, 
para comer, dois, para beber, cantar e conversar, dois, para falar, um, para engolir, e um para outras atividades. Ocorreram outras anormalidades em 42 doentes (Tabela 20).

Tabela 20 - Distribuição dos doentes em números absolutos (N) e em percentagens (\%) quanto à ocorrência de outras anormalidades na avaliação de 120 dias

\begin{tabular}{|c|c|c|}
\hline ANORMALIDADES & $\mathrm{N}$ & $\%$ \\
\hline Úlcera cutânea & 1 & 1,0 \\
\hline Úlcera mucosa & 6 & 6,0 \\
\hline Incômodo em olhos & 5 & 5,0 \\
\hline Disestesia grave & 5 & 5,0 \\
\hline Perda de paladar & 3 & 3,0 \\
\hline Eritema e hiperqueratose no tegumento & 2 & 2,0 \\
\hline Hiperqueratose no pálato & 2 & 2,0 \\
\hline Incômodo nos olhos e ouvidos & 2 & 2,0 \\
\hline Dificuldades visuais & 2 & 2,0 \\
\hline Perda de audição & 2 & 2,0 \\
\hline Mucosite & 2 & 2,0 \\
\hline Queilite angular & 2 & 2,0 \\
\hline Impossibilidade de uso de prótese total por abertura bucal limitada & 1 & 1,0 \\
\hline Limitação grave para abertura bucal & 1 & 1,0 \\
\hline Xerostomia & 1 & 1,0 \\
\hline Máculas escurecidas & 1 & 1,0 \\
\hline Depressão & 1 & 1,0 \\
\hline Dor miofascial intensa & 1 & 1,0 \\
\hline Sensação de orelha tapada e atrofia do músculo temporal ipsilateral & 1 & 1,0 \\
\hline TOTAL & 100 & 100,0 \\
\hline
\end{tabular}

$\mathrm{Na}$ avaliação de 210 dias, 32 doentes ainda apresentavam queixas de dor com intensidades variando de 1,0 a 10,0 (média: 5,688; DP=3,0737). Outras anormalidades foram descritas em 36 doentes (Tabela 21). As complicações graves 
observadas foram: anquilose da ATM direita em um doente (Figura 11), despapilação lingual em cinco (Figuras 12 e 13); outras alterações tróficas como hiperqueratose em mucosa jugal ocorreu em um doente (Figura 14).

Tabela 21 - Distribuição dos doentes em números absolutos (N) e em percentagens (\%) quanto à ocorrência de outras anormalidades na avaliação de 210 dias

\begin{tabular}{l|c|c}
\hline \multicolumn{1}{c|}{ ANORMALIDADES } & $\mathrm{N}$ & $\%$ \\
\hline Ouvido tapado & 6 & 6,3 \\
Disestesia grave & 5 & 5,2 \\
Alteração trófica lingual & 4 & 4,2 \\
Alteração de paladar & 3 & 3,1 \\
Incômodo nos olhos e lacrimejamento & 3 & 3,1 \\
Ulcerações em lábio superior ipsolateral & 3 & 3,1 \\
Candidíase em palato e queilite angular & 2 & 2,1 \\
Neuralgia no lado oposto & 2 & 2,1 \\
Alteração do olfato e da audição & 1 & 1,0 \\
DTM grave & 1 & 1,0 \\
Depressão de causas externas & 1 & 1,0 \\
Prurido na orelha & 1 & 1,0 \\
Anquilose em ATM & 1 & 1,0 \\
Hiperqueratose em rebordo alveolar inferior & 1 & 1,0 \\
Alteração trófica em margem gengival & 1 & 1,0 \\
Hiperqueratose em mucosa jugal & 1 & 1,0 \\
TOTAL & 96 & 100,0 \\
\hline
\end{tabular}




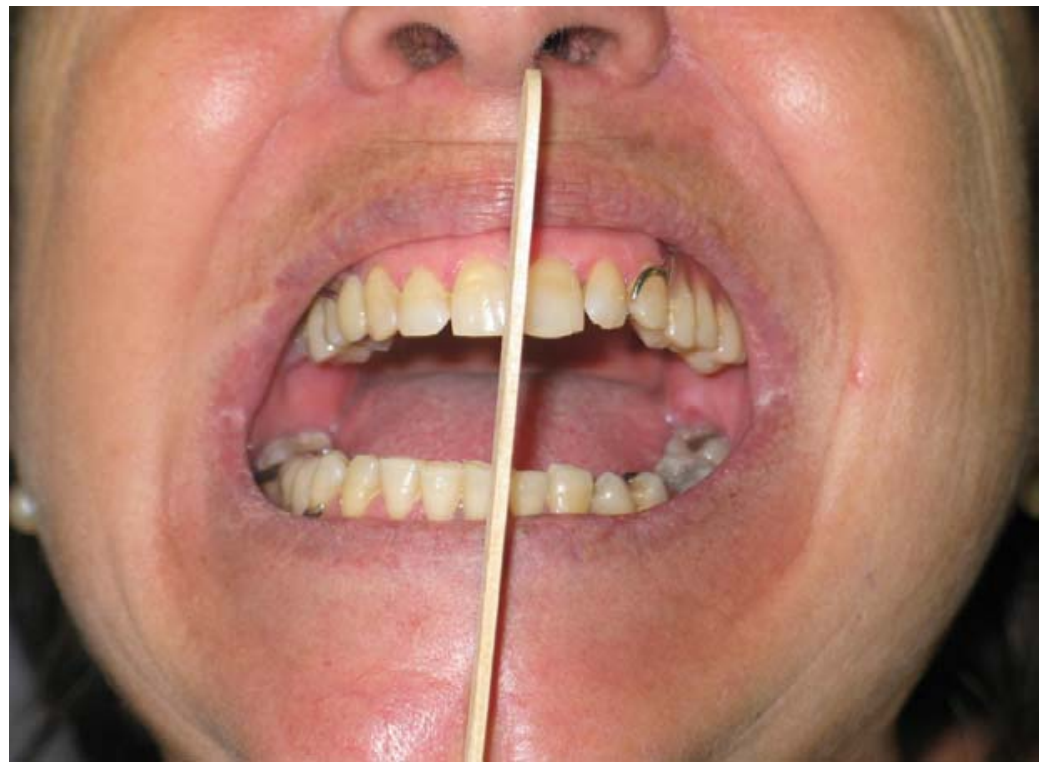

Figura 11 - Anquilose em articulação temporomandibular direita na avaliação de 210 dias

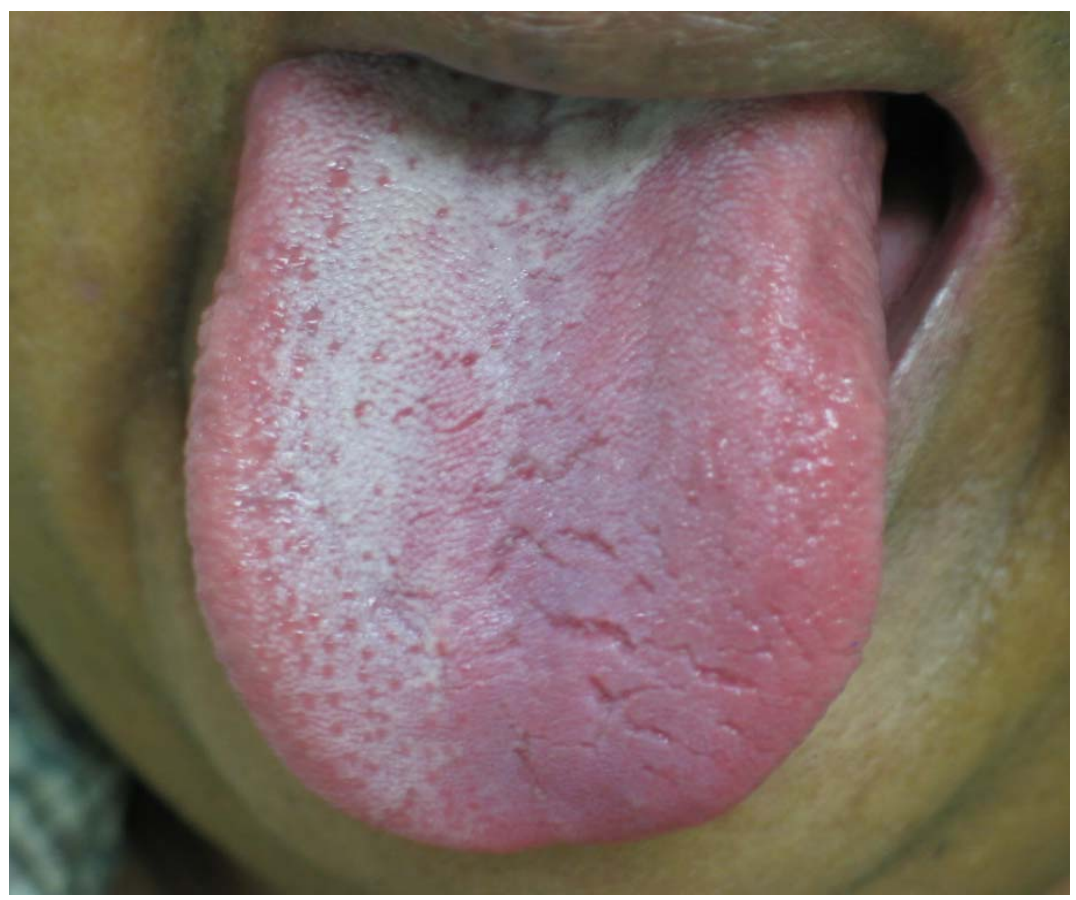

Figura 12 - Despapilação lingual no lado operado (esquerdo), na avaliação de 210 dias 


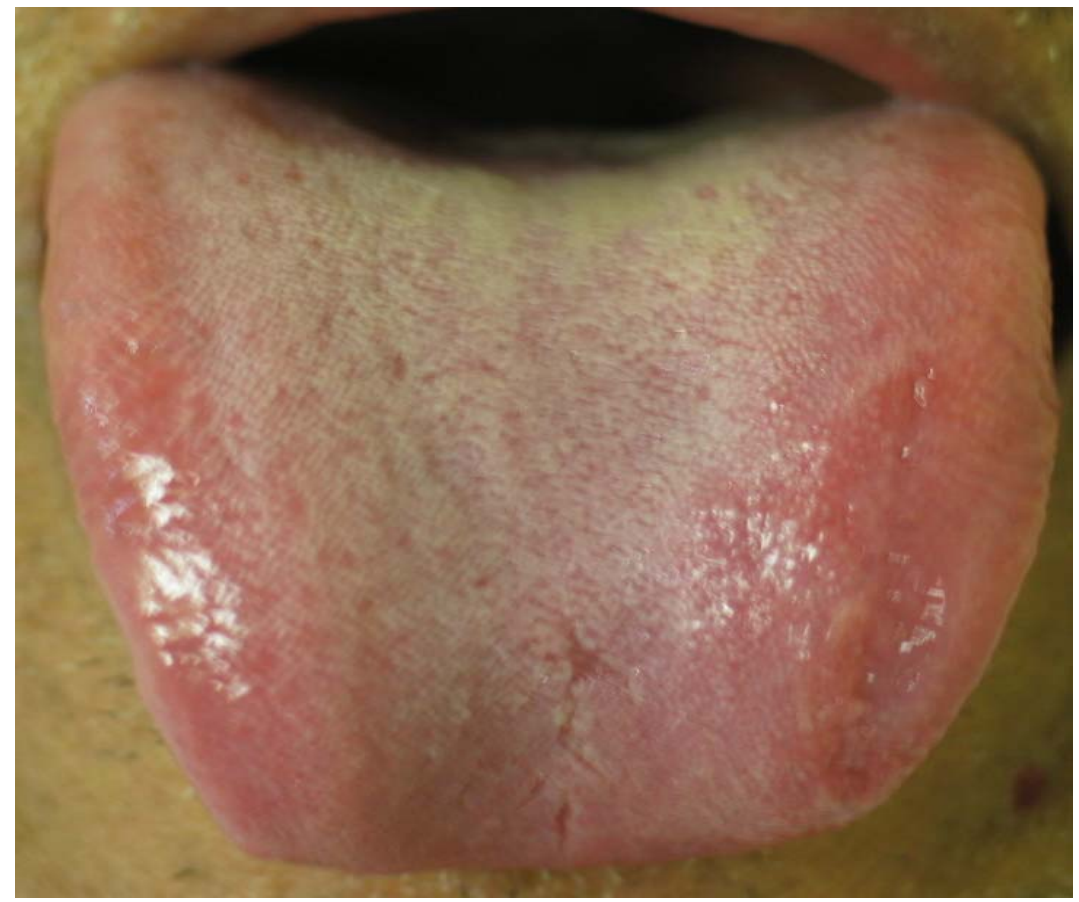

Figura 13 - Despapilação lingual em região anterior esquerda na avaliação de 210 dias

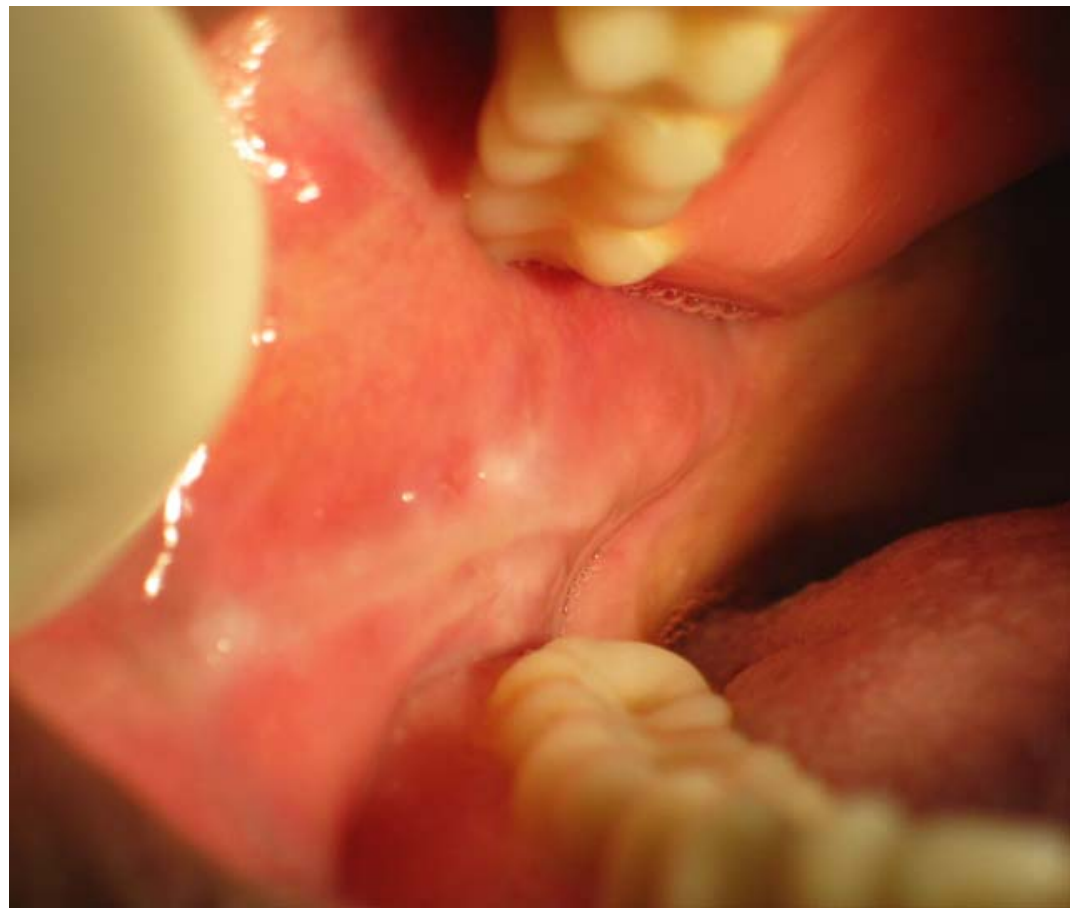

Figura 14 - Hiperqueratose em mucosa jugal no lado direito ou seja, o mesmo da cirurgia, na avaliação de 210 dias 


\section{DISCUSSÃO}

Mais de 75\% dos doentes com NIT necessita tratamento cirúrgico para controlar a dor (Graff-Radford, 1991). A seleção do método operatório deve adequarse ao diagnóstico, considerar a idade dos doentes, respeitar a presença de fatores de risco do procedimento, possibilitar o tratamento de condições nosológicas associadas e vislumbrar a possibilidade de ocorrência de complicações (Teixeira, 1984).

Os doentes incluídos no presente estudo foram submetidos à compressão do gânglio e da raiz trigeminal com balão. A distribuição dos doentes quanto às idades, ramo e lado afetados, expressões realizadas para descrever a dor, intensidade da dor e ocorrência de zonas de gatilho foram semelhantes ao descrito em outros trabalhos publicados (Teixeira, 1984; Siqueira et al., 2004).

$\mathrm{Na}$ presente casuística, houve predomínio dos indivíduos do sexo feminino (57,1\%), o que está de acordo com o observado por outros autores (Teixeira, 1984; Siqueira e Teixeira, 2003).

A média das idades foi 60 anos, achado que também coincide com o observado por outros pesquisadores (Moura et al., 1979; Teixeira, 1984).

A dor é intensa em casos de NIT (Teixeira, 1984); a intensidade foi moderada ou elevada na maioria dos doentes da presente casuística (médica da EVA $=8,245$; $\mathrm{DP}=2,27)$

O lado direito foi o mais acometido (69,5\%), achado coincidente com o de outros autores que observaram que tal ocorria em mais de 50\% dos casos (Lazar et al., 1980; Graff-Radford, 1991; Teixeira, 1995; Loh et al., 1998; Patterson, 1999). 
Foi bilateral em apenas 1,9\% dos casos, o que também coincide com o observado por outros investigadores (Teixeira, 1984; Graff-Radford, 1991; Siqueira e Teixeira, 2003).

A dor localizou-se mais freqüentemente na região inervada pelos ramos maxilar e mandibular do nervo trigêmeo, ou seja, acometeu o território de V2 em $29,5 \%$ dos casos presentes, de V3 em $29,5 \%$ e de V2-3 em 20,1\%, achado que coincide com o observado em outras casuísticas (Henderson, 1967). O acometimento do ramo oftálmico é raro (2\% a 7\%) (Stookey e Ransohoff, 1959). Entretanto, foi afetado em $11,4 \%$ dos casos, o que pode refletir maior ocorrência de acometimento desse ramo em nosso meio observação, já evidenciada previamente (Teixeira, 1984). As razões dessa discrepância ainda não foram elucidadas.

A dor era freqüentemente desencadeada por estímulos das regiões anteriores da face $(61,9 \%)$, achado coincidente com os de outros autores (Teixeira, 1984; Stoockey e Ronsohoff, 1959), e muitas vezes na região bucal, o que dificultava a higiene oral e facilitava a evolução das doenças regionais. Quinze (14,3\%) doentes queixavam-se de otalgia, sendo em dez $(9,5 \%)$ à direita. A causa da otalgia pode ser primariamente otológica, representar a dor própria da NIT ou a dor referida de áreas adjacentes como a ATM (Siqueira e Teixeira, 2001). Devido ao desencadeamento da dor pela estimulação de amplas regiões do segmento cefálico podem ocorrer limitações funcionais orofaciais, algumas graves e comprometedoras importantes da qualidade de vida dos indivíduos que dela padecem. Observou-se comprometimento grave das atividades, incluindo os cuidados de higiene, fala, mastigação e deglutição,devido à dor em aproximadamente um quinto dos doentes $(20,3 \%)$, achado já observado por outros autores (Teixeira, 1984); (Siqueira e Teixeira, 2003) 
A expressão mais comumente empregada para descrever a dor foi choque (69,5\%). A dor nos doentes com NIT pode também pode ser descrita como sucessivas pontadas, facadas, choques elétricos, relâmpagos ou penetração de calor de forte intensidade na face (Frazier e Russel, 1924; Penman, 1950; Henderson, 1967; Lazar et al., 1980).

A dor relacionada à NIT, os medicamentos utilizados para controlá-la, o tratamento neurocirúrgico funcional e suas complicações não interferiram na qualidade subjetiva do sono ao longo do período de avaliação $(p=0,670)$ (Tabela 13).

A reabilitação do doente no período pós-operatório pode tornar-se comprometida devido à instalação da hipoestesia ou de disestesia resultantes da cirurgia. A avaliação pré-operatória possibilita identificar anormalidades que, quando tratadas, podem prevenir seqüelas pós-operatórias.

Apesar de a dor poder localizar-se nos dentes, não há geralmente alterações radiográficas ou ao exame físico que justifiquem causas odontológicas (Patterson, 1999). Isso significa que o diagnóstico diferencial deve fundamentar-se no histórico e no quadro clínico que deve revelar ausência de evidências de anormalidades dentárias ou orais compatíveis (Patterson, 1999; Siqueira e Siqueira, 2003; Siqueira et al., 2004). Muito freqüentemente há erros diagnósticos em casos de NIT (Lazar et al., 1980), pois sua caracterização clínica pode assemelhar-se à da dor secundária a anormalidades músculo-esqueléticas craniofaciais ou mastigatórias (Kerr, 1963c; Hotta et al., 1997) ou a afecções orofaríngeas, oculares, nasais ou cranianas (Sessle, 2000). A dor facial pode também ser referida de regiões corpóreas distantes (GraffRadford, 1991; Thomé, 1993; Brunetti e Oliveira, 1995) especialmente cervicais ou torácicas devido à ampla e densa convergência das aferências nociceptivas da face, do crânio e da região cervical nos neurônios do complexo nuclear trigeminal (Sessle 
et al., 1986; Sessle, 2000; Davis e Dostrovsky, 1986) onde ocorrem sensibilização neuronal, facilitação e somação de estímulos (Hardy et al., 1950; Ingle et al., 1979).

Imprecisões diagnósticas podem resultar na adoção de tratamentos impróprios, muitos dos quais causadores de seqüelas, ocorrência não incomum em doentes com NIT, devido às semelhanças que esta apresenta com a odontalgia, especialmente quando as zonas de gatilho situam-se em regiões próximas dos dentes (Siqueira et al. 2004). Foi o que se observou em 66 (62,9\%) doentes da presente casuística que haviam sido submetidos a diversos tratamentos odontológicos desnecessários incluindo a exodontia e a cirurgia óssea.

Evidenciou-se edentulismo em muitos doentes da presente casuística, sendo bimaxilar em 43,8\% dos doentes e unimaxilar em 18,1\% (Tabela 6). Segundo o Ministério da Saúde do Brasil (1986), há elevada prevalência de edentulismo (72\%) na população brasileira adulta, especialmente em indivíduos com mais de 60 anos de idade. O elevado número de exodontias e de cirurgias inapropriadamente realizadas nesses doentes, o não-uso de próteses e os inadequados procedimentos técnicos para sua confecção e adaptação foram razões que tornaram os estímulos das zonas de gatilho mais facilmente eliciáveis e induziram a instalação de DTM. Estas anormalidades, somadas a hipoestesia orofacial e na mucosa oral, podem facilitar a instalação de ferimentos orais e dificultar a reabilitação da função mastigatória. Ao longo do tempo, estas queixas podem intensificar-se e agravar ou causar desconforto durante a mastigação (Siqueira, 2001).

Fatores oclusais predisponentes para DTM representados por mordida cruzada e perda de dentes posteriores foram apresentados por $54,2 \%$ dos doentes edêntulos parciais ou dentados (Pullinger et al., 1993), o que justificou o índice de disfunção de Helkimo ter sido moderado em $26,7 \%$ dos casos e grave em achado de $61,9 \%$. Outro 
fator de risco para DTM foi o bruxismo noturno, observado em $21,9 \%$ dos casos e o diurno, em 21,9\%, também já constatado por outros autores (Siqueira e Ching, 2001). A DTM foi expressa como queixas de cansaço, peso e ou incômodo ao mastigar por 31,4\% dos doentes incluídos na presente casuística, como mordida desconfortável por $38,1 \%$, rigidez ou dor matinal por $31,4 \%$ e ou dor à palpação da musculatura mastigatória por 56,2\%. A elevada ocorrência de contrações faciais prolongadas devidas às crises de dor ou ao temor de sua ocorrência foi outro fator predisponente para DTM.

É possível que a acalmia observada em alguns doentes da presente casuística após a aplicação de calor $(3,8 \%)$ ou uso de analgésicos $(1,9 \%)$ durante o período préoperatório tenha sido relacionada à melhora da dor miofascial. Dores de origem pulpar ou periodontal podem causar dor facial ou agravar a dor relacionada a NIT. Estas condições tornam-se relevantes, pois os doentes com NIT tornam-se impossibilitados de realizar a higiene oral o que os predispõe a doenças bucais infecciosas. Infecções gengivais são também bastante prevalentes no Brasil nestas faixas etárias (95\%) (Ministério da Saúde, 1986) e podem causar dor facial crônica (Siqueira e Teixeira, 2001); foi diagnosticada doença periodontal em $40(67,8 \%)$ os 59 doentes com dentes da presente casuística.

Classicamente não se evidenciam anormalidades neurológicas nos doentes com NIT (Henderson, 1967; Teixeira, 1998). No período pré-operatório, 10,5\% dos doentes da presente casuística sem história de traumatismos ou cirurgias faciais prévias apresentavam discreta dormência facial; as anormalidades nos territórios nos ramos maxilar e mandibular $(\mathrm{p}<0,001)$ foram mais intensas que no primeiro ramo. Sabe-se que discretas anormalidades podem ser identificadas nos doentes com NIT, incluindo a hipoestesia táctil e térmica da face (Synai et al., 2003) e, eventualmente, 
hipalgesia, hiperalgesia, hiperpatia e/ou panestesia não somente na região do ramo afetado, mas também nas regiões adjacentes (Forsell et al., 2002). Paresia da musculatura mastigatória homolateral e alteração do reflexo córneo-palpebral também podem estar presentes (Teixeira, 1984; Marbach, 1999; Gruccu et al., 2006).

A compressão do gânglio trigeminal com balão proporciona melhora imediata da dor em 92,1\% a 100\% dos casos (Lichtor e Mullan, 1990). Apenas um (1,0\%) dos 105 doentes da presente casuística não apresentou alívio da dor após a primeira operação e necessitou outra cirurgia (rizotomia por radiofreqüência). A ausência de melhora e a recorrência após poucos dias parecem ser devidas à compressão insuficiente em alguns doentes (Lobato et al., 1990)

Ocorreu redução significativa das queixas de cefaléia em $21,4 \%$ dos doentes $(p<0,001)$ e de dor no corpo em 15,0\% $(p=0,002)$ nas avaliações realizadas de 30 dias que se mantiveram significativas mesmo na avaliação de 210 dias (Figura 8). A melhora pode ser justificada porque cefaléia e dores musculares generalizadas podem ser manifestações físicas da tensão emocional secundária à dor e da convergência, facilitação, somação de estímulos e sensibilização de neurônios do $\mathrm{SNC}$ onde se projetam aferentes nociceptivos do segmento cefálico e cervical.

O tratamento neurocirúrgico funcional ablativo para tratamento da NIT pode causar diversas complicações incluindo os déficits sensitivos, a infecção pelo vírus do Herpes simplex, as úlceras labiais, os transtornos do aparelho mastigatório, as anormalidades oculares, as infecções etc (Teixeira, 1984; Teixeira, 1998).

Apesar das inúmeras publicações relatando complicações após tratamentos neurocirúrgicos funcionais destinados ao tratamento da NIT, não há até o momento relato de investigações sistemáticas sobre essas anormalidades, exceção feita aos transtornos graves. Considerando-se a importância funcional e estética da face e das 
estruturas que alberga, muitas destas complicações, mesmo de pequena monta, necessitam ser identificadas para que cuidados especiais sejam prontamente adotados para prevenir repercussões desfavoráveis ulteriores.

As complicações decorrentes da compressão radículo-ganglionar trigeminal geralmente são de pequena magnitude e são representadas pela hipoestesia da face na maioria dos doentes, paralisia do músculo masseter $(20 \%)$, hematoma facial $(10 \%)$ (Úrculo et al., 1998), déficit auditivo (11,5\%), comprometimento temporário da função mastigatória (5\%) e comprometimento do reflexo córneo-palpebral $(2,5 \%)$ (Abdennebi et al., 1997). As complicações graves decorrentes da compressão radículo-ganglionar trigeminal são raras. Durante a insuflação do balão no gânglio trigeminal podem ocorrer bradicardia (Brown e Preul, 1989; Preul et al., 1990; Úrculo et al., 1998; Peters e Nurmikko, 2002) e fenômenos hipertensivos devidos à ativação dos neurônios do núcleo do trato solitário pelas projeções das fibras trigeminais (Lobato et al., 1990; Preul et al., 1990). As questões relacionadas a essas anormalidades intra-operatórias não foram objeto do presente trabalho.

Muitas anormalidades pós-operatórias relacionadas ao aparelho mastigatório identificadas nos doentes incluídos na presente casuística foram transitórias. Anormalidades mastigatórias ipsilaterais foram associadas ao desuso do lado acometido e desapareceram três meses após nos doentes de Lichtor e Mullan (1990). A dor durante a mastigação observada na avaliação de sete dias $(p=0,180)$ apresentava outras causas que não a NIT na maioria dos casos; algumas eram características de doenças dentárias e ou do aparelho mastigatório e manifestadas como cansaço ou fraqueza mastigatória.

O traumatismo necessário para a realização do procedimento, incluindo o causado pela transfixação muscular durante a transfixação pelo cateter do espaço 
pterigoídeo, somado à compressão do ramo motor do nervo trigêmeo pelo balão, pode agravar a mobilidade mandibular e resultar em fibrose tecidual que contribuiu secundariamente para agravá-la. A dor e as limitações dos movimentos observados nos primeiros dias de pós-operatório são geralmente associadas ao traumatismo e têm etiologia inflamatória.

A queixa de mordida desconfortável, observada principalmente na avaliação de sete dias $(\mathrm{p}=0,006)$, pode decorrer do comprometimento desvias nervosas relacionadas à sensibilidade facial ou à motricidade mastigatória. $\mathrm{O}$ déficit sensitivo também pode resultar em lesões da mucosa oral decorrentes da mordida dos lábios, da bochecha e ou da língua, incoordenação da mastigação e ou dificuldade para o uso de próteses (Figura 2). Esses achados reforçam o conceito de que a sensibilidade orofacial e a função motora mastigatória são interdependentes entre si pois a atividade normal do aparelho mastigatório depende da integridade da propriocepção e da exterocepção dos tecidos a ele relacionados (Siqueira, 2001).

A compressão radículo-ganglionar trigeminal com balão é a neurocirurgia funcional destinada ao tratamento da NIT que mais causa complicações motoras (18\% a 66\%) (Brown e Preul, 1989; Taha e Tew, 1996); essas são graves em cerca de 10\% dos casos, sendo a recuperação lenta (Lobato et al., 1990; Kanpolat et al., 2001). Ocorreram marcantes anormalidades do aparelho mastigatório na avaliação de sete dias. Foram representadas em $55(52,4 \%)$ casos pela limitação da abertura bucal, cuja média no período pré-operatório era de 45,97 mm e na avaliação pós-operatória de sete dias tornou-se $37,84 \mathrm{~mm}(\mathrm{p}=0,0148)$, desvio da mandíbula foi observado em $51 \%(\mathrm{p}<0,001)$ (Tabela 10) e comprometimento da mobilidade mandibular segundo o índice de Helkimo em 14,7\% ( $\mathrm{p}=0,016)$ (Figura 3). Estas anormalidades tenderam retornar aos valores iniciais ao longo do período de acompanhamento. 
As anormalidades mecânicas mandibulares comprometem a função mastigatória, contribuem para a instalação das síndromes dolorosas miofasciais, predispõem os doentes ao desenvolvimento de doenças infecciosas dentárias, pois dificultam a higiene oral e podem gerar complicações graves, como a anquilose da ATM, observada em um doente de presente casuística, mas nunca descrita anteriormente como complicação da compressão radículo-ganglionar trigeminal com balão e que necessitou intervenção cirúrgica de porte médio e de intensivo acompanhamento pós-operatório para prevenir outras limitações funcionais (Figura $11)$.

A unilateralização da mastigação observada antes da cirurgia parece ter-se devido à própria NIT. Ocorreu melhora da distribuição da mastigação para o lado da NIT em 15\% dos casos na avaliação de 210 dias $(p=0,023)$ (Figura 5), fenômeno atribuído ao alívio da dor neuropática. As perdas de saliva e de alimentos observadas na avaliação de sete dias período pós-operatório imediato em 45,5\% dos doentes $(\mathrm{p}=0,002)$ também tenderam a retornar aos valores pré-operatórios, ou seja, passaram a ocorrer em 35,4\% dos doentes $(\mathrm{p}=0,194)$. Esses achados parecem refletir a adaptação dos doentes às alterações extero e proprioceptivas ocorridas no lado operado.

A diminuição do número de casos catalogados como grau 4 na escala de gravidade de dor crônica avaliada pelo Eixo II do RDC/TMD em 9,4\% dos casos $(\mathrm{p}=0,034)$ assim como a melhora da depressão $(\mathrm{p}=0,007)$ e dos sintomas físicos nãoespecíficos $(p=0,028)$ correspondentes aos sintomas de ansiedade na avaliação 210 dias enfatizou a melhora observada nas atividades dos doentes avaliados na presente casuística (Tabela 12; Figuras 6 e 7). Ocorrem sintomas emocionais na maioria dos doentes com síndromes álgicas crônicas e podem ser envolvidos nos mecanismos 
fisiopatológicos da dor (Sessle, 2000). Entretanto, podem persistir mesmo após o tratamento e serem secundários à doença primária. A redução de sua gravidade certamente contribuiu para a melhora funcional dos doentes após a cirurgia, o que salienta a marcante limitação funcional resultante impacto da dor na vida dos doentes com NIT.

Algum grau de hipoestesia facial ocorre em mais de 75\% dos doentes (Úrculo et al., 1998). Dormência e comprometimento objetivo da sensibilidade apresar de freqüentes após a compressão radículo-ganglionar trigeminal, são geralmente bem tolerados e tendem a sofrer normalização progressiva com o passar do tempo, apesar de raramente desaparecerem totalmente. Houve aumento do número de doentes com sensação de dormência e de incômodo de $29 \%$ para $88 \%$ dos casos na avaliação de sete dias $(p<0,001)$ achado que se manteve ao longo do tempo ( $\mathrm{p}=0,0292)$ (Figura 9). É provável que a hipoestesia, as parestesias e as disestesias sejam relacionadas à compressão prolongada (Lichtor e Mullar, 1980). Na presente casuística, as queixas subjetivas foram mais prevalentes que as alterações evidenciadas durante a avaliação da sensibilidade superficial com algiometria, termometria e determinação da sensação táctil $(p<0,001)$ (Figura 9). E sempre salientar que os exames psicofísicos possibilitam obter dados quantitativos objetivos para analisar doentes, mas sofrem a influência das emoções e de fatores ambientais que também interferem nas queixas.

O comprometimento adicional de algumas qualidades sensitivas (calor, frio, o tato e dor) observadas no período pós-operatório foi decorrente da cirurgia e persistiu ao longo dos períodos de avaliação, apesar de se tornar menos expressivo com o passar do tempo. Isso significa que ocorreu reversibilidade parcial dessas alterações com a progressão do seguimento $(\mathrm{p}<0,01)$ (Figura 9). 
Disestesias podem ser complicações de qualquer técnica ablativa (Teixeira, 1984); são consideradas mais freqüentes após a rizotomia por radiofreqüência (9\%) (Taha e Tew, 1996). Entretanto, foram bastante comuns nos doentes da presente casuística e manifestaram-se em 22,9\% dos casos na avaliação após 210 dias (Tabela 15). Esse achado contradiz os resultados do trabalho de Abdennebi et al. (1997) que avaliaram 200 doentes tratados com compressão radículo-ganglionar com balão e observaram disestesias e hipoestesia graves em apenas 1,5\% deles.

A compressão radículo-ganglionar com balão não é seletiva para os ramos trigeminais e a dormência induzida não pode ser controlada (Brown et al., 1993). As alterações da sensibilidade ocorreram mais nos territórios inervados pelos ramos maxilar e mandibular do nervo trigêmeo $(p<0,001)$, foram mais relevantes na avaliação de sete dias (V2, $\mathrm{p}=0,007 ; \mathrm{V} 3, \mathrm{p}=0,002)$ e tenderam a normalizar-se com o passar do tempo $(\mathrm{p}=0,5650)$, o que sugere que se devam a neuropraxia (Figura 10). Não se observaram anormalidades algiométricas significativas no território do ramo oftálmico ao longo do tempo $(\mathrm{p}=0,1815)$ ou anormalidades do reflexo córneopalpebral, achados que evidenciam que o procedimento é seguro quanto à preservação do reflexo córneo-palpebral e à proteção corneana e sugerem que talvez seja apropriado para tratar NIT que afeta o primeiro ramo (Teixeira, 1998). Em coelhos, há mais susceptibilidade das fibras de calibre médio e grosso ao efeito da compressão com balão o que justifica o fato de o reflexo córneo-palpebral, mediado por fibras finas, não se comprometer após a compressão radículo-ganglionar e de a anestesia da córnea, a ceratite e a anestesia dolorosa serem raras após o procedimento (Lobato et al., 1990; Preul et al., 1990; Brown et al., 1993). O comprometimento mais expressivo do ramo mandibular possivelmente decorreu do traumatismo de suas 
fibras ou dos corpos celulares correspondentes pela agulha e do fato de estes disporem-se mais ventralmente no gânglio trigeminal.

Alguns doentes passaram a queixar-se de anormalidades visuais, auditivas ou do paladar após a cirurgia (Tabelas 17, 18, 19 e 20). As anormalidades auditivas podem dever-se à transfixação ou edema da trompa de Eustáquio ou à disfunção do músculo tensor do tímpano (Brown e Preul, 1989). As anormalidades visuais e, especialmente as gustativas, possivelmente devem-se ao comprometimento do mecanismo de interação sensitiva que ocorre no SNC (Melzack e Wall, 1965). Esse mecanismo e a desinibição causada pela desaferentação gerariam alterações no processamento sensitivo, tal como ocorre em casos de SAB (Grushka, 1987). Mecanismos semelhantes justificariam a ocorrência de disestesias nas áreas trigeminais desaferentadas. Alterações gustativas também foram evidenciadas em casos de dor facial, incluindo a SAB (Grushka, 1987; Nasri e Siqueira, 2001) ou após a rizotomia química por injeção de álcool no gânglio e raiz trigeminal e não são relacionadas à lesão das vias gustativas conhecidas (Grant et al., 1987). As papilas gustativas são compostas de cinco tipos diferentes de células intimamente relacionadas às fibras amielínicas e à corda do tímpano (VII par craniano) e são estimuladas por íons ou moléculas. No SNC de primatas há convergência das informações sensitivas trigeminais e gustatórias; fibras do nervo lingual projetam-se no núcleo solitário lateral onde também há projeções da corda do tímpano de modo que a degeneração tecidual desta área poderia gerar dor trigeminal e ageusia (Grant et al., 1987). Apesar de a estimação gustatória pelo sabor doce poder desencadear crises de NIT (Scrivani et al., 1998), o controle da dor pela carbamazepina e a ausência de alterações gustativas observados em doentes com NIT sugerem que a 
anormalidade causal é mais importante no complexo nuclear trigeminal do que no gustativo (Sharav et al., 1991).

Foi elevada a ocorrência de infecção cutânea pelo vírus do Herpes simplex na presente casuística $(44,6 \%)$, semelhantemente ao observado em outros estudos em que foi diagnosticado em $38 \%$ a $94 \%$ dos doentes durante período pós-operatório imediato (Úrculo et al., 1998; Cohrs e Gilden, 2001).

A infecção pode também resultar em esofagite herpética quando ocorre traumatismo da faringe pela intubação naso ou orotraqueal (Pazin, 1978), método não aplicado durante a realização das operações na presente casuística. Os mecanismos pelos quais os procedimentos cirúrgicos reativam o vírus do Herpes simplex latente no gânglio trigeminal ainda não foram determinados (Martilla et al., 1977). É possível a contaminação ocorre pela via oral, uma vez que a neuralgia acomete mais o segundo e o terceiro ramos do nervo trigêmeo e a cavidade oral é altamente infectada (Kerr, 1963c). Os antivirais podem prevenir seu aparecimento (Schädelin et al., 1988; Kriesel, 1999; Cohrs e Gilden, 2001), mas o interferon revelou-se ineficaz (Pazin et al., 1984).

Nos doentes incluídos foi rara a ocorrência de lesões tróficas pós-operatórias; foram identificadas em apenas seis doentes, valor inferior ao observado após outros procedimentos ablativos para tratar a NIT (Freeman, 1967; Dicken, 1997; Kavanagh et al., 1996; Urabe et al., 1999; Ferrara et al., 2000; Sadeghi et al., 2004). As lesões mucosas e cutâneas são decorrentes do comprometimento da sensibilidade superficial e dos traumatismos repetidos e facilitam a instalação de doenças infecciosas orais incluindo a candidíase e podem simular infecções (sífilis, lesão herpética, hanseníase, blastomicose, paracoccidioidomicose, leishmaniose, tumores) (Cliff e Demis, 1967; Goodnight e Calcaterra, 1994). Comprometimento exteroceptivo e proprioceptivo, 
devido às interações com fibras motoras, poderia induzir hipotonia muscular facial, que não foi observada através da metodologia utilizada nessa casuística.

Apesar de considerada inócua (Lichtor e Mullan, 1980), a compressão radículo-ganglionar trigeminal com balão resultou em algumas complicações graves, como meningite bacteriana, observada em um doente e pseudoaneurisma da artéria carótida em outro. Um doente de Abdennebi et al. (1997) faleceu devido à ocorrência de hematoma no tronco encefálico decorrente da penetração da agulha de punção no encéfalo. Na casuística de Brown e Preul (1989), um doente com atrofia cerebral faleceu em decorrência de hemorragia subaracnoídea desencadeada pela operação.

A taxa de recidiva da dor na avaliação de 210 dias foi elevada $(16,2 \%)$, mas similar à observada por outros autores que observaram recorrência em $25 \%$ a $40 \%$ dos doentes ao longo dos três primeiros anos após a operação (Lichtan e Mullan, 1980, Úrculo et al., 1998). A recidiva é mais precoce e mais freqüente que a proporcionada pela rizotomia por radiofreqüência (Teixeira, 1984). Quando há recidiva, pode haver necessidade de reoperação ou de reinstituição do tratamento farmacológico.

A adesão durante o período de acompanhamento foi elevada (91,4\%), o que traduz a intensidade do sofrimento e a gravidade do comprometimento da qualidade de vida dos doentes com NIT. A taxa de insatisfação como tratamento foi apenas de 11\%. É possível que nesse valor tenham sido agregados resultados insatisfatórios de procedimentos anteriores (Peters e Nurmikko, 2002).

Portanto, a compressão radículo-ganglionar do nervo trigêmeo é útil para controlar a NIT. É técnica eficaz e segura, especialmente quando a dor acomete o território do ramo oftálmico do nervo trigêmeo. Entretanto, a recidiva é freqüente e 
as diversas complicações que dela podem resultar devem ser identificadas e tratadas, prontamente para que o doente seja apropriadamente reabilitado. Essas observações e as de outros autores sugerem que ainda não há técnica em que a recidiva seja rara ou em que as seqüelas sejam escassas e que não há estudos controlados que determinem qual dos procedimentos é mais eficaz e seguro. 


\section{CONCLUSÕES}

1. A compressão radículo-ganglionar trigeminal foi eficaz no tratamento de doentes com NIT;

2. A freqüência de recidiva da dor foi elevada;

3. A compressão redículo-ganglionar proporcionou melhora da cefaléia, da dor generalizada e da qualidade de vida;

4. Anormalidades sensitivas pré-operatórias podem ser observadas nos doentes com NIT;

5. Edentulismo e infecção periodontal ocorreram em freqüência semelhante ao de população brasileira;

6. DTM e anormalidades mastigatórias pré-operatórias foram muito freqüentes nos doentes avaliados;

7. As anormalidades da movimentação mandibular induzidas pela cirurgia mantiveram-se ao longo do período de acompanhamento de 210 dias;

8. Ocorreu aumento temporário na ocorrência da dor miofascial durante a avaliação de 30 dias;

9. O acometimento das sensibilidades para calor, tato, frio e dor observado após o tratamento tendeu a normalizar-se ao longo do tempo;

10. O ramo oftálmico foi mais preservado que os demais ramos trigeminais;

11. Anormalidades gustatórias e da visão foram freqüentes no período pósoperatório; 
12. Anormalidades cosméticas e tróficas foram raras;

13. Complicações graves decorrentes da compressão radículo-ganglionar foram incomuns. 


\section{ANEXOS}

Anexo A. Aprovação pela CAPpesq

Anexo B. RDC - Research Diagnostic Criteria

Anexo C. Ficha Clínica EDOF/HC

Anexo D. Questionário de Dor McGill

Anexo E. Índice de Helkimo

Anexo F. Questionário Reduzido

Anexo G. Pontos faciais intra e extra orais utilizados na avaliação sensitiva 
Anexo A. Aprovação pela CAPpesq

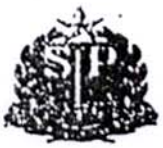

HOSPITAL DAS CLINICAS

da FICULDADE oE MEOICINA DA UNIVERSIDADE DE SAO PAULO CAIXA POSTAL, 3471 - SAO PAULO - BRASII.

\section{DIRETORIA CLÍNICA}

\section{Comissão de Ética para Análise de Projetos de Pesquisa}

\section{APROVACÃO}

A Comissão de Ética para Análise de Projetos 12 Pesquisa - CAPPes da Diretoria Clínica do Hospital das Clínicas e da sculdade de Medic na da Universidade de São Paulo, em sessão de :3.08.03, APROVOU o Protocolo de Pesquisa $n^{\circ}$ 551/03, intitulado: "Avaliação sensitiva orofacial e funcional mandibular de doentes com .uralgia trigeminal" apresentado pelo Departamento de NEUROLOGIA, inclusive o Termo de Conseritimento Livre e Esclarecido.

$\therefore$ syuisador(a) Respgrisúvel: UR. MAPOEL JACOBSEN TEIXEIRA

.squisador(a) Executante: SRA. SILVIA REGINA DOWGAN TESSEROLI DE SIQUEIRA

CAPPesq. 13 de Agosto de 2003.

$$
\text { Cullite catillo }
$$

PROF. DR. EUCLIDES AYRES DE CASTILHO

Presidente da Comissão de Ética para Análise de Projetos de Pesquisa

\footnotetext{
SERVAÇÃO: Cabe ao pesquisador elaborar e opresentar a CAPPesq, os relatórios porciais e final sob.-e a pesquisa (Resolusado do Conselho Nacional de Saúde $n^{\circ} 196$. de 10.10.1996, inciso IX.2, letro "c")
} 


\section{Anexo B. RDC - Research Diagnostic Criteria \\ RDC - Research Diagnostic Criteria \\ Critérios de Diagnóstico em Pesquisa para DTM \\ Tradução Oficial Autorizada Através do RDC International Project \\ Inglês - Português}

\section{História-Questionário}

Favor ler cada pergunta e responder de acordo. Para cada pergunta abaixo, circule somente uma resposta.

1. Você diria que a sua saúde em geral é excelente, muito boa, boa, razoável, ou precária ?

$\begin{array}{ll}\text { Excelente } & 1 \\ \text { Muito boa } & 2 \\ \text { Boa } & 3 \\ \text { Razoável } & 4 \\ \text { Precária } & 5\end{array}$

2. Você diria que a sua saúde oral em geral é excelente, muito boa, boa, razoável, ou precária ?

$\begin{array}{ll}\text { Excelente } & 1 \\ \text { Muito boa } & 2 \\ \text { Boa } & 3 \\ \text { Razoável } & 4 \\ \text { Precária } & 5\end{array}$

3. Você já teve dor na face, nos maxilares, têmpora, na frente do ouvido, ou no ouvido no mês passado ?

$\begin{array}{ll}\text { Não } & 0 \\ \text { Sim } & 1\end{array}$

[Em caso de Não ter tido dor no mês passado, PULE para a pergunta 14]

Se a sua resposta foi $\underline{\mathrm{Sim}}$,

4.a. Há quantos anos atrás a sua dor facial começou pela primeira vez ?

anos

[Se há um ano atrás ou mais, PULE para a pergunta 5]

[Se há menos de um anos atrás, marque 00]

4.b. Há quantos meses atrás a sua dor facial começou pela primeira vez ? meses

5. A sua dor facial é persistente, recorrente, ou foi um problema que ocorreu somente uma vez?

$\begin{array}{ll}\text { Persistente } & 1 \\ \text { Recorrente } & 2 \\ \text { Uma vez } & 3\end{array}$

6. Você alguma vez já foi a um médico, dentista, quiroprático ou outro profissional de saúde devido a dor facial ?

Não

1

Sim, nos últimos seis meses

2

Sim, há mais de seis meses atrás

7. Como você classificaria a sua dor facial em uma escala de 0 a 10 no presente momento, isto é exatamente agora, onde 0 é "sem dor" e 10 é a "pior dor possível" ?

Sem dor $1 \begin{array}{lllllllllll} & 2 & 3 & 4 & 5 & 6 & 7 & 8 & 9 & 10 & \text { A pior dor possível }\end{array}$

8. Nos últimos seis meses, qual foi a intensidade da sua pior dor, classificada pela escala de 0 a

10 , onde 0 é "sem dor" e 10 é a "pior dor possível" ?

Sem dor $\begin{array}{lllllllllll}1 & 2 & 3 & 4 & 5 & 6 & 7 & 8 & 9 & 10 & \text { A pior dor possível }\end{array}$ 
9. Nos últimos seis meses, em média, qual foi a intensidade da sua dor, classificada pela escala de 0 a 10, onde 0 é "sem dor" e 10 é a "pior dor possível" ? [Isto é, sua dor usual nas horas que você estava sentindo dor].

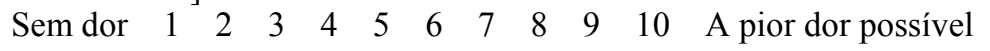

10. Aproximadamente quantos dias nos últimos 6 meses você esteve afastado de suas atividades usuais (trabalho, escola, serviço doméstico) devido a dor facial ? dias

11. Nos últimos 6 meses, o quanto esta dor facial interferiu com suas atividades diárias de acordo com uma escala de 0 a 10, onde 0 é "nenhuma interferência" e 10 é "incapaz de realizar qualquer atividade"?

Nenhuma interferência $11253 \quad 4 \quad 5 \quad 6 \quad 7 \quad 8 \quad 9 \quad 10 \quad$ Incapaz de realizar qualquer atividade

12. Nos últimos 6 meses, o quanto esta dor facial alterou a sua capacidade de participar de atividades recreativas, sociais e familiares onde 0 é "nenhuma alteração" e 10 é "alteração extrema"?

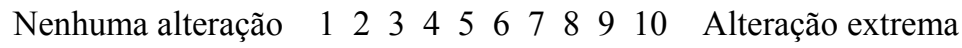

13. Nos últimos 6 meses, o quanto esta dor facial alterou a sua capacidade de trabalhar (incluindo serviço domésticos) onde 0 é "nenhuma alteração" e 10 é "alteração extrema" ?

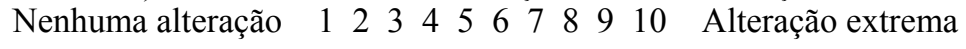

14.a. Você alguma vez teve travamento articular de forma que não foi possível abrir a boca por todo o trajeto?

$$
\text { Não } \quad 0 \quad \text { Sim } \quad 1
$$

[se nunca apresentou este tipo de problema, PULE para a pergunta 15]

Se a sua resposta foi $\underline{\mathrm{Sim}}$,

14.b.Esta limitação de abertura mandibular foi severa a ponto de interferir com a sua capacidade de mastigar?

$$
\text { Não } 0 \quad \text { Sim } 1
$$

15.a. Os seus maxilares estalam quando você abre ou fecha a boca ou quando você mastiga?

$$
\text { Não } 0 \quad \text { Sim } 1
$$

15.b. Os seus maxilares crepitam quando você abre e fecha ou quando você mastiga ?

$$
\text { Não } 0 \quad \text { Sim } 1
$$

15.c. Alguém lhe disse, ou você nota, se você range os seus dentes ou aperta os seus maxilares quando dorme a noite ?
Não 0
Sim 1

15.d. Durante o dia, você range os seus dentes ou aperta os seus maxilares ?

Não 0

Sim 1

15.e. Você sente dor ou rigidez nos seus maxilares quando acorda de manhã ?

$$
\text { Não } 0 \quad \text { Sim } 1
$$

15.f. Você apresenta ruídos ou zumbidos nos seus ouvidos?
Não 0
Sim 1

15.g. Você sente a sua mordida desconfortável ou incomum ?

Não 0

Sim 1

16.a. Você tem artrite reumatóide, lúpus, ou qualquer outra doença artrítica sistêmica?
Não 0
Sim 1

16.b. Você conhece alguém na sua família que tenha qualquer uma destas doenças?
Não 0
Sim 1 
16.c. Você já apresentou ou apresenta inchaço ou dor em qualquer das articulações que não sejam as articulações perto dos seus ouvidos (ATM)?
Não 0
Sim 1

[em caso de Não ter tido inchaço ou dor nas articulações, PULE para a pergunta 17.a.]

Se a sua resposta foi $\underline{\mathrm{Sim}}$,

16.d. É uma dor persistente que você vem tendo por pelo menos um ano ?

$$
\text { Não } 0 \quad \text { Sim } 1
$$

17.a. Você teve alguma injúria recente contra sua face ou seus maxilares?

Não 0

Sim 1

[ em caso de Não ter tido injúria, pule para a pergunta 18]

Se sua resposta foi $\underline{\operatorname{Sim}}$,

17.b. Você teve dor nos maxilares antes da injúria?

Não $0 \quad \operatorname{Sim} 1$

18. Durante os últimos 6 meses você teve dor de cabeça ou enxaquecas ?

Não $0 \quad$ Sim 1

19. Que atividades o seu problema atual dos maxilares impedem ou limitam ?
a. Mastigar
Não 0
$\operatorname{Sim} 1$
b. Beber
Não 0
$\operatorname{Sim} 1$
c. Exercitar-se
Não 0
$\operatorname{Sim} 1$
d. Comer alimentos duros
Não $0 \quad$ Sim 1
e. Comer alimentos moles
Não $0 \quad$ Sim 1
f. Sorrir/gargalhar
Não $0 \quad$ Sim 1
g. Atividade sexual
Não $0 \quad$ Sim 1
h. Limpar os dentes ou a face
Não $0 \quad$ Sim 1
i. Bocejar
Não $0 \quad$ Sim 1
j. Engolir
Não $0 \quad$ Sim 1
k. Conversar
Não $0 \quad$ Sim 1
1. Manter a sua aparência facial usual
Não $0 \quad$ Sim 1

20. No último mês, o quanto você tem estado angustiado por:

a. Dores de cabeça

Nem um pouco Um pouco Moderadamente Muito Extremamente 
b. Perda de interesse ou prazer sexual

Nem um pouco Um pouco Moderadamente Muito

Extremamente

c. Fraqueza ou tontura

Nem um pouco Um pouco 0

$$
\text { Moderadamente Muito }
$$$$
2
$$

Extremamente 3

d. Dores no coração ou peito

Nem um pouco Um pouco

Moderadamente Muito 2

Extremamente 3

e. Sensação de falta de energia ou lerdeza

Nem um pouco Um pouco Moderadamente Muito

$$
0
$$
2
Extremamente

f. Pensamentos sobre morte ou relacionados ao ato de morrer Nem um pouco Um pouco Moderadamente Muito

Extremamente 0 1 2 3

g. Falta de apetite Nem um pouco Um pouco 0

h. Chorar facilmente Nem um pouco Um pouco 0

i. Culpar a si mesmo pelas coisas

Nem um pouco Um pouco Moderadamente Muito 0 1 2

Extremamente

j. Dores na parte inferior das costas Nem um pouco Um pouco Moderadamente Muito

k. Sentir-se só

Nem um pouco Um pouco Moderadamente Muito 0 1

1. Sentir-se triste

Nem um pouco Um pouco 0

Extremamente

m. Preocupar-se muito com as coisas Nem um pouco Um pouco Moderadamente Muito 0 1

n. Sentir nenhum interesse pelas coisas

Nem um pouco Um pouco Moderadamente Muito

0
o. $\quad$ Náusea ou distúrbio gástrico

Extremamente

Nem um pouco Um pouco Moderadamente Muito Músculos doloridos 1

p. Músculos doloridos 12

Extremamente Nem um pouco Um pouco 0 1

q. Dificuldade em adormecer 
Nem um pouco Um pouco

Moderadamente Muito

Extremamente

0

2

r. Dificuldade em respirar

Nem um pouco Um pouco

Moderadamente Muito

Extremamente 0 1

s. Acessos calor / frio Nem um pouco Um pouco

Moderadamente Muito

Extremamente 0 1

2 3

t. Dormência ou formigamento em partes do corpo Nem um pouco Um pouco

Moderadamente Muito 0 1 2

Extremamente

u. Inchaço/protuberância na sua garganta

Nem um pouco Um pouco Moderadamente Muito 0 1

Extremamente

v. Sentir-se desanimado sobre o futuro

Nem um pouco Um pouco Moderadamente Muito 0 1

Extremamente

w. Sentir-se fraco em partes do corpo

Nem um pouco Um pouco Moderadamente Muito 0 1

x. Sensação de peso nos braços ou pernas

Nem um pouco Um pouco Moderadamente Muito

0
$\begin{gathered}0 \\ \text { y. Pensamentos sobre acabar com a sua vida }\end{gathered}$
m um pouco Um pouco $\quad$ Moderadamente Muito $\begin{array}{rrr}\text { Nem um } & \\ 0 & 1 & \end{array}$

Extremamente 3

Extremamente

z. Comer demais Nem um pouco Um pouco Moderadamente Muito

Extremamente 0 1 2 3

aa. Acordar de madrugada

Nem um pouco Um pouco

Extremamente 0 1

bb. Sono agitado ou perturbado

Nem um pouco Um pouco Moderadamente Muito 0 1

Extremamente

cc. Sensação de que tudo é um esforço/sacrifício Nem um pouco Um pouco Moderadamente Muito $\begin{array}{llll}0 & 1 & 2 & 3\end{array}$ 3

dd. Sentimentos de inutilidade

Nem um pouco Um pouco Moderadamente Muito 0 Moderadamente 2

ee. Sensação de ser enganado ou iludido

Nem um pouco Um pouco Moderadamente Muito 0 1

Extremamente 4

Extremamente 3

Extremamente

ff. Sentimentos de culpa Nem um pouco Um pouco

Extremamente 
21. Como você classificaria os cuidados que tem tomado para com a sua saúde de uma forma geral ?

$\begin{array}{ll}\text { Excelente } & 1 \\ \text { Muito bom } & 2 \\ \text { Bom } & 3 \\ \text { Satisfatório } & 4 \\ \text { Insatisfatório } & 5\end{array}$

22. Como você classificaria os cuidados que tem tomado para com a sua saúde oral ?

$\begin{array}{ll}\text { Excelente } & 1 \\ \text { Muito bom } & 2 \\ \text { Bom } & 3 \\ \text { Satisfatório } & 4 \\ \text { Insatisfatório } & 5\end{array}$

23. Quando você nasceu ?

Dia Mês _ Ano

24. Sexo masculino ou feminino?

Masculino ----- 1

Feminino ------ 2

25. Qual dos grupos abaixo melhor representa a sua raça ?

Aleútas, Esquimó ou Indio Americano 1

Asiático ou Insulano Pacífico 2

Negro 3

Branco 4

Outro 5

26. Alguns destes grupos representa a sua origem nacional ou ancestralidade ?

Porto Riquenho 1

Cubano 2

Mexicano 3

Mexicano Americano 4

Chicano 5

Outro Latino Americano 6

Outro Espanhol 7

Nenhum acima 8

27. Qual o seu grau de escolaridade mais alto ou último ano de escola que você completou?

Nunca freqüentou a escola / jardim de infância

00

$\begin{array}{lll}2 & 3 & 4\end{array}$

Escola Primária

Escola Ginasial

Científico

Faculdade $\begin{array}{llll}9 & 10 & 11 & 12\end{array}$

$13 \quad 14 \quad 15 \quad 16 \quad 17 \quad 18+$

28a. Durante as últimas 2 semanas, você trabalhou no emprego ou negócio não incluindo trabalho em casa (inclui trabalho não remunerado em negócios/fazenda da família) ?

Não

$$
\text { Sim } 1
$$

[Se a sua resposta foi Sim, pule para a pergunta 29]

Se a sua resposta foi Não,

28b. Embora você não tenha trabalhado nas duas últimas semanas, você tinha um emprego ou negócio?

$$
\begin{array}{ll}
\text { Não } & 0 \\
\text { Sim } & 1
\end{array}
$$

[Se a sua resposta foi $\underline{\operatorname{Sim}}$, PULE para a pergunta 29]

Se a sua resposta foi Não,

28c. Você estava procurando emprego ou de dispensa, durante aquelas duas semanas ?

Sim, procurando emprego 1

Sim, de dispensa

2

Sim, ambos de dispensa e procurando emprego 3

Não

29. Qual o seu estado civil? 
Casado (a) - esposa (o) em casa

Casado (a) - esposa (o) fora de casa

Viúvo (a)

Divorciado (a)

Separado (a)

Nunca casei

30. Qual a sua foi a sua renda doméstica durante os últimos 12 meses ?

$\mathrm{R} \$$ (Reais, moeda brasileira)

Não preencher. Deverá ser preenchido pelo profissional US\$ 0 - US\$ 14,999

US\$ 15,000 - US\$24,999

US\$ 25,000 - US\$ 34,999

US\$ 35,000 - US\$ 49,999

US\$ 50,000 ou mais

31. Qual o seu CEP ?

\section{Formulário de Exame}

1. Você tem dor no lado direito da sua face, lado esquerdo ou ambos os lados ?

nenhum 0

direito 1

esquerdo 2

ambos 3

2. Você poderia apontar as áreas aonde você sente dor ?

\begin{tabular}{|l|l|l|l|}
\hline Direito & Esquerdo & \multicolumn{2}{l|}{} \\
\hline Nenhuma & 0 & Nenhuma & 0 \\
\hline Articulação & 1 & Articulação & 1 \\
\hline Músculos & 2 & Músculos & 2 \\
\hline Ambos & 3 & Ambos & 3 \\
\hline
\end{tabular}

Examinador apalpa a área apontada pelo paciente, caso não esteja claro se é dor muscular ou articular

3. Padrão de Abertura

Reto

Desvio lateral direito (não corrigido)

\section{0}

Desvio lateral direito corrigido ("S")

Desvio lateral esquerdo (não corrigido)

Desvio lateral corrigido ("S")

Outro

Tipo

(especifique)

4. Extensão de movimento vertical incisivos maxilares utilizados

21

a. Abertura passiva sem dor

b. Abertura máxima passiva

c. Abertura máxima ativa

d. Transpasse incisal vertical

Tabela abaixo: Para os itens "b" e "c" somente

\begin{tabular}{|l|l|l|l|l|l|l|l|}
\hline \multicolumn{2}{|l|}{ DOR MUSCULAR } & \multicolumn{5}{l|}{ DOR $\boldsymbol{A R T I C U L A R}$} \\
\hline nenhuma & direito & esquerdo & ambos & Nenhuma & direito & esquerdo & ambos \\
\hline 0 & 1 & 2 & 3 & 0 & 1 & 2 & 3 \\
\hline 0 & 1 & 2 & 3 & 0 & 1 & 2 & 3 \\
\hline
\end{tabular}

5. Ruídos articulares (palpação)

a. abertura

Nenhum

Estalido

Crepitação grosseira

Direito
0
1
2

Esquerdo

0

1

2 
Crepitação fina 3 3

Medida do estalido na abertura

$\mathrm{mm} \quad-\mathrm{mm}$
Direito
0
1
2
3

Esquerdo
0
1
2
3

Medida do estalido de fechamento $\mathrm{mm} \quad \ldots \mathrm{mm}$

5c. Estalido recíproco eliminado durante abertura protrusiva

Sim

Não

NA
Direito

0
1
8

Esquerdo

0

6. Excursões
a. Excursão lateral direita
- $\mathrm{mm}$
b. Excursão lateral esquerda

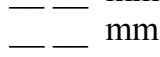
c. Protrusão
$-\ldots \mathrm{mm}$

Tabela abaixo: Para os itens "a", "b" e "c"

\begin{tabular}{|l|l|l|l|l|l|l|l|}
\hline \multicolumn{2}{|l|}{ DOR MUSCULAR } & \multicolumn{5}{l|}{ DOR ARTICULAR } \\
\hline nenhuma & direito & esquerdo & ambos & nenhuma & direito & esquerdo & ambos \\
\hline 0 & 1 & 2 & 3 & 0 & 1 & 2 & 3 \\
\hline 0 & 1 & 2 & 3 & 0 & 1 & 2 & 3 \\
\hline 0 & 1 & 2 & 3 & 0 & 1 & 2 & 3 \\
\hline
\end{tabular}

d. Desvio de linha média

$\mathrm{mm}$

\begin{tabular}{|l|l|l|}
\hline direito & esquerdo & NA \\
\hline 1 & 2 & 8 \\
\hline
\end{tabular}

7. Ruídos articulares nas excursões

Ruídos direitos

\begin{tabular}{|l|l|l|l|l|}
\hline & nenhum & estalido & $\begin{array}{l}\text { Crepitação } \\
\text { grosseira }\end{array}$ & $\begin{array}{l}\text { Crepitação } \\
\text { leve }\end{array}$ \\
\hline Excursão Direita & 0 & 1 & 2 & 3 \\
\hline Excursão Esquerda & 0 & 1 & 2 & 3 \\
\hline Protrusão & 0 & 1 & 2 & 3 \\
\hline
\end{tabular}

\section{Ruídos esquerdos}

\begin{tabular}{|l|l|l|l|l|}
\hline & nenhuma & estalido & $\begin{array}{l}\text { Crepitação } \\
\text { grosseira }\end{array}$ & $\begin{array}{l}\text { Crepitação } \\
\text { leve }\end{array}$ \\
\hline Excursão Direita & 0 & 1 & 2 & 3 \\
\hline Excursão Esquerda & 0 & 1 & 2 & 3 \\
\hline Protrusão & 0 & 1 & 2 & 3 \\
\hline
\end{tabular}

INSTRUÇÕES, ÍTENS 8-10

$\mathrm{O}$ examinador irá palpar (tocando) diferentes áreas da sua face, cabeça e pescoço. Nós gostaríamos que você indicasse se você não sente dor ou apenas sente pressão (0), ou dor (1-3). Por favor, classifique o quanto de dor você sente para cada uma das palpações de acordo com a escala abaixo. Circule o número que corresponde a 
quantidade de dor que você sente. Nós gostaríamos que você fizesse uma classificação separada para as palpações direita e esquerda.

$0=$ Sem dor $/$ somente pressão

$1=$ dor leve

$2=$ dor moderada

$3=$ dor severa

8. Dor muscular extra-oral com palpação

DIREITO

ESQUERDO

a. Temporal (posterior)

"parte de trás da têmpora"

b. Temporal (médio)

"meio da têmpora"

c. Temporal (anterior)

"parte anterior da têmpora"

d. Masseter (superior)

"bochecha/abaixo do zigoma"

e. Masseter (médio)

"bochecha/lado da face"

f. Masseter (inferior)

"bochecha/linha da mandíbula"

g. Região mandibular posterior

(estilo-hióide/região posterior do digástrico)

"mandíbula/região da garganta"

h. Região submandibular

(pterigoide medial/supra-hióide/região

anterior do digástrico) "abaixo do queixo"

9. Dor articular com palpação

a. Polo lateral

"por fora"

b. Ligamento posterior

"dentro do ouvido"

$0123 \quad 0123$

$\begin{array}{llllllll}0 & 1 & 2 & 3 & 0 & 1 & 2 & 3\end{array}$

$\begin{array}{llllllll}0 & 1 & 2 & 3 & 0 & 1 & 2 & 3\end{array}$

$\begin{array}{llllllll}0 & 1 & 2 & 3 & 0 & 1 & 2 & 3\end{array}$

$\begin{array}{llllllll}0 & 1 & 2 & 3 & 0 & 1 & 2 & 3\end{array}$

$\begin{array}{llllllll}0 & 1 & 2 & 3 & 0 & 1 & 2 & 3\end{array}$

$\begin{array}{llllllll}0 & 1 & 2 & 3 & 0 & 1 & 2 & 3\end{array}$

$\begin{array}{llllllll}0 & 1 & 2 & 3 & 0 & 1 & 2 & 3\end{array}$

DIREITO

ESQUERDO

$\begin{array}{llllllll}0 & 1 & 2 & 3 & 0 & 1 & 2 & 3\end{array}$

$\begin{array}{llllllll}0 & 1 & 2 & 3 & 0 & 1 & 2 & 3\end{array}$

10. Dor muscular intra-oral com palpação

a. Área do pterigoide lateral

DIREITO

ESQUERDO

$\begin{array}{llll}0 & 1 & 2 & 3\end{array}$

$\begin{array}{llll}0 & 1 & 2 & 3\end{array}$

"atrás dos molares superiores"

b. Tendão do temporal

$\begin{array}{llll}0 & 1 & 2 & 3\end{array}$

$\begin{array}{llll}0 & 1 & 2 & 3\end{array}$

"tendão" 


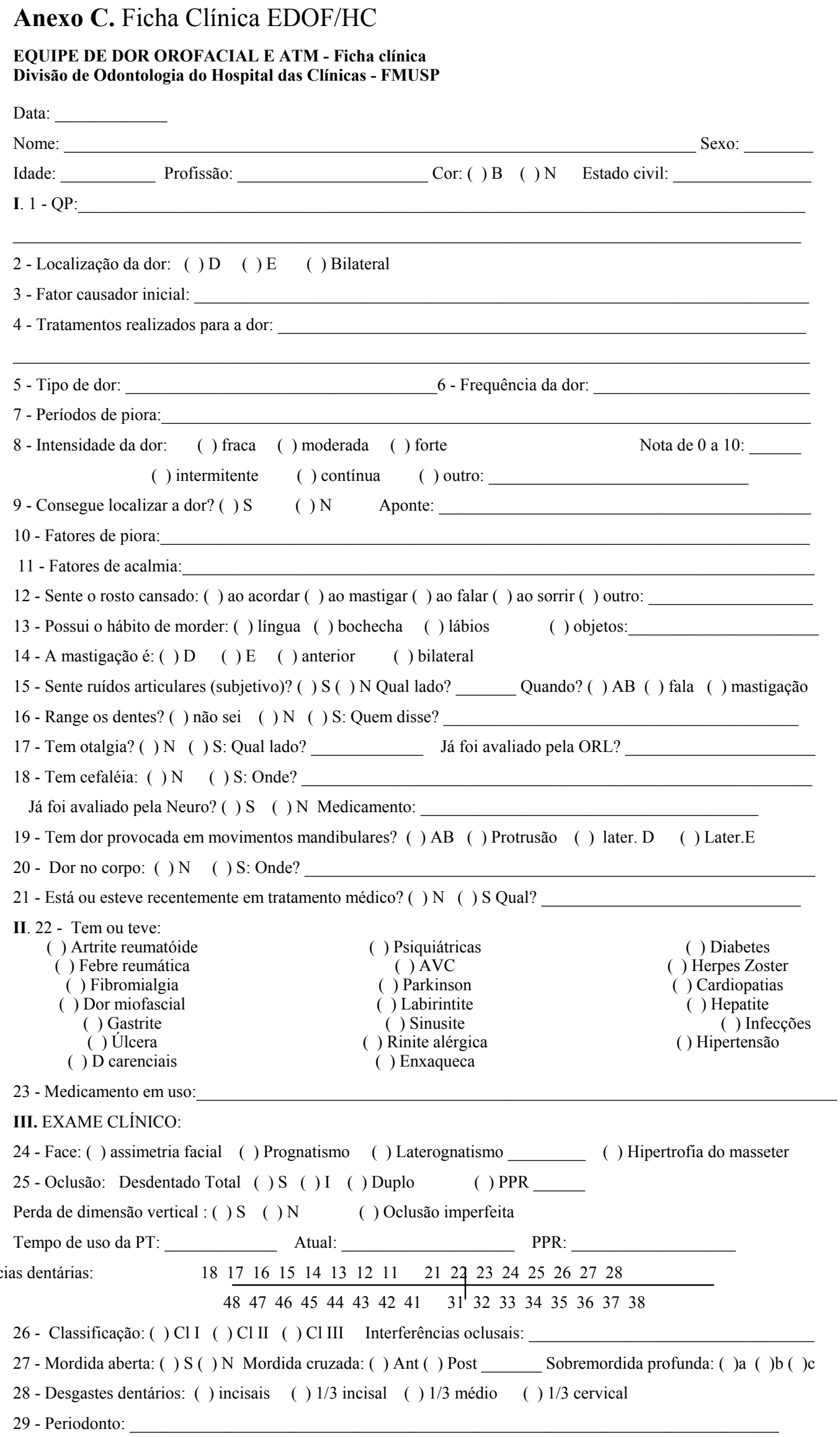


30 - Ruídos: ( )normal ( )POP ( )crepitação ( )D ( )E Estalo D ( ) IA ( ) MA ( ) FA ( ) IF ( ) MF ( ) FF Estalo E ( )IA ( ) MA ( ) FA ( ) IF ( ) MF ( ) FF

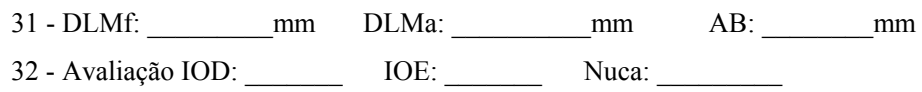

33 - Rx solicitados:

34 - Hipóteses Diagnósticas:

IV. TRATAMENTO INICIAL:

$1^{\circ}$ retorno - data: ( ) SM ( ) PM ( ) S ( ) O ( ) SD

( ) M: $\% \quad() P() \mathrm{I}$

Tratamento realizado:

$2^{\circ}$ retorno - data: ( ) SM ( ) PM ( ) S ( ) O ( ) SD

( ) M: $\% \quad$ ( ) P ( ) I

Tratamento realizado:

$3^{\circ}$ retorno - data: ( ) SM ( ) PM ( )S ( ) O ( ) SD

( ) M: $\% \quad$ ( ) P ( ) I

Tratamento realizado:

4 retorno - data:

( ) SM ( ) PM ( ) S ( ) O ( ) SD

( ) $\mathrm{M}:$ $\%$

( ) P ( ) I

Tratamento realizado:

$5^{\circ}$ retorno - data:

( ) SM ( ) PM ( ) S ( ) O ( ) SD

( ) M: $\%$

( ) P ( ) I

Tratamento realizado:

V. DIAGNÓSTICO FINAL:

Músculos sensíveis à palpação:

Índice de dor à palpação Bale Bross

0- Sem dor 1- Dor leve

2- Dor moderada

3- Reflexos

4- Fuga
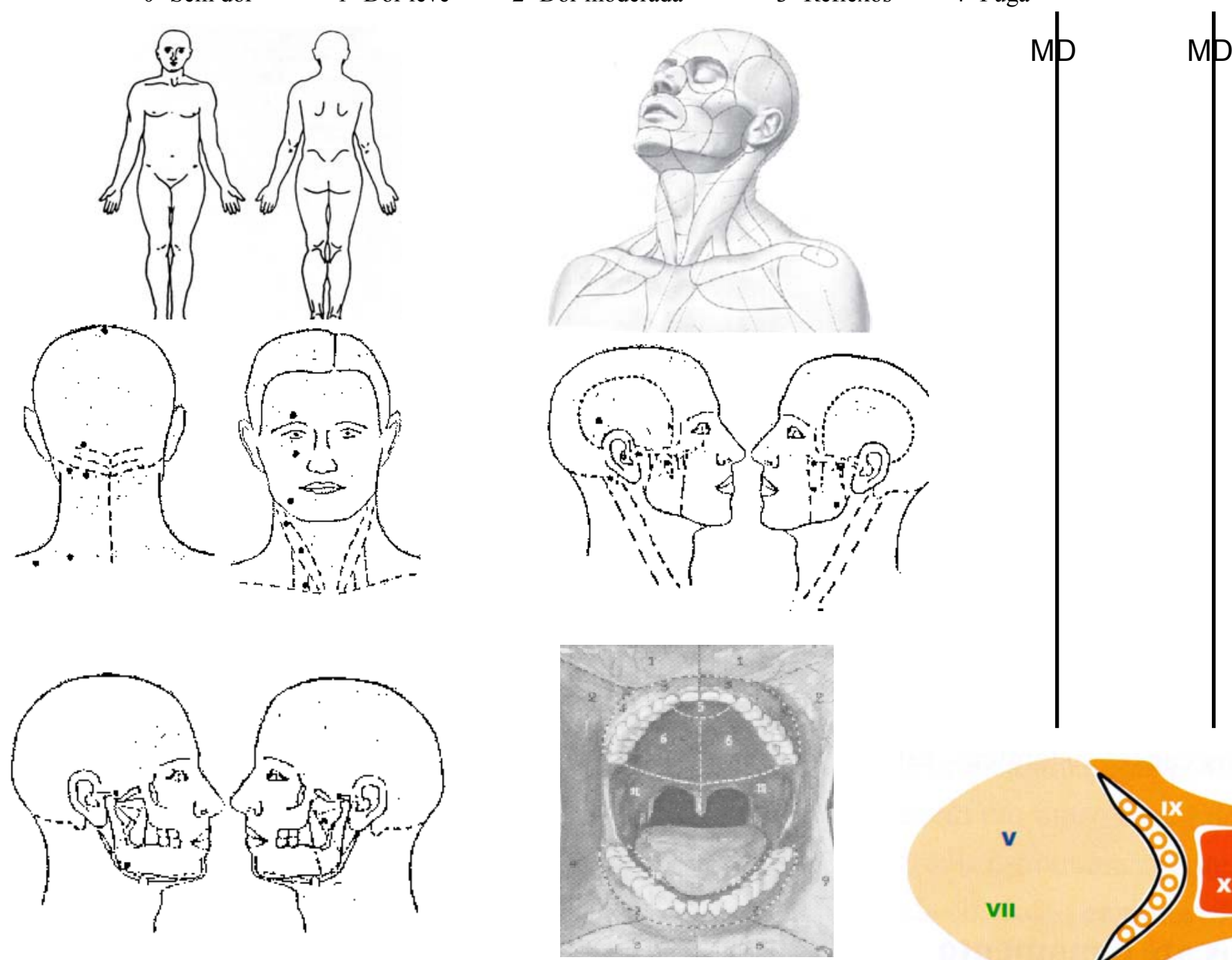
Anexo D. Questionário de Dor McGill

\section{QUESTIONÁRIO McGILL}

Nome: $R G$

Idade:

Sexo:

Algumas palavras que eu vou ler descrevem a sua dor atual. Diga-me quais são as palavras que melhor descrevem a sua dor. Não escolha aquelas que não se aplicam. Escolha somente uma palavra de cada grupo, a mais adequada para a descrição da sua dor

1.

1 - vibração

2 - tremor

3 - pulsante

4 - latejante

5 - como batida

6 - como pancada

2.

1 - pontada

2 - choque

3 - tiro

3.

1 - agulhada

2 - perfurante

3 - facada

4 - punhalad

5 - em lança

4.

1 - fina

2 - cortante

3 - estraçalna
5.

1 - beliscão

2 - aperto

3 - mordida

4 - cólica

1 - fisgada

2 - puxão
3 - em torção

7.

1 - calor

2 - queimação

3 - fervente

4 - em brasa

8.

1 - formigamento

2 - coceira

3 - ardor

4 - ferroada
9.

1 - mal localizada

2 - dolorida

3 - machucada

4 - doida

10.

1 - sensivel

2 - esticada

3 - esfolante

4 - rachando

11.

1 - cansativa

2 - exaustiva

12.

1 - enjoada

2 - sufocante
13.

1 - castigante

2 - atomenta

3 - cruel

14.

1 - amedrontadora

2 - apavorante

3 - aterrorizante

4 - maldita

5 - mortal

15.

1 - miserável

2 - enlouquecedora 19

1 -fria

16

1 - chata

2 - que incomoda

3 - desgastante

4 - forte

5 - insuportáve
17.

1 - espalha

2 - irradia

3 - penetra
4 - atravessa

18.

1 - aperta

2- adormece

3 - repuxa

4 - espreme

5 - rasga

19. - fria

2 - gelada

20.

20.

1 - aborrecida

2 - dá náusea

3 - agonizant

4 - pavorosa

5 - torturante
Número de Descritores

Sensorial

Afetivo

Avaliativo

Miscelânea

TOTAL
Índice de dor

Sensorial

Afetivo

Avaliativo

Miscelânea

TOTAL 
Anexo E. Índice de Helkimo

\section{Índice de Helkimo}

- $\quad$ 1.Índice Anamnético

1.1. Não apresentam nenhum sintoma de disfunção. ( )

1.2. Sintomas leves de disfunção, apresentando um ou mais dos seguintes sintomas:

- ruído na ATM...

- cansaço mandibular

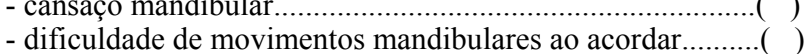

- nenhum dos sintomas de 1.3 .

1.3. Sintomas severos de disfunção, apresentando um ou mais dos seguintes sintomas:

- dificuldades de AB.

- travamento mandibular.

- luxação.

- dor em movimentos mandibulares.

- dor na região de ATM.

- dor na musculatura mastigatória.

- $\quad$ 2. Índice de disfunção clínica

- Sintoma: Comprometimento do indice de mobilidade mandibular

Critério: Movimentos normais

Ligeiro comprometimento do movimento

Severo comprometimento do movimento

- Sintoma: Comprometimento funcional da ATM

Critério: Movimento suave, sem ruído articular e desvio em $\mathrm{AB}$ e $\mathrm{FEC}<2 \mathrm{~mm}$

Ruído articular uni ou bilateral e/ou desvio $>2 \mathrm{~mm}$ na $\mathrm{AB}$ ou FEC

Travamento ou luxação da ATM

- Sintoma: Dor muscular

Critério: Sem dor a palpação muscular

Dor em 1-3 locais

Dor em quatro ou mais locais

- Sintoma: Dor em ATM

Critério: Sem dor à palpação

Dor à palpação lateral

Dor à palpação posterior

- Sintoma: Dor em movimentos mandibulares

Critério: Sem dor

Dor em 1 movimento

Dor em 2 ou mais movimentos

Score

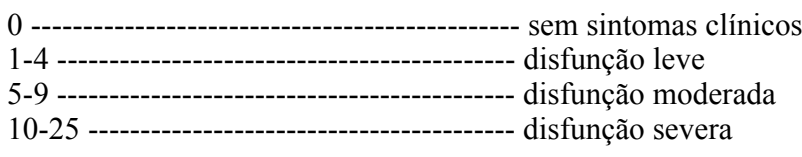

- $\quad 3$. Índice de mobilidade mandibular

- Abertura bucal máxima de

$>40 \mathrm{~mm}$

$30-39 \mathrm{~mm}$

$<30 \mathrm{~mm}$

- Máximo movimento de lateralidade D de

$>7 \mathrm{~mm}$

4-6 $\mathrm{mm}$

0-3 $\mathrm{mm}$

- Máximo movimento de lateralidade E de $\quad \mathrm{mm}$

$>7 \mathrm{~mm}$

4-6 mm

0-3 mm

- Máxima protrusão de __

$>7 \mathrm{~mm}$

4-7 $\mathrm{mm}$ disfunção severa

0-3 $\mathrm{mm}$ 0 
$1-4$ mobilidade ligeiramente comprometida $5-20$ mobilidade severamente comprometida

- 4. Índice oclusal

- Número de Dentes

28-32 dentes

20-27 dentes

$<20$ dentes

- Dentes em oclusão

24-32 dentes em oclusão

16-23 dentes em oclusão

2-15 dentes em oclusão

- Interferências oclusais entre RC e OC

sem interferência - deslizamento anterior reto e simétrico de RC para OC (distância $<2 \mathrm{~mm}$ )

interferência leve - com um ou ambos os seguintes sintomas:

a.contato unilateral em $\mathrm{RC}$ e durane o deslizamento para $\overline{\mathrm{OC}(\text { distância }<2 \mathrm{~mm} \text { ) }}$

b.desvio lateral da mandíbula $<0,5 \mathrm{~mm}$ durante o deslizamento de RC para OC interferência severa - com um ou ambos os seguintes sintomas:

c.desvio lateral da mandíbula $>0,5 \mathrm{~mm}$ durante o deslizamento de $\mathrm{RC}$ para $\mathrm{OC}$

d.a distância entre RC para $\mathrm{OC}>2 \mathrm{~mm}$

- Interferências articulares

sem distúrbio articular

interferência leve - com um ou ambos os seguintes sintomas:

a. interferências (= único contato dentário) no lado de trabalho distalmente b. contato unilateral na protrusão

interferência severa - interferência no lado de balanceio (uni ou bilateralmente)

Score

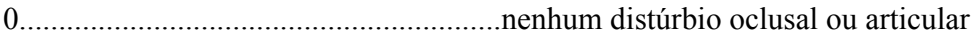

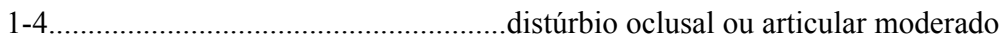

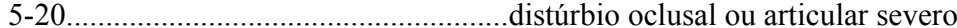




\section{Anexo F. Questionário Reduzido}

\section{DESCRIÇÃO DA DOR}

Qual das frases abaixo melhor descreve a ocorrência da sua dor (sinalize apenas uma): rápida duração.

I - ( ) Eu sinto dor constantemente e, de vez em quando, dor mais intensa e com

a. Descreva a dor constante:

b. Descreva a dor mais intensa:

II - ( ) Eu sinto uma única dor o tempo todo. Outras vezes eu não tenho dor.

A. Descreva esta dor

\section{AVALIAÇÃO FUNCIONAL}

Mastigação: Queixa espontânea: não( ） $\operatorname{sim}($ )

1.Você acha que sua mastigação está normal? Não ( ) $\operatorname{sim}(\quad)$

2.Se há alteração de mastigação, isto provoca algum incômodo? Não ( ) $\operatorname{sim}($ )

3.Quantifique este incômodo:

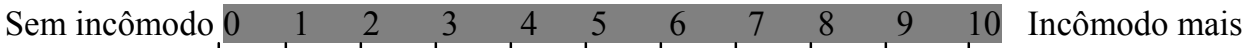

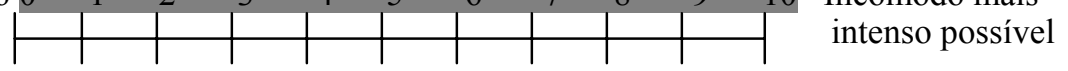

Perda de elementos pela boca:

Saliva: não ( ) eventualmente ( ) freqüentemente ( ) $\operatorname{sim}($ )

Alimentos: não ( ) eventualmente ( ) freqüentemente ( ) $\operatorname{sim}($ )

\section{AVALIAÇÃO DE SENSIBILIDADE}

Percepção de dormência:

1. Quão intensa é sua dormência:

Sem dormência

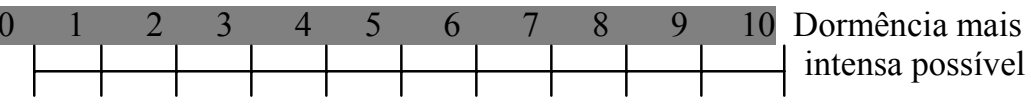

2. Qual das frases melhor descrevem a ocorrência de dormência (sinalize apenas uma):

( ) Eu constantemente sinto dormência.

( ) Eu freqüentemente sinto dormência.

( ) Eu eventualmente sinto dormência.

( ) Eu não sinto dormência.

3. Informe quão desagradável é sua dormência:

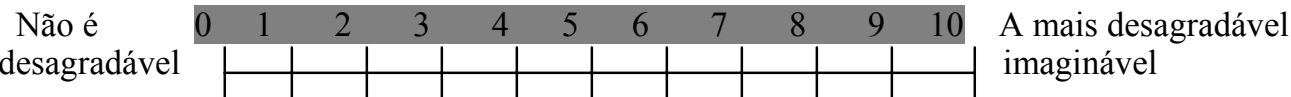

Disestesia:

1. Quão intensa é sua dor:

Sem dor

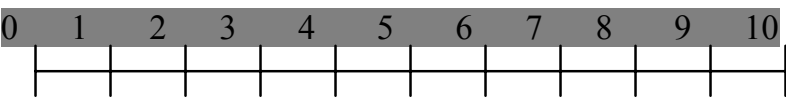

Dor mais intensa possível

2. Qual a freqüência de sua dor: não tem dor ( ) eventualmente tem dor ( ) freqüentemente tem dor ( )

OUTRAS ALTERAÇÕES tem dor constante ( )

- Herpes simplex: sim( ) não( )

- Úlcerações: Pele não ( ) $\operatorname{sim}($ )

- Trofismo: Pilosidades:

Pregas cutâneas:

Coloração da pele: 
Anexo G. Pontos faciais intra e extra orais utilizados na avaliação sensitiva

Sensibilidade da face:

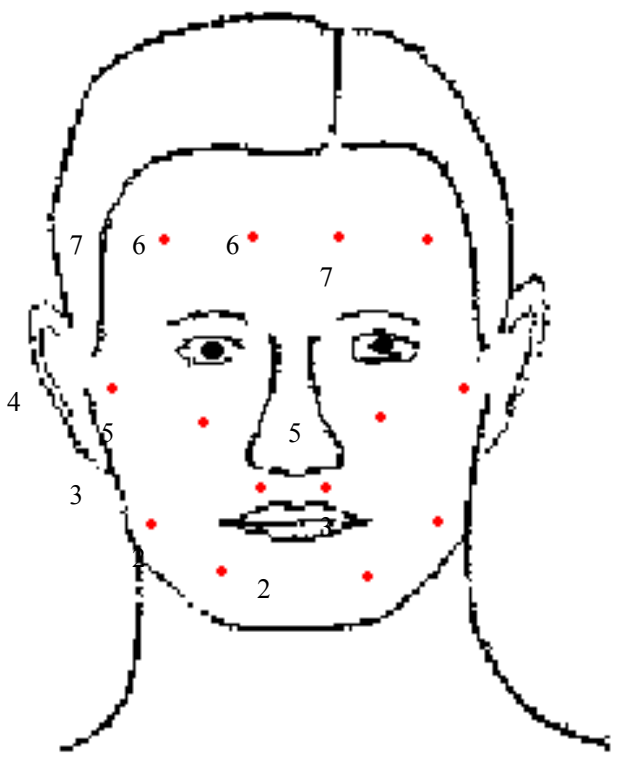

SENSIBILIDADE EXTRA-ORAL

1 - filtro nasal

$2-1 \mathrm{~cm}$ abaixo da comissura labial

3 - ângulo mandibular

4 - região pré-auricular

$5-2 \mathrm{~cm}$ abaixo do centro da pupila

$6-3 \mathrm{~cm}$ acima da comissura interna do olho

$7-3 \mathrm{~cm}$ acima da comissura externa do olho

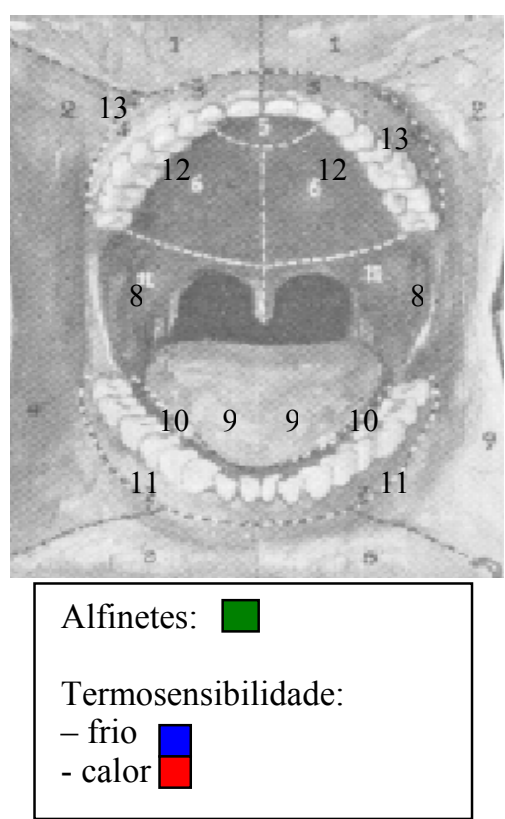

SENSIBILIDADE INTRA-ORAL

8 - mucosa jugal

9 - língua - terço anterior

10 - gengiva lingual inferior

11 - gengiva vestibular inferior

12 - gengiva palatina superior

13 - gengiva vestibular superior 


\section{REFERÊNCIAS*}

Abdennebi B, Bounatta F, Chitti M, Bougatene B. Percutaneous balloon compression of the Gasserian ganglion in trigeminal neuralgia. Long-term results in 150 cases. Acta Neurochir (Wien), 1995; 136(1-2):72-74.

Abdennebi B, Mahfouf L, Nedjahi T. Long-term results of percutaneous compression of the gasserian ganglion in trigeminal neuralgia (Series of 200 patients). Stereotact Funct Neurosurg, 1997; 68(1-4 Pt 1):190-195.

Alper MG. The anesthetic eye: an investigation of changes in the anterior ocular segment of the monkey caused by interrupting the trigeminal nerve at various levels along its course. Trans Am Ophthalmol Soc, 1975; 73:313-365.

Ameli NO. Avicenna and Trigeminal Neuralgia. J Neurol Sci, 1965; 2:105107.

Andersen S, Worn-Pedersen J. The prevalence of persistent pain in a Danish population. Pain, 1987; 4:332 (Suppl).

Anderson LC, Vakoula A, Vainote R. Inflammatory hypersensitivity in a rat model of trigeminal neuropathic pain. Arch Oral Biol, 2003; 48(2):161-169.

Beaver DL. Electron microscopy of the gasserian ganglion in trigeminal neuralgia. J neurosurg, 1963; 20:138-150.

Beaver DL, Moses HL, Ganote CE. Electron microscopy of the trigeminal ganglion. III. Trigeminal neuralgia. Arch Pathol, 1965; 79:571-582.

Belber CJ, Rak RA. Balloon compression rhizolysis in the surgical management of trigeminal neuralgia. Neurosurgery, 1987; 20(6):908-913. 
Benoliel R, Eliav E, Tal M. No sympathetic nerve sprouting in rat trigeminal ganglion following painful and non-painful infraorbital nerve neuropathy. Neurosci Lett, 2001; 19:297(3):151-4.

Bilgin H, Kelebek N, Korfali G, Bekar A, Kerimogl U. A rare complication of trigeminal nerve stimulation during radiofrequency thermocoagulation. $J$ Neurosurg Anesthesiol, 2002; 14(1):47-49.

Bohm E, Strang RR. Glossopharyngeal Neuralgia. Brain, 1962; 85:371-388.

Broggi G, Franzini A, Lasio G, Giorgi C, Servello D. Long-term results of percutaneous retrogasserian thermorhizotomy for "essencial" trigeminal neuralgia: considerations in 1000 consecutive patients. Neurosurgery, 1990; 26(5):783-787.

Brown JA, Preul MC. Percutaneous trigeminal ganglion compression for trigeminal neuralgia. Experience in 2 patients and review of the literature. $J$ Neurosurg, 1989; 70:900-904.

Brown JA, McDaniel BA, Weaver MT. Percutaneous trigeminal nerve compression for treatment of trigeminal neuralgia results in 50 patients. Neurosurgery, 1993; 32(4):570-573.

Brown JA, Hoeflinger B, Long PB et al. Axon and ganglion cell injury in rabbits after percutaneous trigeminal balloon compression. Neurosurgery, 1996; 38(5):993-1004.

Brunetti RF, Oliveira W. Diagnóstico diferencial. In: Barros JJ, Rodes SM, editores. Tratamento das disfunções craniomandibulares. São Paulo: Santos, 1995.

Bruzustowcz RJ. Combined trigeminal and glossopharyngeal neuralgia. Neurology, 1955; 5:1-10.

Buscaino GA. Fisiologia della nevralgia essenziale del trigemino. Acta Neurol, (Napoli), 1980; 35:137-44. 
Chapman V, Suzuki R, Chamarette HLC, Rygh LJ, Dickenson AH. Effects of systemic carbamazepine and gabapentin on spinal neuronal responses in spinal nerve ligated rats. Pain, 1998; 75:261-272.

Chawla JC, Falconer MA. Glossopharyngeal and vagal neuralgia. $\mathrm{Br} M e d \mathrm{~J}$, $1967 ; 3: 529-531$.

Chidia ML, Ng'ang'a PM. Alcohol injection in the management of paroxysmal trigeminal neuralgia: a report of six cases. East Afr Med J, 1994; 71(1):49-50.

Choudhury BK, Pahari S, Acharyya A, Goswami A, Bhattacharyya MK. Percutaneous retrogasserian radiofrequency thermal rhizotomy for trigeminal neuralgia. J Indian Med Ass, 1991; 89(10):294-296.

Christensen D, Gautron M, GguilbaudG, Kayser V. Effect of gabapentin and lamotrigine on mechanical allodynia-like behaviour in a rat model of trigeminal neuropathic pain. Pain, 2001; 93(2):147-153.

Cliff IS, Demis J. Giant ulcer of the face following surgery for trigeminal neuralgia. Arch Intern Med, 1967; 119(2):218-222.

Cohrs RJ, Gilden DH. Human Herpesvirus latency. Brain Pathol, 2001; $11: 465-474$

Teixeira MJ. 1o. Estudo Master em dor. In: $1^{\circ}$ Simbidor. Limay: São Paulo, 1994.

Dalessio DJ. Trigeminal neuralgia. A practical approach to treatment. Drugs, $1982 ; 24: 248-255$.

Davidoff LM, Feiring EH. Ferrous carbonate in the treatment of tic doloureux. Acta Psyhiat Neurol, 1949; 24:403-410.

Davis KD, Dostrovsky JO. Activation of trigeminal brainstem nociceptive neurons by dural artery stimulation. Pain, 1986; 25:395-401. 
Deseure K, Koek W, Colpaert FC, Adriaensen H. The $5 \mathrm{HT}_{1 \mathrm{~A}}$ receptor agonist F 13640 attenuates mechanical allodynia in a rat model of trigeminal neuropathic pain. Eur J Pharmacol, 2002; 5;456(1-3):51-57.

Devor M, Govrin-Lippmann R, Rappaport ZH. Mechanism of trigeminal neuralgia: an ultrastructural analysis of trigeminal root specimens obtained durig microvascular decompression surgery. J Neurosurg, 2002; 96 (3):532-543.

Dicken CH. Trigeminal trophic syndrome. Mayo Clin Proc, 1997; 72(6):543545.

Dworkin SF, LeResche L. Research diagnostic criteria for temporomandibular disorders: review, criteria, examinations an specifications, critique. J Craniomand Disord, 1992; 6(4):301-355.

Ecker AD, Smith JE. Are latent, immediate-early genes of Herpes simplex círus-1 essential in causing trigeminal neuralgia? Med Hypotheses, 2002; 29(5):603606.

Egan, RA, Pless M, Shults WT. Monocular blinbness as a complication of trigeminal radiofrequency rhizotomy. Am J Ophthalmol, 2001; 131(2):146-147.

Eide PK, Rabben P. Trigeminal neuropathic pain: pathophysiological mechanisms examined by quantitative sensory assessment of abnormal pain and sensory perception. Neurosurgery, 1998; 43(5):1103-1109.

Eide K, Stubhaug A. Sensory perception in patients with trigeminal neuralgia: effects of percutaneous retrogasserian glycerol rhizotomy. Stereotact Funct Neurosurg, 1998; 68 (1-4 Pt 1):207-211.

Fardy MJ, Patton DW. Complication associated with peripheral alcohol injections in the management of trigeminal neuralgia. Br J Oral Maxillofac Surg, 1994; 32(6):387-391. 
Ferrara G, Argenziano G, Cicarelli G, Cusano F, Delfino M. Post-apopletic trigeminal trophic syndrome. J Eur Acad Dermatol Venereol, 2000; 15(2):153-155.

Forssell H, Jääskeläinen S, Tenovuo O, Hinkka S. Sensory dysfunction in burning mouth syndrome. Pain, 2002; 99:41-47.

Frazier CH, Russel EC. Neuralgia of the face. Arch Neurol Psychiatry (Chicago), 1924; 11:557-563.

Freeman AG. Trigeminal neuralgia: complication of its surgical treatment. $\mathrm{Br}$ Med J, 1967; 11;1(540): 631-632.

Fromm GH, Terrence CF, Chattha AS, Glass JD. Baclofen in trigeminal neuralgia. Its effect on the spinal trigeminal nucleus; a pilot study. Arch Neurol, 1980; 37(12):786-771.

Fromm GH, Graff-Radford SB, Terrence CF, Sweet WH. Pre-trigeminal Neuralgia. Neurology, 1990; 40:1493-1495.

Garcia-Callejo FJ. Velert-Vila MM, Talamantes-Escribá F, Blay-Galaud L. Respuesta clínica a la gabapentina en la neuralgia del glosofaríngeo. Rev Neurol, $1999 ; 28(4): 380-384$.

Göçer AI, Çetinalp E, Tuna M, Gezercan Y, Ildan F. Fatal complication of the percutaneous radiofrequency trigeminal rhizotomy. Acta Neurochir (Wien), 1997; 139: $373-374$.

Goodnight JW, Calcaterra T. Trigeminal trophic syndrome: a report of two cases and review. Am J Otolaryngol, 1994; 15(3):219-222.

Goto F, Ishizaki K, Yoshikawa D, Obata H, Arii H, Terada M. The long lasting effects of peripheral nerve blocks for trigeminal neuralgia using a high concentration of tetracaine dissolved in bupivacaine. Pain, 1999; 79:101-103. 
Graff-Radford SB. Headache that can present as toothache. Dent Clin North Am, 1991; 35(1):155-170.

Grant R, Ferguson MM, Strang R, Turner JW, Bone I. Evoked taste thresholds in a normal population and the application of electrogustometry to trigeminal nerve disease. J Neurol Neurosurg Psychiatry, 1987; 50(1):12-21.

Gregg JM, Banerjee T, Ghia JN, Campbell R. Radiofrequency of peripheral nerves for control of trigeminal neuralgia. Pain, 1978; 5(3):231-243.

Gredoret J. Exame da Face. In: Gregoret J, ed. Ortodontia e cirurgia ortognática - diagnóstico e planejamento, São Paulo: Santos, 1999.

Gruccu G, Biasiotta A, Galeotti F, Iannetti GD, Truini A, Gronseth G. Diagnostic accuracy reflex testing in trigeminal neuralgia. Neurology, 2006; 66:139141

Grushka M. Clinical features of burning mouth syndrome. Oral Surg Oral Med Oral Pathol Oral Radiol Endod, 1987; 63:30-36.

Guerrero-Figueroa AR, Escobar-Juyo A, Caballero-Garcia G, Blanco-Castillo IP. Efecto de la gabapentina en la alodinia buco-facial. Correlactión experimental de neuralgia trigeminal. Rev Neurol, 1999; 29(12):1147-1153.

Hardy JD, Wolff HG, Goodell H. Experimental evidence on the nature of cutaneous hyperalgesia. J Clin Invest, 1950; 29:115-140.

Headache Classification Commitee of the Internatinal Headache Society. Classification and diagnostic criteria for headache disorders, cranial neuralgias and facial pain. Cephalalgia 2004; Suppl 1:1-150.

Helkimo H. Studies on function and dysfunction of the masticatory system. II. Index for anamnestic dysfunction and occlusal state. Swed Dent J, 1974; 67:101-119. 
Henderson WR. Trigeminal neuralgia: the pain and its treatment. $\mathrm{Br}$ Med, 1967 1:7-15.

Hotta TH, Bataglion A, Bataglion C, Bezzon OL. Involvement of dental occlusion and trigeminal neuralgia: a clinical report. J Prosthet Dent, 1997; 77(4):343-345

Hussein M, Wilson LA, Illingworth R. Patterns of sensory loss following fractional posterior fossa $\mathrm{Vth}$ nerve section for trigeminal neuralgia. J Neurol Neurosurg Psych, 1982; 45(9):786-790.

Ichikawa K, Koyama N, Kiguchi S, Kojima M, Yokota T. Inhibitory effect of oxcarbazepine on high-frequency firing in peripheral nerve fibers. E $J$ Pharmacol, 2001; 420:119-122.

Idapaan-Heikkila JJ, Guilbaud G. Pharmacological studies on a rat model of trigeminal neuropathic pain: baclofen, but not carbamazepine, morphine or tricyclic antidepressants, attenuates the allodynia-like behaviour. Pain, 1999; 79(2-3):281290.

Ingle JI, Glick DH, Scheffer D. Diagnóstico diferencial e tratamento das dores oral e perioral. In: Ingle JI, Beveridge EE, editors. Endodontia. 2nd ed. Rio de Janeiro:Interamericana Ltda, 1979.

International Association for the Study of Pain. Proceedings of the $8^{\text {th }}$ World Congress on Pain. Seattle: IASP Press, 1996.

Jannetta PJ. Gross (Mesoscopic) description of the human trigeminal nerve and ganglion. J neurosurg, 1963a; 20:109-111.

Jannetta PJ. Arterial compression at the pons. J Neurosurg, 1963; 20:159162(b). 
Jannetta PJ. Microsurgical approach to the trigeminal nerve for tic doloureux. Prog Neurol Surg, 1976; 7:180-200.

Jaaskelainen SK, Teerijoki-Oksa T, Forssell H. Neurophysiologic and qualtitative sensory testing in the diagnosis of trigeminal neuropathy and neuropathic pain. Pain, 2005; 117:349-57.

Jensen TS, Krebs B, Nielsen J, Rammussen P. Immediate and long term phantom limb pain in amputees incidence, clinical characteristics and relationship to pre-amputation limb pain. Pain, 1985; 21:267-278.

Jho HD, Lunsford LD. Percutaneous retrogaserian glycerol rhizotomy. Current Technique and results. Neurosurg Clin North America. 1997; 8(1):63-74.

Kanpolat Y, Savas A, Bekar A, Berk C. Percutaneous controlled radiofrequency trigeminal rhizotomy for the treatment of idiopathic trigeminal neuralgia; 25-years experience with 1600 patients. Neurosurgery, 2001; 48(3):524534.

Katusic S, Beard MB, Bergstralh E, Kurland LT. Incidence and clinical features of trigeminal neuralgia, Rochester, Minnesota, 1945-1984. Ann Neurol, $1990 ; 27: 89-95$.

Kato S, Papuashvili N, Okada YC. Identification and functional characterization of the trigeminal ventral cervical reflex pathway in the swine. Clin Neurophysiol, 2003; 114(2):263-271.

Kavanagh GM, Tidman MJ, McLaren KM, Goldberg A, Benton EC. The trigeminal trophic syndrome: an under-recognized complication. Clin Exp Dermatol, 1996; 21(4):299-301. 
Kerr FWL. Corelated light and electron microscopic observations on the normal trigeminal ganglion and sensory root in man. J Neurosurg, 1963a; 20:132137.

Kerr FWL. Pathology of trigeminal neuralgia: light and electron microscopic observations. J Neurosurg, 1963b; 20:151-156.

Kerr FWL. Evidence for a peripheral etiology. J Neurosurg, 1963c; 20:168174.

Kiguchi S, Ichikawa K, Kojima M. Suppressive effects if oxcarbazepine on tooth pulp-evoked potencials recorded at the trigeminal spinal tract nucleus in cats. Clin Exp Pharmacol Physiol, 2001; 28(3):165-175.

Kondo A. Follow-up results of microvascular decompression in trigeminal neuralgia and hemifacial spasm. Neurosurgery, 1997; 40(1):46-52.

Kondziolka D, Lunsford LD, Habeck M, Flickinger JC. Gamma knife radiosurgery for trigeminal neuralgia. Neurosur Clin North America. 1997; 8(1):7985.

Kondziolka D, Lacomis D, Niranjan A, Mori Y, Maesawa S, Fellows W, Lunsford LD. Histological effects of trigeminal nerve radiosurgery in a primate model: implications for trigeminal neuralgia radiosurgery. Neurosurgery, 2000; 46(4):971-976.

Krisel J. Reactivation of Herpes simplex virus: the role of cytokines and intracelluar factors. Curr Opin Infect Dis, 1999; 12(3):235-238.

Krmpotic-Nematic J, Vinter I, Hat J, Jalsovec D. Mandibular neuralgia due to anatomical variations. Arch Otorhinolaryngol, 1999; 256:205-8.

Kruger GO, Reynolds DC. Diagnosis of acute maxillofacial pain. Dental Clin North Am, 1965; 11:557-576. 
Kumar R, Mahapatra AK, Dash HH. The blink reflex before and after percutaneous glycerol rhizotomy in patients with trigeminal neuralgia - a prospective study of 28 patients. Acta Neurochir (Wien), 1995; 137(1-2):85-88.

Kurtzke JF. Epidemiology of Multiple Sclerosis. In: Vinken PJ, Bryn GW, Klawans HL, eds. Handbook of Clinical Neurology, vol.4. Amsterdan: Elsevier, 1985.

Lang E, Kaltenhausen M, Seidlerm S, Mattenklodt P, Neundorfer B. Persistent idiopathic facial pain exists independent of somatosensory input from the painful region: findings from quantitative sensory functions and somatotopy of the primary somatosensory cortex. Pain, 2005; 118:80-91.

Lazar ML, Greenlee Jr RG, Naarden AL. Facial pain of neurologic origin mimicking oral pathologic conditions: some current concepts and treatment. $J \mathrm{Am}$ Dent Ass, 1980; 100(6):884-888.

Law AS, Lilly JP. Trigeminal neuralgia mimicking odontogenic pain. Oral Surg Oral Med Oral Pathol, 1995; 80(1):96-100.

Lichtor T, Mullan JF. A 10-year follw-up review of percutaneous microcompression of the trigeminal ganglion. J Neurosurg, 1990; 72:49-54.

Lipton RB. Diagnosis and epidemiology of pediatric migraine. Current Opinion Neurol, 1997; 10:231-236.

Lipton RB, Swart W. Prevalence and impact of migraine. In: Ninan MT, editor. Neurologic clinics. Philadenphia: W B Saunders Company, 1997.

Lobato RD, Rivas JJ, Sarabia R, Lamas E. Percutaneous microcompression of the gasserian ganglion for trigeminal neuralgia. J Neurosurg, 1990; 72: 546-553.

Loeser JD. Tic doulourex and atypical facial pain. J Canadian Dent Ass, 1985; 51:917-923. 
Loh HS, Ling SY, Shammuhasuntharam P, Zain R, Yeo JF, Khoo SP. Trigeminal neuralgia. A retrospective survey of a sample of patients in Singapure and Malaysia. Aust Dent J, 1998; 43(3):188-191.

Malis LI. Petrous ridge compression. J neurosurg, 1963; 20:163-167.

Martilla RJ, Frey H, Kalimo KOK, Rautakorpi I, Törmä T. Antibodies against Herpes simplex virus type 1 subunit antigens in patients with trigeminal neuralgia and controls. Ascand, 1977; 56(2):177-180.

Marbach JJ. Medically Unexplained Chronic Orofacial Pain. Med Clin North Am, 1999; 83(3):691-709.

Mathews ES, Scrivani SJ. Percutaneous stereotactic radiofrequency thermal rhizotomy for the treatment of trigeminal neuralgia. Mt Sinai J Med, 2000; 67(4):288-299.

Maxwell DS. Fine structure of the normal trigeminal ganglion in the cat and monkey. J Neurosurg, 1963; 20:127-131

Melzack R, Wall PD. Pain mechanisms: a new theory. Science, 1965; 150:971-979.

Merskey H, Bogduk N. Classification of chronic pain. 2nd ed. Seattle: IASP Press, 1994.

Michell F, Scorticati MC, Raina G. Beneficial effects of botulinum toxin type A for patients with painful tic convulsif. Clin Neuropharmacol, 2002; 25(5):260-262. Ministério da Saúde do Brasil. Levantamento epidemiológico. Prevalência de anormalidades odontológicas. Brasil, 1986.

Moses HL. Comparative fine structure of the trigeminal ganglia, including human autopsy studies. J Neurosurg, 1963; 20:112-126. 
Moura AAM, Bombana AC, Barros JJ. O problema da dor-orofacial. Quintessencia, 1979; 6(1):83-88.

Nasri C, Siqueira JTT. Síndrome da ardência bucal (SAB). In: Siqueira JTT, Teixeira MJ, eds. Dor Orofacial Diagnóstico, Terapêutica e Qualidade de Vida. Curitiba:Maio, 2001.

Natarajan M. Percutaneous trigeminal ganglion balloon compression: experience in 40 patients. Neurol india, 2000; 48(4):330-332.

Neidle EA, Yagiela JA. Farmacologia e terapêutica para dentistas. 3 ed. Rio de Janeiro:Guanabara Koogan, 1989.

Okeson JP, Falace DA. Nonodontogenic toothache. Dent Clin North Am, 1997; 41(2):367-383.

Oturai AB, Jensen K, Eriksen J, Madsen F. Neurosurgery for trigeminal neuralgia: comparison of alcohol block, neurectomy, and radiofrequency coagulation. Clin J Pain, 1996; 12(4):311-315.

Patterson CW. Trigeminal neuralgia - a dental diagnosis challenge. Northwest Dent, 1999; 78(3):19-24.

Pazin GJ. Herpes simplex esophagitis after trigeminal nerve surgery. Gastroenterology, 1978; 74(4):741-743.

Pemberton MN, Dewi PS, Hindle I, Thornhill MH. Investigation and medical management of trigeminal neuralgia by consultant oral and maxillofacial surgeons in the British Isles. Br J Oral Maxillof Surg, 2001; 39(2):114-119.

Penman J. The differential diagnosis and treatment of tic doloureux. Post Grad Med J, 1950; 26:627-636.

Perkin GD, Illingworth. The association of hemifacial spasm and facial pain. $J$ Neurol Neurosurg Psychiatry, 1989; 52(5):663-665. 
Peters G, Nurmikko TJ. Peripheral and gasserian ganglion-level precedures for the treatment of trigeminal neuralgia. Clin J Pain, 2002; 18(1):28-34.

Pimenta CAM, Teixeira MJ. Proposta de adaptação do questionário de dor McGill para a língua portuguesa. Rev Esc Enf USP, 1996; 30(3):473-483.

Pollack IF, Janetta PJ, Bissonette DJ. Bilateral trigeminal neuralgia: a 14-years experience with microvascular decompression. J Neurosurg, 1988; 68:559-565.

Pollock BE, Foote RL, Stafford SL, Link MJ, Gorman DA, Schomberg PJ. Results of repeated gamma knife radiosurgery for medically unresponsive trigeminal neuralgia. J Neurosurg, 2000; 93(suppl3):162-164.

Prado EB. Dor Facial Atípica [dissertação]. São Paulo: Faculdade de Medicina, Universidade de São Paulo; 2002.

Reisner L, Pettengill CA. The use of anticonvulsivants in orofacial pain. Oral Surg Oral Med Oral Pathol Oral Radiol Endod, 2001; 91(1):2-7.

Preul MC, Long PB, Brown JA, Velasco ME, Weaver MT. Autonomic and histopathological effects of percutaneous trigeminal ganglion compression in the rabbit. J Neurosurg, 1990; 72:933-940.

Pullinger AG, Seligman DA, Gornbein JA. A multiple regression analysis of the risk and relative odds of temporomandibular disorders as a function of common occlusal features. J Dent Res, 1993; 72:968-979.

Ramsbacher J, Vesper J, Brock M. Permanent postoperative anosmia: a serious complication of neurovascular decompression in the sitting position. Acta Neurochir (Wien), 2000; 142(11):1259-1261.

Renton T, Thexton A, Hankins M, McGurk M. Quantitative thermosensory testing of the lingual and inferior alveolar nerves in health and after iatrogenic injury. Br J Oral Maxilofac Surg, 2003; 41: 36-42. 
Rosner B. Fundamentals of Biostatistics. 2nd ed, Boston: PWS Publishers, 1986.

Rothman KJ, Monson RR. Epidemiology of trigeminal neuralgia. J Chron Dis, $1973 ; 26: 2-12$.

Sadeghi P, Papay FA, Vidimos AT. Trigeminal trophic syndrome - report of four cases and review of the literature. Dermatol Surg, 2004; 30(5):807-812.

Salar G, Mingrino S, Iob I. Alterations of facial sensitivity induced by percutaneous thermocoagulation for trigeminal neuralgia. Surg Neurol, 1983; $19(2): 126-130$.

Saunders RL, Krout R, Sachr E. Masticator electromyography in trigeminal neuralgia. Neurology, 1971; 21(12):1221-1225.

Schädelin J, Schilt U, Rohner M. Preventive therapy of Herpes Labialis associated with trigeminal surgery. Am J Med, 1988; 85(suppl 2A):46-48.

Schoenen J, Sandor PS. Headache. In: Wall P, Melzack R, editors. Textbook of Pain, 4th ed. Edinburg: Churchill Livingstone, 1999.

Scrivani SJ, Keith DA, Kulich R, Mehta N, Maciewicz RJ. Posttraumatic gustatory neuralgia: a clinical model of trigeminal neuropathic pain. J Orofac Pain, $1998 ; 12(4): 287-292$.

Sessle BJ, Hu JW, Amano N, Zhong G. Convergence of cutaneous, tooth pulp, visceral, neck and muscle afferents onto nociceptive and non-nociceptive neurones in trigeminal subnucleus caudalis (medullary dorsal horn) and its implications for referred pain. Pain, 1986; 27:219-235.

Sessle BJ. Acute and chronic cranifacial pain: brainstem mechanisms of nociceptive transmission and neuroplasticity, and their clinical correlates. Crit Rev Oral Biol Med, 2000; 11(1):57-91. 
Sharav Y, Benoliel R, Schnarch A, Greenberg L. Idiopathic trigeminal pain associated with gustatory stimuli. Pain, 1991; 44(4):171-4.

Shira RB. Further observations on dental parameters of trigeminal and atypical facial neuralgias. Oral Surg Oral Med Oral Pathol, 1984; 58(2):121-129.

Sindrup SH, Jensen TS. Efficacy of pharmacological treatments of neuropathic pain: an update and effect related to mechanism of drug action. Pain, 1999; 83:389400.

Siqueira JTT. Dores Dentárias Difusas/Odontalgia Atípica. In: Siqueira JTT, Teixeira MJ, editores. Dor Orofacial Diagnóstico, Terapêutica e Qualidade de Vida. Curitiba:Maio, 2001.

Siqueira JTT, Ching LH. Dificuldades no diagnóstico diferencial de dores dentárias referidas à face. Conduta clínica e considerações sobre uma amostra. $J B C$, 1997; 1(2):11-18.

Siqueira JTT, Ching LH. Dificuldades no diagnóstico diferencial das dores dentárias referidas à face. Conduta clínica. In: Siqueira JTT, Ching LH, editores. Dor Orofacial/Atm, Bases para o diagnóstico clínico, 2. ed, Curitiba:Maio, 2001.

Siqueira JTT, Teixeira MJ. Dor Orofacial. Diagnóstico, terapêutica e qualidade de vida. Curitiba, Maio, 2001.

Siqueira SRDT, Teixeira MJ. Neuralgias do Segmento Facial. JBA, 2003; 3(10):101-110.

Siqueira SRDT, Siqueira JTT. Neuralgia do trigêmeo: Diagnóstico diferencial com odontalgia. Revista da APCD - Associação Paulista dos Cirurgiões-Dentistas, 57(5):354-6, 2003. 
Siqueira SRDT, Nóbrega JCM, Valle LBS, Teixeira MJ, Siqueira JTT. Idiopathic trigeminal neuralgia: Clinical aspects and dental procedures. Oral Surg Oral Med Oral Pathol Oral Radiol Endod, 2004; 98(3):311-315.

Stookey B, Ransohoff J. Trigeminal neuralgia. Its history and treatment. Springfield: Charles C. Thomas Publisher, 1959.

Synai VJ, Bonamico LH, Dubrovsky A. Subclinical abnormalities in trigeminal neuralgia. Cephalalgia, 2003; 23:541-544.

Taha JM, Tew JM, Buncher R. A prospective 15-years follow up of 154 consecutive patients with trigeminal neuralgia treated by percutaneous stereotactic radiofrequency thermal rhizotomy. J Neurosurg, 1995; 83:989-993.

Taha JM, Tew JM. Comparison of surgical treatments for trigeminal neuralgia: Reevaluation of radiofrequency rhizotomy. Neurosurgery, 1996; 38(5):865-871.

Teixeira MJ. A lesão por radiofrequência e a descompressão neurovascular para o tratamento da neuralgia do trigêmeo [dissertação]. São Paulo: Faculdade de Medicina da Universidade de São Paulo; 1984.

Teixeira MJ. A lesão do trato de Lissauer e do corno posterior da medula espinal e a estimulação elétrica do sistema nervoso central para o tratamento da dor por desaferentação [tese]. São Paulo: Faculdade de Medicina da Universidade de São Paulo; 1990.

Teixeira MJ. Conduta em neuralgia do trigêmio. Condutas em Neurologia, São Paulo: Clínica Neurológica HC/FMUSP, 1991.

Teixeira MJ. Fisiopatologia da dor. Rev Med, 1995; 73(2):55-64.

Teixeira MJ. Tratamento da neuralgia do trigêmeo. In: Pré-Congresso. São Paulo: $4^{\circ}$ Congresso Brasileiro de Neurocirurgia, 1998. 3:18.25-36. 
Teixeira MJ. Fisiopatologia da Nocicepção e da Supressão da Dor. In: Siqueira JTT, Teixeira MJ, editores. Dor Orofacial. Diagnóstico, Terapêutica e Qualidade de Vida. Curitiba:Maio, 2001.

Timm NH. Multivariate analysis with applications in educations and psychology. Monterrey: Brooks, 1975.

Thomé W. Dores referidas nas regiões orofaciais [dissertação]. São Paulo: Hospital das Clínicas da Faculdade de Medicina da Universidade de São Paulo, 1993.

Thurel R. Névralgie trijumeau et spasm faciale périphérique. Rev Neurol (Paris), 1961; 104:534-535.

Urabe K, Kim Y, Okuda Y, Kitajima T. Lower lip ulceration after neurolytic mandibular nerve block. Reg Anesth Pain Med, 1999; 24(2):188-189.

Úrculo E, Arrazoa M, Gereka L, Olasagasti V, Olascoaga J, Urcola J, Zabalza R. Valoración de la técnica de Mullan em el tratamiento de la neuralgia Del trigémino. Rev Neurol, 1998; 27(157):477-484.

VonKorff A, Dworkin SF, LeResche L, Kruger A. An epidemiologic comparison of pain complaints. Pain, 1988; 32:173-183.

White JC, Sweet WH. Intermedius, vago glossopharyngeal and upper cervical neuralgia. Pain and the Neurosurgeon. Springfield: Charles C. Thomas, 1940; 257305.

Yoon KB, Wiles JR, Miles JB, Nurmikko TJ. Long-term outcome of percutaneous thermocoagulation for trigeminal neuralgia. Anaesthesia, 54(80): 798808, 1999.

Yoshimasu F, Kurland LT, Elvelvack LR. Tic doloureux in Rochester, Minnesota, 1945-1969. Neurology (Minneap), 1972; 22:952-956. 
Yoshino N, Akimoto H, Yamada I et al. Trigeminal neuralgia: evaluation of neuralgic manifestation and site of neurovascular compression with 3D CISS MR imaging and MR angiography. Radiology, 2003; 228(2):539-45.

Zakrzewska JM. Trigeminal eye and ear pain. In: Wall, PD, Melzack R, editors. Textbook of Pain. 4th ed. Edinburgh: Churchill Livingstone, 1999; 739-60.

Zakrzewska JM, Patsalos PN. Long-term cohort comparing medical (oxcarbazepine) and surgical management of intractable trigeminal neuralgia. Pain, 2002; 95:259-266.

Zakrzewska JM, Lopez BC. Quality of reporting in evaluations of surgical treatment of trigeminal neuralgia: Recommendations for future reports.

Neurosurgery, 2003; 53(1):110-122.

\footnotetext{
* De acordo com:

Adaptado de International Committee of Medical Journals Editors (Vancouver).

Universidade de São Paulo, Faculdade de Medicina, Serviço de Biblioteca e Documentação. Guia de apresentação de dissertações, teses e monografias da FMUSP. Elaborado por Anneliese Carneiro da Cunha, Maria Júlia A.L. Freddi, Maria F. Crestana, Marinalva de S. Aragão, Suely C. Cardoso, Valéria Vilhena. São Paulo : Serviço de Biblioteca e Documentação; 2004.

Abreviaturas dos títulos dos periódicos de acordo com List of Journals Indexed in Index Medicus.
} 


\section{Apêndice}

Este trabalho faz parte da linha de pesquisa sobre Dor Orofacial (neuralgia idiopática do trigêmeo). O primeiro estudo, já finalizado, foi apresentado em Monografia de finalização do Curso de Aprimoramento em Odontologia Hospitalar e foi publicado em inglês na revista Oral Surgery, Oral Medicine, Oral Pathology, Oral Radiology and Endodontics (Apêndice 1), volume 98 (3), 2004 (p311-15).

A metodologia de avaliação sensitiva foi apresentada no artigo: Siqueira SRDT, Okada M, Lino AMM, Teixeira MJ, Siqueira JTT. Systematic orofacial exam of Hereditary Sensory Radicular Neuropathy. Proposal of a standardised protocol. Int Endod J. 2006. In press.

Os resultados desta tese foram aceitos para publicação sob os seguintes artigos:

1. Siqueira SRDT, Lara C, Nóbrega JCM, Siqueira JTT, Teixeira MJ. Sensitive evaluation of patients with idiopathic trigeminal neuralgia treated with functional neurosurgery. The Pain Clin, 2006. In press.

2. Siqueira SRDT, Nóbrega JCM, Teixeira MJ, Siqueira JTT. Olfactory threshold increase in trigeminal neuralgia after balloon compression. Clin Neurol Neurosurg, 2006, 27. Jan.

3. Siqueira SRDT, Nóbrega JCM, Teixeira MJ, Siqueira JTT. Frequency of postoperative complications after balloon compression for idiopathic trigeminal neuralgia - prospective study. Oral Surg Oral Med Oral Pathol Oral Radiol Endod, 2006. In press.

4. Siqueira SRDT, Nóbrega JCM, Teixeira MJ, Siqueira JTT. Masticatory problems after balloon compression, a longitudinal study. J Oral Rehabil. 2006. In press.

5. Siqueira SRDT, Siqueira JTT, Teixeira MJ. Neuralgia do Trigêmeo: protocolo de tratamento atual. Rev Dor, 7(2):785-73, 2006. 